This document was prepared in conjunction with work accomplished under Contract No. DE-AC09-96SR18500 with the U. S. Department of Energy.

\title{
DISCLAIMER
}

This report was prepared as an account of work sponsored by an agency of the United States Government. Neither the United States Government nor any agency thereof, nor any of their employees, nor any of their contractors, subcontractors or their employees, makes any warranty, express or implied, or assumes any legal liability or responsibility for the accuracy, completeness, or any third party's use or the results of such use of any information, apparatus, product, or process disclosed, or represents that its use would not infringe privately owned rights. Reference herein to any specific commercial product, process, or service by trade name, trademark, manufacturer, or otherwise, does not necessarily constitute or imply its endorsement, recommendation, or favoring by the United States Government or any agency thereof or its contractors or subcontractors. The views and opinions of authors expressed herein do not necessarily state or reflect those of the United States Government or any agency thereof. 


\section{EFFECT OF MERCURY-NOBLE METAL INTERACTIONS ON SRAT PROCESSING OF SB3 SIMULANTS (U)}

D. C. Koopman

M. A. Baich

December 2004

Immobilization Technology Section Savannah River National Laboratory Aiken, SC 29808 


\section{DISCLAIMER}

This report was prepared by Westinghouse Savannah River Company (WSRC) for the United States Department of Energy under Contract No. DE-AC09-96SR18500 and is an account of work performed under that contract. Neither the United States Department of Energy, nor WSRC, nor any of their employees makes any warranty, expressed or implied, or assumes any legal liability or responsibility for the accuracy, completeness, or usefulness, of any information, apparatus, or product or process disclosed herein or represents that its use will not infringe privately owned rights. Reference herein to any specific commercial product, process, or service by trademark, name, manufacturer or otherwise does not necessarily constitute or imply endorsement, recommendation, or favoring of same by WSRC or by the United States Government or any agency thereof. The views and opinions of the authors expressed herein do not necessarily state or reflect those of the United States Government or any agency thereof.

\section{Printed in the United States of America \\ Prepared For U.S. Department of Energy}


Key Words: SRAT, Noble Metals, Hydrogen, Mercury

Retention: permanent

\section{EFFECT OF MERCURY-NOBLE METAL INTERACTIONS ON SRAT PROCESSING OF SB3 SIMULANTS (U)}

Authors

D. C. Koopman

M. A. Baich

December 2004

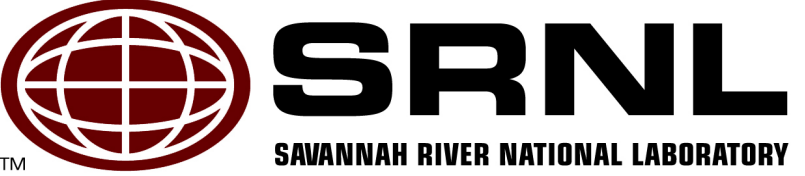


WSRC-TR-2004-00548

Revision 0

\section{REVIEWS AND APPROVALS}

\section{AUTHORS:}

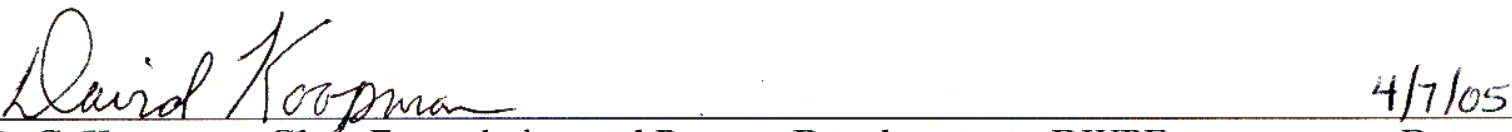

D. C. Koopman, Glass Formulation and Process Development - DWPF Date<smiles>CCCCCCCCCCCCCCCCCCCC</smiles>

M. A. Baich, Glass Formulation and Process Development - DWPF

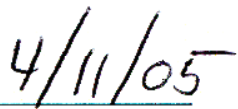

Date

\section{TECHNICAL REVIEWERS:}

Suriżleni

T. L. Fellinger, Glass Formutgtion and Process Development - DWPF Date

\section{APPROVERS:}

En ktaltzenls

E. W. Holtzscheiter, Manager, Immobilization Technology Section

Shavon fNhara

S. L. Marra, Manager, Glass Formulation \& Process Development
$4 / 11 / 2005$ 


\section{EXECUTIVE SUMMARY}

Controlling hydrogen generation below the Defense Waste Processing Facility (DWPF) safety basis constrains the range of allowable acid additions in the DWPF Chemical Processing Cell. This range is evaluated in simulant tests at the Savannah River National Laboratory (SRNL). A minimum range of allowable acid additions is needed to provide operational flexibility and to handle typical uncertainties in process and analytical measurements used to set acid additions during processing. The range of allowable acid additions is a function of the composition of the feed to DWPF. Feed changes that lead to a smaller range of allowable acid additions have the potential to impact decisions related to wash endpoint control of DWPF feed composition and to the introduction of secondary waste streams into DWPF.

A limited program was initiated in SRNL in 2001 to study the issue of hydrogen generation. The program was reinitiated at the end of fiscal year 2004. The primary motivation for the study is that a real potential exists to reduce the conservatism in the range of allowable acid additions in DWPF. Increasing the allowable range of acid additions can allow decisions on the sludge wash endpoint or the introduction of secondary waste streams to DWPF to be based on other constraints such as glass properties, organic carbon in the melter off-gas, etc.

The initial phase of the study consisted of a review of site reports and off-site literature related to catalytic hydrogen generation from formic acid and/or formate salts by noble metals. Many things are already known about hydrogen generation during waste processing. This phase also included the development of an experimental program to improve the understanding of hydrogen generation. This phase is being documented in WSRC-TR-2002-00034. A number of areas were identified where an improved understanding would be beneficial. A phased approach was developed for new experimental studies related to hydrogen generation.

The first phase of new experimental work consisted of six simulations of the DWPF Sludge Receipt and Adjustment Tank (SRAT). This phase had four objectives, but the primary focus was on the effect of mercury on hydrogen generation and SRAT processing. These objectives were to:

- Obtain SRAT processing data at three different mercury concentrations.

- Obtain comparable data for mercury added as $\mathrm{HgO}$ or as $\mathrm{Hg}\left(\mathrm{NO}_{3}\right)_{2}$.

- Obtain process data that could lead to more prototypical performance of the experimental equipment.

- Use data from enhanced gas chromatographs to improve the understanding of acid consumption during processing.

Mercury was selected as the main focus because of conflicting data about its role in the historical tests, and because it was anticipated to be a significant factor in the next sludge batch (Sludge Batch 4). The form of mercury was a secondary issue related to the possible effect of different degrees of dispersion of the mercury precipitate in the slurry, and the impact that could have on processing issues including mercury stripping. The third objective was motivated by the desire to duplicate DWPF processing as closely as possible. The final objective arose because these were the first simulations that could take advantage of the upgraded gas chromatograph capabilities to measure NO and $\mathrm{CO}$ in addition to previously measured gases.

Experimental work was completed, and significant findings include: 
- Increasing initial concentrations of mercury led to significantly reduced levels of hydrogen generation in the SRAT. Mercury had been reported as both an inhibitor and a promoter of hydrogen generation in different previous studies. The effect of initial mercury concentration on other observable process variables, such as $\mathrm{NO}$ production, $\mathrm{N}_{2} \mathrm{O}$ production, $\mathrm{CO}_{2}$ production, formate loss, and nitrite to nitrate conversion was relatively minor.

- Changing the form of added mercury produced only small changes in the above variables. There was no reason to choose one form over the other purely from a hydrogen generation perspective. The mercury nitrate at high concentrations, however, did adversely effect the measurement of base equivalents. There were also some secondary issues with the monitoring of both forms of mercury in the slurry during processing. Mercury stripping did not appear to proceed as expected. This could be due to sampling or analytical issues.

- Test data have led to a redesign of the experimental SRAT condenser and mercury water wash tank. Further analysis led to a general recommendation to minimize internal refluxing in the glassware during acid addition. This is the most likely reason that nitrite to nitrate conversion in bench-scale tests is higher than that observed in DWPF. Excess nitrite to nitrate conversion relates directly to reduced acid consumption. Reduced acid consumption leads to more excess acid available for hydrogen generation. Mitigating these issues should remove some of the conservatism in the allowable acid range determined by simulant testing.

- Catalytic wet air oxidation (CWAO) is a parallel reaction that consumes formic acid and formate ions and that is catalyzed by noble metals. It produces water instead of hydrogen. It requires oxygen, which could be more readily available to slurries in the bench-scale equipment than in DWPF. The tests determined that CWAO was occurring, but it was not competing with hydrogen generation for the noble metal catalyst sites at the test concentrations. Therefore, bench-scale hydrogen generation was not being artificially suppressed by CWAO. This was a potential factor that would not have been conservative in setting the allowable acid addition range using benchscale tests.

This phase of experimental work represents a significant advance in the understanding of catalytic hydrogen generation in DWPF. The incorporation of the correct initial concentration of mercury impacts hydrogen generation which is necessary in determining the allowable acid addition window. Modified test equipment should produce less conservative and more realistic results. Potential issues related to a competing reaction are not leading to understated hydrogen generation levels and a lack of conservatism. The next phase of the program will focus on the chemical form of the noble metals palladium, rhodium, and ruthenium in the simulated waste and the potential impact this has on peak hydrogen generation levels. 


\section{TABLE OF CONTENTS}

$\begin{array}{lr}\text { EXECUTIVE SUMMARY } & \mathrm{v} \\ \text { LIST OF TABLES } & \text { viii } \\ \text { LIST OF FIGURES } & \text { ix } \\ \text { LIST OF ACRONYMS } & \text { ix } \\ \text { 1.0 INTRODUCTION AND BACKGROUND } & 1 \\ \text { 1.1 Review of potential factors affecting hydrogen generation } & 1 \\ \text { 2.0 APPROACH } & 3 \\ \text { 2.1 SRAT Test Matrix } & 3 \\ \text { 2.2 Sludge preparation } & 4 \\ \text { 2.3 Stoichiometric acid calculations } & 6 \\ \text { 2.4 SRAT cycle description } & 8 \\ \text { 3.0 RESULTS } & 11 \\ \text { 3.1 Mercury-Noble Metal Interactions and Hydrogen Off-gas Data } & 11 \\ \text { 3.2 SRAT Product Composition Data } & 12 \\ \text { 3.3 Formate Loss and Nitrate Gain during Processing } & 14 \\ \text { 3.4 Process Titration Data } & 15 \\ \text { 3.5 The Effect of Hg on the Other Off-gas Data } & 16 \\ \text { 3.6 Competing Catalytic Reactions } & 18 \\ \text { 3.7 Effect of Nitrite on Excess Acid and Hydrogen Generation } & 21 \\ \text { 4.0 CONCLUSIONS } & 23 \\ \text { 5.0 RECOMMENDATIONS/PATH FORWARD } & 25 \\ \text { 6.0 REFERENCES } & 27 \\ \text { 7.0 ACKNOWLEDGEMENTS } & 28 \\ \text { APPENDIX A. General SRAT Material Balance Closure } & 29 \\ \text { APPENDIX B. Base Equivalents Titration Data } & 31 \\ \text { APPENDIX C. Carbon Dioxide and pH } & 36 \\ \text { APPENDIX D. Condensate Composition During Boiling } & 38 \\ \text { APPENDIX E. Changes in Hg Concentration During Boiling } & 43 \\ \text { APPENDIX F. Changes in Anion Concentrations during Boiling } & 48 \\ \text { APPENDIX G. Supplemental Off-gas Data } & 51 \\ \text { APPENDIX H. Assessment of Nitrite Destruction Chemistry } & 59\end{array}$




\section{LIST OF TABLES}

Table 1. Nominal SB3 Mercury and Noble Metal Concentrations ..................................... 3

Table 2. SRAT Test Matrix ......................................................................................... 4

Table 3. Calcined Elementals in Starting Sludge and Four Trimmed Sludges ..................... 5

Table 4. Wt. \% Solids Data for Starting Sludges ................................................... 5

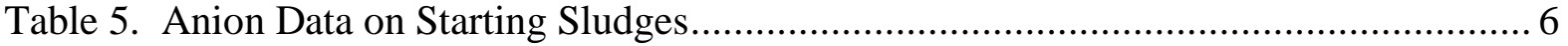

Table 6. Factors for the Stoichiometric Acid and Redox Calculation.................................. 7

Table 7. Inputs for the Stoichiometric Acid Requirement ........................................... 7

Table 8. Summary of Acid Additions in the Scoping Test Program .................................. 8

Table 9. Elemental Composition Data for the SRAT Product Samples ............................ 13

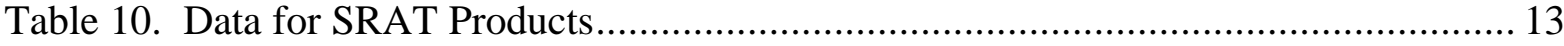

Table 11. Anion Data on SRAT Products................................................................... 14

Table 12. Formate Change During SRAT Processing ..................................................... 14

Table 13. Nitrite and Nitrate Changes During SRAT Processing .................................. 15

Table 14. SRAT Product Material Balance Closure...................................................... 30

Table 15. Comparison of Base Equivalents Measurements....................................... 32

Table 16. Base Equivalents of SRAT Receipt samples ............................................ 32

Table 17. Base Equivalents of Special Samples...................................................... 33

Table 18. Test 1 Condensate Sample Results ....................................................... 40

Table 19. Initial Dewatering Period Condensate Comparison ..................................... 41

Table 20. Middle Dewatering Period Condensate Comparison ...................................... 41

Table 21. Final Dewatering Period Condensate Comparison ...................................... 41

Table 22. MWWT Composition at End of SRAT Cycle ................................................ 42

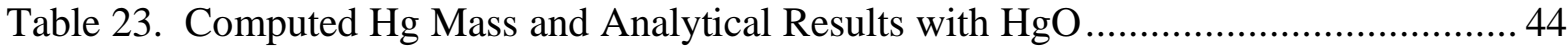

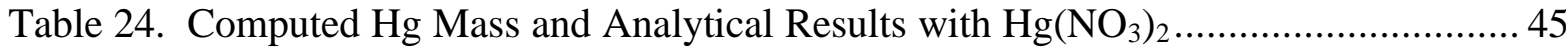

Table 25. Nitrite Ion Concentrations After Acid Addition ............................................... 49 


\section{LIST OF FIGURES}

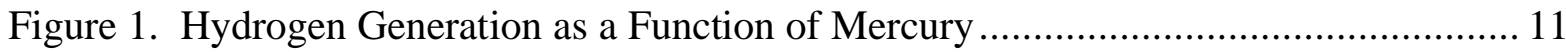

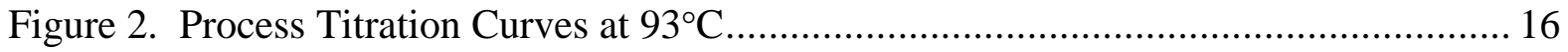

Figure 3. Carbon Dioxide Generation early in the SRAT Cycle......................................... 17

Figure 4. Effect of Oxygen on Peak Hydrogen Generation Rate......................................... 19

Figure 5. Carbon Dioxide in Excess of Hydrogen During Boiling ..................................... 20

Figure 6. Data from Auto-Titrator for Untrimmed Sludge and $\mathrm{Hg}-\mathrm{NaOH}$ Sludge ................ 33

Figure 7. Comparison of Cold and in situ Acid vs. pH Data .................................................. 35

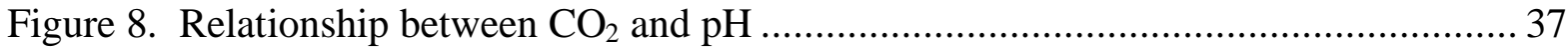

Figure 9. $\mathrm{Hg}$ Mass versus Boiling Time at 2\% Initial $\mathrm{Hg}$.................................................. 46

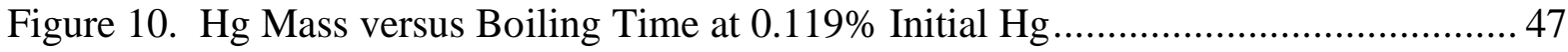

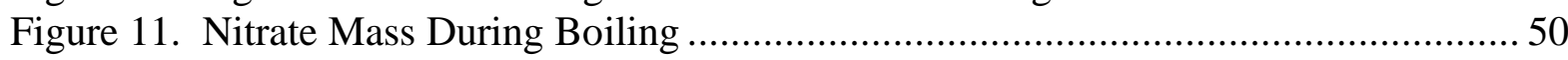

Figure 12. Carbon Dioxide Generation early in the SRAT Cycle .......................................5 52

Figure 13. Carbon Dioxide Generation During Boiling ...................................................5 53

Figure 14. Nitrous Oxide $\left(\mathrm{N}_{2} \mathrm{O}\right)$ Generation During SRAT Cycle ....................................5 54

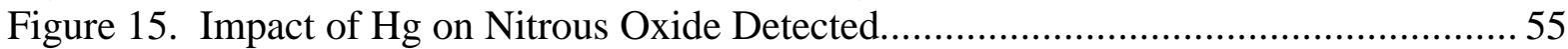

Figure 16. Nitric Oxide (NO) Generation During SRAT Cycle ………............................. 56

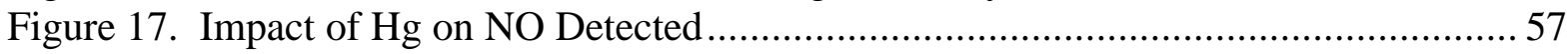

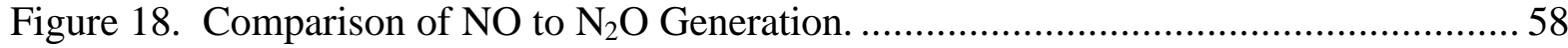

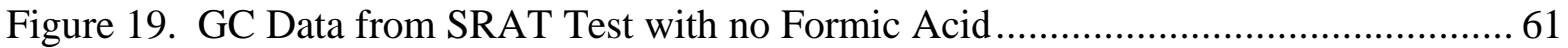

\section{LIST OF ACRONYMS}

$\begin{array}{ll}\text { ACTL } & \text { Aiken County Technical Laboratory } \\ \text { ADS } & \text { Analytical Development Section } \\ \text { CETL } & \text { Clemson Environmental Technologies Laboratory } \\ \text { CPC } & \text { Chemical Process Cell } \\ \text { DWPF } & \text { Defense Waste Processing Facility } \\ \text { FAVC } & \text { Formic Acid Vent Condenser } \\ \text { GC } & \text { Gas Chromatograph or Gas Chromatography } \\ \text { IC } & \text { Ion Chromatograph or Ion Chromatography } \\ \text { ICP-ES } & \text { Inductively Coupled Plasma-Emission Spectroscopy } \\ \text { MWWT } & \text { Mercury Water Wash Tank } \\ \text { SB3 } & \text { Sludge Batch 3 } \\ \text { SB4 } & \text { Sludge Batch 4 } \\ \text { SME } & \text { Slurry Mix Evaporator } \\ \text { SRAT } & \text { Sludge Receipt and Adjustment Tank } \\ \text { SRNL } & \text { Savannah River National Laboratory } \\ \text { TIC } & \text { Total Inorganic Carbon }\end{array}$


WSRC-TR-2004-00548

Revision 0

This page intentionally left blank. 


\subsection{INTRODUCTION AND BACKGROUND}

A review was performed of available data and outside literature related to catalytic hydrogen generation in the Defense Waste Processing Facility (DWPF) Sludge Receipt and Adjustment Tank (SRAT) prior to performing any experimental work, Koopman (2002). This review is being issued concurrently with this report. The reader is directed to the review document for further details about the various factors already known to affect hydrogen generation. The review produced a short list of potential factors that might be significant to hydrogen generation, but which had not been systematically studied by previous researchers.

One of the factors needing further study was the effect of the form and quantity of mercury on hydrogen generation. This factor was the primary emphasis of this phase of the hydrogen generation program. A second factor was the simultaneous reaction between oxygen and formic acid/formate to produce carbon dioxide and water. This reaction is similar to hydrogen generation in that it uses noble metals as catalysts and destroys formic acid/formate. The two reactions could be competing for catalyst sites. A factor related to the second was the role of mixing intensity in bringing oxygen into the slurry, since oxygen would be the limiting reagent. These two factors were of secondary importance in this study, and were investigated using a single SRAT simulation.

\subsection{Review of potential factors affecting hydrogen generation}

Conflicting data was found for the effect of mercury on hydrogen generation during the review. The available data did indicate that mercury would probably have a significant impact. Mercury was reported as being able to form amalgams with the reduced noble metals. Amalgams are solutions of one or more metals in liquid mercury. The amalgams were reported to have different catalytic activities in general than those of the pure noble metals. A second potential issue had been identified with respect to mercury processing. This involved the choice of the species used to spike mercury into the simulants. $\mathrm{HgO}$ had been used for the past seven years. There was a possibility that $\mathrm{Hg}\left(\mathrm{NO}_{3}\right)_{2}$ would offer more prototypical behavior. Scoping studies were initiated with the goal of quantifying the issues related to mercury during SRAT processing.

Another leading candidate for future study is the insoluble form of the noble metals themselves. Simulant studies trim the noble metals into the available sludge simulant at the desired target compositions for palladium, rhodium, and ruthenium. The palladium and rhodium concentrations are obtained by adding nitrate solutions which disperse and precipitate in the sludge simulant. Ruthenium is added as the dry chloride salt. None of the noble metals are incorporated into the existing insoluble solids matrix by this strategy. The trimmed noble metals are potentially activated more completely and readily than noble metals in real waste. This could be leading to overly conservative estimates of the potential hydrogen generation during SRAT and Slurry Mix Evaporator (SME) processing. A program is underway to investigate this issue in fiscal year 2005.

Noble metals are not limited to catalyzing hydrogen generation. There have been indications that noble metals accelerate nitrite destruction. Other catalytic reactions can occur in the SRAT and SME. One of these is catalytic wet air oxidation (CWAO) of organics, e.g. formic acid, oxalic acid, and antifoam. Noble metals catalyze this class of reactions at temperatures that include typical DWPF processing temperatures, see Koopman et al. (2004, 2003a, and 2003b) for a review of CWAO and data supporting it. CWAO, however, requires oxygen while hydrogen generation does not. The ultimate products from a series of reactions on almost any organic molecule are carbon dioxide and water. 
Removing oxygen from the SRAT or SME should eliminate CWAO of formate. The primary question of relevance to the hydrogen program was whether or not CWAO was competing with hydrogen generation for the same catalytic sites. A SRAT experiment was designed with a nitrogen purge instead of an air purge to monitor the extent of increased hydrogen generation and decreased carbon dioxide generation that might occur without CWAO occurring in parallel. This would also give information related to the significance of mixing in the SRAT simulations, since this is the primary mechanism for transporting oxygen into the slurry where the reactions are occurring. If CWAO is not competing with hydrogen generation, then the role of mixing intensity in transporting oxygen into the slurry is not critical to the observed hydrogen generation rate.

The list of other potential factors impacting hydrogen generation that need further study included:

- the role of silver, which was also reported to be able to form amalgams with the noble metals

- the role of sludge composition, and of nitrite ion in particular, which experiments show has a complex role in hydrogen generation

- the role of washing in general, since the species that may be gradually poisoning the noble metal catalysts are presumably soluble, but have not been identified

- the impact of secondary waste streams (such as canyon streams, salt processing streams) on the acid requirement and the amount of excess acid

In addition to these factors, there are still some open questions regarding the relative roles of the three noble metals, $\mathrm{Pd}, \mathrm{Rh}$, and $\mathrm{Ru}$. Work by $\mathrm{C}$. W. Hsu with early flow sheets showed significant roles for both $\mathrm{Rh}$ and Ru. Scoping work with the nitric acid-sludge only flow sheet has not shown a significant role for Ru. Literature studies indicate that Pd should be the easiest noble metal to activate, and that it may be the most active of the three. In the SRS sludge waste, however, Pd is typically present in lower concentrations than either $\mathrm{Rh}$ or Ru. Summaries and references of the earlier studies can be found in WSRC-TR-2002-00034. 


\subsection{APPROACH}

Sludge Batch 2 (SB2) combined with Sludge Batch "3" (the contents of Tank 51 prior to transfer to Tank 40) is now referred to as Sludge Batch 3 (SB3). SB3 simulant has been well studied in the past eighteen months and was selected for this work. SB3 also represents a relatively less washed sludge than previously studied, and it has higher noble metal concentrations than either Sludge Batch 1A or 1B. The acid requirement that would produce significant hydrogen in the SRAT cycle was previously determined, Baich (2004). The expected values of the inputs to the stoichiometric acid addition equation were also available both to use as checks and to set factors such as the fraction of formate destroyed or the fraction of nitrite converted to nitrate. These last two inputs are used to balance the nitric and formic acids to give a reasonable predicted $\mathrm{Fe}^{+2} / \Sigma \mathrm{Fe}$ (redox) for the waste glass.

\subsection{SRAT Test Matrix}

The primary test matrix for SRAT simulations was developed to assess the impact of mercury on hydrogen generation. The matrix used the $185 \%$ of stoichiometry SRAT simulation from the SB3 acid window study as the baseline, Baich (2004). That run produced a scaled peak hydrogen generation rate above the DWPF design basis limit of $0.65 \mathrm{lbs} / \mathrm{hr}$ in the SRAT. The preferred test strategy for factors that affect hydrogen generation is to perform the simulations with hydrogen generation rates near the DWPF design basis limit.

The SB3 baseline mercury concentration is $0.119 \mathrm{wt} . \%$ in the dried solids. While the mercury content of SB3 waste is relatively low, it is still significant when compared to the noble metal concentrations on a molar basis, Table 1. The mercury concentration was adjusted both up and down from SB3 levels in the test matrix. The minimum mercury concentration was chosen to be zero. The maximum mercury concentration was chosen to be $2 \mathrm{wt} . \%$ in the dried solids. The high mercury choice was an opportunity to gain a better understanding of how potentially high levels of mercury in SB4 or future sludge batches might influence hydrogen generation. The $2 \%$ level had a high likelihood of bounding the $\mathrm{Hg}$ concentration in Tank 11 (a principle component of SB4) following washing based on the information in Bannochie (2004).

Table 1. Nominal SB3 Mercury and Noble Metal Concentrations

\begin{tabular}{|l|c|c||}
\hline Element & Wt. \% in Dried Solids & Moles Hg/mole element \\
\hline $\mathrm{Hg}$ & 0.119 & 1.00 \\
\hline $\mathrm{Ag}$ & 0.0115 & 5.57 \\
\hline $\mathrm{Pd}$ & 0.0014 & 45.1 \\
\hline $\mathrm{Rh}$ & 0.0076 & 8.03 \\
\hline $\mathrm{Ru}$ & 0.036 & 1.67 \\
\hline
\end{tabular}

Testing at the two non-zero mercury levels was done using both $\mathrm{HgO}$ and $\mathrm{Hg}\left(\mathrm{NO}_{3}\right)_{2} . \mathrm{Hg}\left(\mathrm{NO}_{3}\right)_{2}$ reacts with caustic in the supernate when it is trimmed into sludge simulant. It forms freshly precipitated $\mathrm{HgO}$. The freshly precipitated $\mathrm{HgO}$ is potentially more susceptible to chemical reactions than commercial $\mathrm{HgO}$. This paired testing also presented an opportunity to assess possible differences in mercury stripping efficiency and mercury sampling in the bench-scale equipment due to the starting trim chemical before the beginning of the SB4 test program. 
The three mercury levels and two types of mercury trim chemical produced a test matrix requiring five SRAT simulations. A sixth run was added at the nominal SB3 mercury concentration. The air purge, however, was switched to a nitrogen purge. This alters the SRAT reaction chemistry in at least two ways. First, removing oxygen as a reactant halts CWAO, a potential competing reaction with hydrogen generation. Second, removing oxygen halts the conversion of $\mathrm{NO}$ to $\mathrm{NO}_{2}$. This reaction is important to the conversion of nitrite to nitrate ion. This is an area where bench-scale simulation results have differed from DWPF results. The run would give an opportunity to learn more about why the results differ.

The combined mercury-oxygen test matrix utilized is shown in Table 2:

Table 2. SRAT Test Matrix

\begin{tabular}{||c|c|c|c||}
\hline & Form of Mercury & Concentration of Mercury & Purge \\
\hline Test $0(2003)$ & $\mathrm{HgO}$ & 0.119 wt. $\%$ & Air \\
\hline Test 1 & No $\mathrm{Hg}$ added & 0 wt. $\%$ & Air \\
\hline Test 2 & $\mathrm{HgO}$ & 2.0 wt. $\%$ & Air \\
\hline Test 3 & $\mathrm{Hg}\left(\mathrm{NO}_{3}\right)_{2}$ & 0.119 wt. $\%$ & Air \\
\hline Test 4 & $\mathrm{Hg}\left(\mathrm{NO}_{3}\right)_{2}$ & 2.0 wt. $\%$ & Air \\
\hline Test 5 & $\mathrm{HgO}$ & 0.119 wt. $\%$ & Air \\
\hline Test 6 & $\mathrm{HgO}$ & 0.119 wt. $\%$ & Nitrogen \\
\hline
\end{tabular}

Test 0 was the name assigned to the previous simulation data set at $185 \%$ of the stoichiometric acid requirement, Baich (2004). Test 5 was a repeat of Test 0 using the fresh blend of SB3 simulant. This data could be used to assess the effect of variations in the outcome of different preparations of the same SB3 sludge simulant recipe on the peak hydrogen generation rate and other parameters.

The acid addition strategy for the low mercury runs was set at $183-185 \%$ of the stoichiometric acid calculation. The acid required for mercury reduction was only $0.12 \%$ of the total stoichiometric demand at 0.119 wt. $\% \mathrm{Hg}$. The acid stoichiometry for the two runs at $2.0 \mathrm{wt}$. \% $\mathrm{Hg}$ was set to $185 \%$ on a mercury free basis plus one mole of acid per mole of mercury. The net result was $183 \%$ of the stoichiometric acid demand with mercury included. This decision drew on experience with mercury processing that indicated that it was readily reduced, combined with a first principles understanding of mercury reduction that indicated that one mole of formic acid could reduce one mole of $\mathrm{Hg}$ (II) to elemental mercury. Controlling acid in this manner ensured that essentially equivalent amounts of excess acid would be available for hydrogen generation in Tests 1-5. This control was implemented assuming that the effect of mercury on hydrogen generation might be subtle while the effect of excess acid was already known to be significant, Koopman (2004).

\subsection{Sludge preparation}

A standard recipe has been developed for the preparation of simulant for SB3 testing. It is based on two simulants prepared at the Clemson Environmental Technologies Laboratory (CETL). These simulants were for SB2 and for Sludge Batch "3" prior to combining it with SB2. These are blended together 40:60 by slurry mass. This gives a generally comparable distribution of non-radioactive species to those measured in the radioactive SB3 waste. Additional species are added to bring the blend into closer agreement with real SB3 waste. These include $\mathrm{Cr}_{2} \mathrm{O}_{3}, \mathrm{Gd}\left(\mathrm{NO}_{3}\right)_{3}, \mathrm{Mg}(\mathrm{OH})_{2}$, and $\mathrm{PbSO}_{4}$, plus eight sodium salts to produce the appropriate supernate composition. Sand, coal, the noble metals, including $\mathrm{AgNO}_{3}$, and one of the mercury salts are only added after the sludge simulant is in the SRAT vessel. This is done to ensure that these critical species are present at the target compositions during processing. 
The measured composition of the major sludge elements was determined by ICP-ES analysis both before and after adding the sand, coal, noble metals, and mercury (Tests 1-4 only, Tests 5-6 were not sampled until the SRAT product due to insufficient slurry mass). Calcined elemental wt. \%'s $\left(1100^{\circ} \mathrm{C}\right)$ for the untrimmed sludge and four trimmed sludge slurry samples are given in Table 3.

Table 3. Calcined Elementals in Starting Sludge and Four Trimmed Sludges

\begin{tabular}{|l|c|c|c|c|c||}
\hline & Sludge & Test 1 & Test 2 & Test 3 & Test 4 \\
\hline $\mathrm{Al}$ & 9.16 & 9.52 & 9.34 & 9.12 & 9.15 \\
\hline $\mathrm{Ba}$ & 0.14 & 0.12 & 0.12 & 0.12 & 0.12 \\
\hline $\mathrm{Ca}$ & 2.43 & 1.97 & 2.00 & 2.13 & 2.10 \\
\hline $\mathrm{Cr}$ & 0.18 & 0.16 & 0.16 & 0.16 & 0.15 \\
\hline $\mathrm{Cu}$ & 0.15 & 0.16 & 0.15 & 0.16 & 0.16 \\
\hline $\mathrm{Fe}$ & 28.9 & 27.8 & 27.9 & 28.2 & 27.7 \\
\hline $\mathrm{Gd}$ & n.a. & 0.08 & 0.07 & 0.07 & 0.07 \\
\hline $\mathrm{K}$ & $<0.45$ & 0.12 & 0.12 & 0.11 & 0.11 \\
\hline $\mathrm{Mg}$ & 2.79 & 2.72 & 2.68 & 2.63 & 2.51 \\
\hline $\mathrm{Mn}$ & 4.04 & 3.87 & 3.77 & 3.95 & 3.91 \\
\hline $\mathrm{Na}$ & 15.5 & 14.7 & 15.7 & 14.5 & 14.8 \\
\hline $\mathrm{Ni}$ & 1.11 & 0.99 & 0.98 & 1.04 & 1.04 \\
\hline $\mathrm{P}$ & 0.10 & 0.05 & 0.05 & 0.05 & 0.05 \\
\hline $\mathrm{Pb}$ & $<0.02$ & 0.03 & 0.01 & 0.01 & 0.01 \\
\hline $\mathrm{S}$ & 0.49 & 0.40 & 0.42 & 0.37 & 0.41 \\
\hline $\mathrm{Si}$ & 1.09 & 1.27 & 1.09 & 1.27 & 1.19 \\
\hline $\mathrm{Zn}$ & 0.34 & 0.32 & 0.32 & 0.33 & 0.30 \\
\hline $\mathrm{Zr}$ & 0.51 & 0.39 & 0.39 & 0.38 & 0.40 \\
\hline $\mathrm{E}$ oxides & 100.6 & 96.9 & 97.5 & 96.5 & 95.9 \\
\hline
\end{tabular}

n.a. $=$ not analyzed

Results are generally consistent. Variations are typical of those seen when submitting multiple samples of the same slurry. The sand $\left(\mathrm{SiO}_{2}\right)$ is not yet present in the first column of results, "Sludge". Coal, mercury, and noble metals are present in the four test samples, but are not included in the sum of oxides.

Wt. \% solids, pH, and density data were also obtained on these five samples. These are given in Table 4.

Table 4. Wt. \% Solids Data for Starting Sludges

\begin{tabular}{|l|c|c|c|c|c||}
\hline & Sludge & Test 1 & Test 2 & Test 3 & Test 4 \\
\hline Total Solids & 22.40 & 22.50 & 21.90 & 22.35 & 23.40 \\
\hline Insoluble Solids & 15.33 & 15.40 & 14.65 & 15.10 & 16.15 \\
\hline Soluble Solids & 7.06 & 7.10 & 7.24 & 7.30 & 7.22 \\
\hline Calcined Solids & 16.28 & 16.35 & 15.50 & 16.20 & 16.55 \\
\hline Density & 1.16 & 1.14 & 1.12 & 1.16 & 1.15 \\
\hline pH & n.a. & 12.2 & 12.0 & 11.8 & 11.6 \\
\hline
\end{tabular}


Wt. \% solids, density, and $\mathrm{pH}$ results showed variations that were typical of repeated samples of the same slurry. The samples for Tests 1-4 were pulled from the 4-L SRAT kettle after all of the final trim chemicals are added. Variations in the insoluble solids content of these samples are usually attributed to the difficulty of keeping the slurries uniformly suspended during sampling, since sampling occurs with the mixer turned off.

Weighted dilution analyses of nitrate and nitrite in the starting sludges were also measured for use in the stoichiometric acid calculation. Measurements were made using the Mobile Lab Ion Chromatograph (IC). These are given in Table 5.

Table 5. Anion Data on Starting Sludges

\begin{tabular}{||l|c|c|c|c|c||}
\hline \hline mg/kg slurry & Sludge & Test 1 & Test 2 & Test 3 & Test 4 \\
\hline Nitrate & 13,650 & 13,550 & 13,650 & 12,200 & 14,900 \\
\hline Nitrite & 18,700 & 18,500 & 18,400 & 16,500 & 17,350 \\
\hline
\end{tabular}

n.a. $=$ not analyzed

Test 4 was expected to be higher in nitrate than Tests 1-3 or the starting sludge due to the higher level of mercury nitrate added. This was dealt with in the acid calculations below. The 12,200 nitrate in Test 3 gave a nearly $10 \%$ difference between the two calculation routes for the starting nitrate in the SRAT (trimmed vs. untrimmed sludge basis).

A set of triplicate samples of the blended sludge without the final trim chemicals were submitted for the determination of TIC-TOC. TIC was measured to be $1250 \mathrm{mg} / \mathrm{kg}( \pm 20 \%$ at $2 \sigma)$ consistent with an expected range of $1300-1470 \mathrm{mg} / \mathrm{kg}$ by recipe. TOC was reported to be $665 \mathrm{mg} / \mathrm{kg}( \pm 50 \%$ at $2 \sigma)$ which would be equivalent to $2400 \mathrm{mg} / \mathrm{kg}$ ( \pm 1200 at $2 \sigma$ ) of oxalate (from calcium oxalate in the SB3 portion of the blend, the only organic carbon species in the recipe). The actual oxalate content is not known with high accuracy, but previous IC measurements place it at about $1700 \mathrm{mg} / \mathrm{kg}( \pm 20 \%)$. The oxalate value calculated from the TOC measurement was consistent with the expected oxalate value.

\subsection{Stoichiometric acid calculations}

The data in section 2.2 includes inputs to the stoichiometric acid calculation. In addition to that information, it was necessary to measure the slurry base equivalents at $\mathrm{pH} 7$, set the redox target, set the projected formate loss, set the projected conversion of nitrite to nitrate, and set the projected destruction of nitrite.

The iron glass redox target for Tests $1,2,5$, and 6 was $0.20 \mathrm{Fe}^{+2} / \Sigma \mathrm{Fe}$. These tests had essentially identical ratios of formic acid to nitric acid. Tests 3 and 4 had additional added nitrate from the mercury nitrate trim chemical. The ratio of nitric to formic acid was not adjusted, however, in order to keep these two tests at comparable formate levels to the other four tests. Formate, either as formic acid or the formate salt, is a reactant for hydrogen generation. Reducing nitric acid in Tests 3 and 4 due to the nitrate from mercury nitrate would have meant adding more formic acid at constant total acid. It was felt that allowing the glass redox to float was a better control for a hydrogen study than adjusting the acid ratio. The predicted redox target for Test 3 was 0.194 , while the predicted target for Test 4 was 0.167 .

The projected formate loss, the projected conversion of nitrite to nitrate, and the projected destruction of nitrite were taken from the $185 \%$ acid stoichiometry run, Test 0 , of the 2003 acid stoichiometry study for SB3, Baich (2004). The percent loss of oxalate is also used in the calculation but has a minimal effect due to the small concentration of oxalate in the sludge simulant. These factors are summarized in Table 6. 
Table 6. Factors for the Stoichiometric Acid and Redox Calculation

\begin{tabular}{|l|c|}
\hline Factor: & $185 \%$ Acid Data from 2003 \\
\hline$\%$ Nitrite Ion Destroyed & 100 \\
\hline$\%$ Nitrite Ion Converted to Nitrate Ion & 46.3 \\
\hline$\%$ Formate Ion Lost & 18.3 \\
\hline$\%$ Oxalate Ion Lost & 10 \\
\hline
\end{tabular}

The remaining input needed for the stoichiometric acid requirement calculation was the base equivalents at $\mathrm{pH} 7$ for the sludge slurry. Titrations of SRAT receipt samples with mercury nitrate present at $2 \% \mathrm{Hg}$ gave unrealistic results. This was investigated further, Appendix B. The ambiguity in the interpretation of the SRAT Receipt sample titration results led to a decision to base all of the acid calculations on the base equivalents result for the simulant sludge free of mercury and noble metals $(0.566 \mathrm{M})$. This result was similar to previous titrations of the SB3 simulant preparation. The inputs that set the stoichiometric acid requirement are given in Table 7.

Table 7. Inputs for the Stoichiometric Acid Requirement

\begin{tabular}{|l|c||}
\hline Input & Value \\
\hline Sludge Mass, g & 2,700 \\
\hline Sludge Density, g/ml & 1.181 \\
\hline Base Equivalents, M & 0.566 \\
\hline Nitrite, mg/kg & 18,700 \\
\hline Wt. \% total solids & 22.4 \\
\hline Wt. \% Mn in total solids & 3.30 \\
\hline TIC, $\mathrm{mg} / \mathrm{kg}$ & 1,250 \\
\hline
\end{tabular}

The potential impact of analytical uncertainty on the inputs to the acid calculation was controlled within this study by preparing enough simulant for all six tests and then using the same inputs in the acid calculations for each test. Comparisons with prior SB3 SRAT tests are most affected by these uncertainties.

The acid additions for the six new tests are summarized in Table 8. Data from the 2003 baseline SRAT run, Test 0 , are also included. All numbers assume a 2700 gram starting basis (0.604 gallons). 
Table 8. Summary of Acid Additions in the Scoping Test Program

\begin{tabular}{|l|l|c|c|c|}
\hline & \multicolumn{1}{|c|}{$\begin{array}{c}\text { Hg in Dried Solids } \\
\text { (source) }\end{array}$} & $\begin{array}{c}\text { \% Stoichiometric } \\
\text { Acid Factor }\end{array}$ & $\begin{array}{c}\text { Formic Acid, } \\
\text { moles }\end{array}$ & $\begin{array}{c}\text { Nitric Acid, } \\
\text { moles }\end{array}$ \\
\hline Test 1 & $0 \%$ & 185 & 5.098 & 0.579 \\
\hline Test 2 & $2 \%(\mathrm{HgO})$ & 183.4 & 5.118 & 0.594 \\
\hline Test 3 & $0.119 \%\left(\mathrm{Hg}\left(\mathrm{NO}_{3}\right)_{2}\right)$ & 183 & 5.039 & 0.579 \\
\hline Test 4 & $2 \%\left(\mathrm{Hg}\left(\mathrm{NO}_{3}\right)_{2}\right)$ & 183.4 & 5.118 & 0.594 \\
\hline Test 5 & $0.119 \%(\mathrm{HgO})$ & 185 & 5.095 & 0.579 \\
\hline Test 6 & $0.119 \%(\mathrm{HgO})$ & 185 & 5.095 & 0.579 \\
\hline Test $0(2003)$ & $0.119 \%(\mathrm{HgO})$ & 185 & 4.916 & 0.565 \\
\hline
\end{tabular}

Variations were present in all of the inputs (Mn and base equivalents discussed earlier), but the net effect was small. Total acid was slightly higher (by less than 1\%) in Tests 2 and 4 to take into account the additional mercury reduction requirement. This was an important control used in an attempt to maintain equivalent quantities of excess acid in the tests regardless of the initial mercury concentration.

\subsection{SRAT cycle description}

The SRAT cycle was performed in the 4-L Chemical Process Cell (CPC) simulation equipment at ACTL. The apparatus simulates the SRAT, SRAT condenser, MWWT, and Formic Acid Vent Condenser (FAVC). Fully trimmed simulant was heated to $93^{\circ} \mathrm{C}$. A 200 ppm 747 antifoam addition was made. Nitric acid, $10.56 \mathrm{M}$, was added ( 75 minutes). This was followed by formic acid addition at 23.7M ( 4 hours, 45 minutes). A $500 \mathrm{ppm} 747$ antifoam addition was made. The SRAT was taken to boiling for dewatering. Dewatering lasted about two hours. The SRAT was then switched to reflux. Refluxing was performed for twelve hours. The heating mantle was turned off at the end of reflux. The SRAT contents were allowed to cool to room temperature.

All SRAT simulations started at about $2700 \mathrm{~g}$ of fully trimmed sludge. Air purges, acid addition rates, and boil-up rates were controlled at prototypical levels equivalent to $230 \mathrm{scfm}$ of air, 2 gallons/minute for acid feeding, and $5000 \mathrm{lbs} /$ hour of steam to the heating coils. All testing had a MWWT that started with about $155 \mathrm{~g}$ of de-ionized water in it. The SRAT condenser and formic acid vent condenser (FAVC) were controlled at $40^{\circ} \mathrm{C}$ and $10^{\circ} \mathrm{C}$ respectively. Each simulation started with a freshly cleaned set of glassware. Test 4 used the glassware from Test 2 in case some residual mercury was still present. The SRAT rig was leak checked before and retested after each simulation. The slurry $\mathrm{pH}$ probes were checked in $\mathrm{pH} 4,7$, and 10 buffers before and after each simulation.

Processing data were taken at regular intervals during all of the test runs. This included temperature, pressure, $\mathrm{pH}$, agitator rpm and torque, and heating mantle power input. Additional data were taken during acid addition to track $\mathrm{pH}$ as a function of the volume (or moles) of acid added. These data were used to produce process titration curves.

Off-gas composition was monitored using either an Agilent 3000A Micro GC or an Agilent M Series Micro GC. These GC's have two separation columns. The first column was calibrated for molecular hydrogen $\left(\mathrm{H}_{2}\right)$, helium $(\mathrm{He})$, molecular oxygen $\left(\mathrm{O}_{2}\right)$, molecular nitrogen $\left(\mathrm{N}_{2}\right)$, carbon monoxide $(\mathrm{CO})$, and nitric oxide $(\mathrm{NO})$. The second column was calibrated for air $\left(\mathrm{O}_{2}-\mathrm{N}_{2}\right)$, carbon dioxide $\left(\mathrm{CO}_{2}\right)$, and nitrous oxide $\left(\mathrm{N}_{2} \mathrm{O}\right)$. Air on the second column, however, may not be free of interferences with the other off-gas species. Two standard calibration gases were available and were used to check the accuracy of 
the GC's before and after each SRAT simulation. These six runs were the first performed with the GC calibrated for NO. A separate instrument had been required in the past to obtain NO data.

Off-gas compositions from the GC can potentially be converted into flow rates. A helium internal standard flow was used for this purpose. The nominal DWPF-scaled air purge was converted to $99.5 \%$ air and $0.5 \%$ helium. The individual volumetric flow rates of air and helium into the SRAT were controlled by a pair of MKS flow controllers. These flow controllers are routinely calibrated for accuracy. Field checks of the controllers from the two rigs against each other indicated that these were performing within $5 \%$ of the indicated flows for both the air pair and the helium pair.

Three sets of samples were taken during SRAT processing. A set of samples was taken to monitor anion reactions starting with the end of formic acid addition. A second set of samples was taken to monitor the mercury concentration during stripping and/or to identify any issues associated with sampling $\mathrm{HgO}$ versus $\mathrm{Hg}\left(\mathrm{NO}_{3}\right)_{2}$ spiked simulants with the existing apparatus. This set also started with the end of formic acid addition. A third set of samples was taken to monitor the MWWT anions. The dewatering mass removed from the MWWT was divided roughly into thirds as it was removed. The contents of the MWWT were also collected at the end of reflux and analyzed.

Samples were taken of the SRAT products from all of the tests. These were characterized for elements, anions, wt. \% solids, $\mathrm{pH}$, and density.

Process equipment and sample mass data were taken to support material balance calculations for each test. All materials added or removed from the SRAT were weighed and recorded (with the exception of the air purge and off-gas). Glassware was weighed prior to each run and following each run, so that the mass of any material adhering to the glassware could be determined and factored into the material balance. 
WSRC-TR-2004-00548

Revision 0

This page intentionally left blank. 


\subsection{RESULTS}

Main results of this phase of the hydrogen program are summarized in this section. These focus on the role of mercury in hydrogen generation. Parameters typically monitored during a SRAT simulation were evaluated to check for any dependence on mercury concentration or form of the salt. This included direct effects on the observed hydrogen generation rate, plus any secondary effects that mercury produced that might have affected the available excess acid for hydrogen generation, etc. Additional supporting information plus further details are included in appendices. Data from Test 6 were also used to assess the role of oxygen in the chemistry related to hydrogen generation.

\subsection{Mercury-Noble Metal Interactions and Hydrogen Off-gas Data}

The main emphasis of this study was on how mercury impacted hydrogen generation. The batching data of Table 3 through Table 5 plus the process titration curves in Figure 2, page 16, indicate that readily comparable hydrogen data should have been obtained. Hydrogen generation was seen in all six tests. It was initially detected shortly after the completion of formic acid addition. Hydrogen generation data from the first five tests are directly comparable (all had air purges). These are shown in Figure 1.

Figure 1. Hydrogen Generation as a Function of Mercury

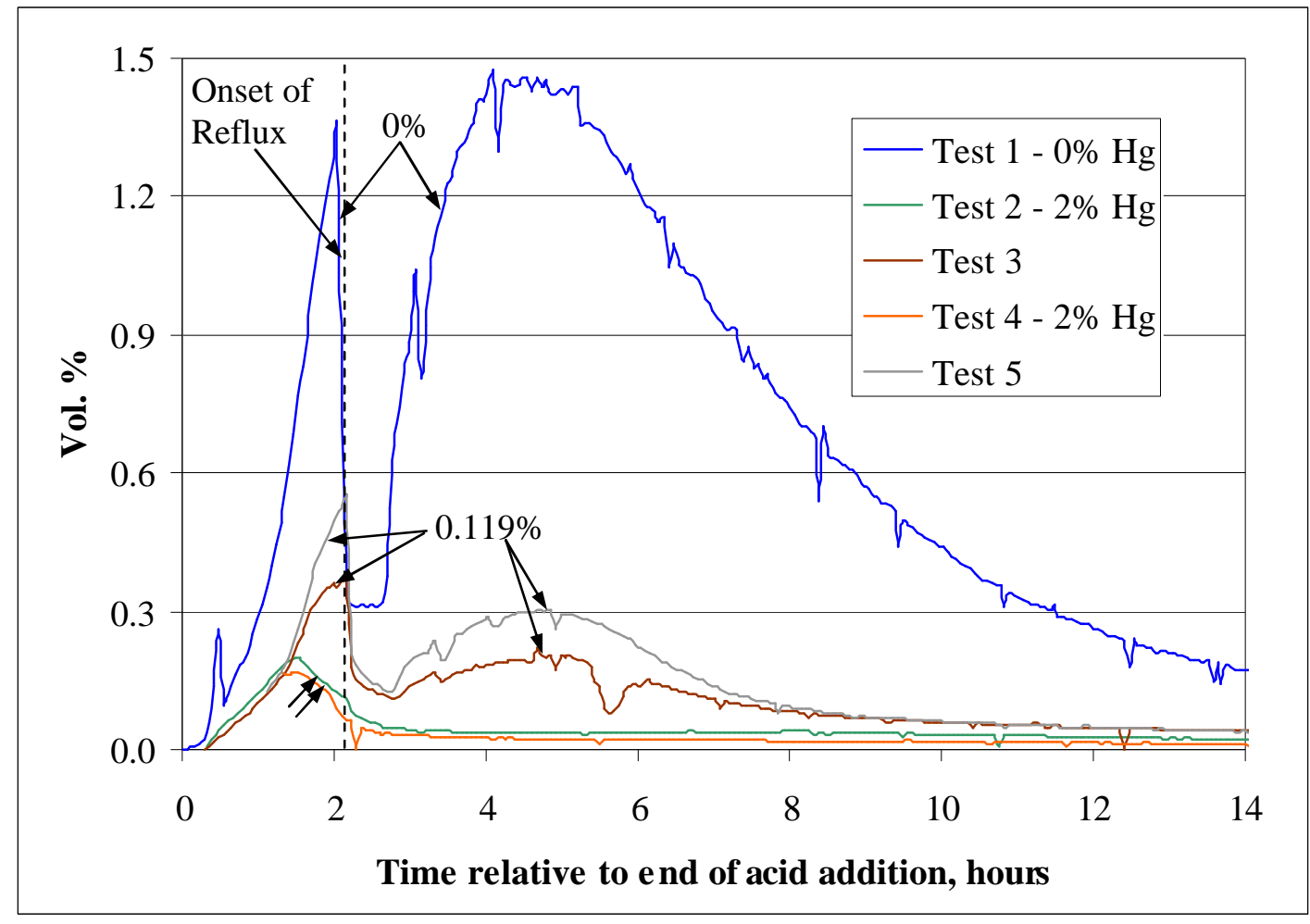

The first significant finding was that three distinct levels of hydrogen generation were seen at the three different mercury levels. There was a very significant drop in hydrogen generation between $0 \% \mathrm{Hg}$ and $0.119 \% \mathrm{Hg}$. A small amount of mercury was still an effective inhibitor. There was a second significant drop in hydrogen generation going from $0.119 \%$ to $2 \% \mathrm{Hg}$. This led to the preliminary conclusion that using less mercury would be conservative for hydrogen generation studies. The second finding was that the impact of the form of mercury trim chemical was small. 
The third significant observation related to Figure 1 was that the hydrogen generation rate was abruptly reduced at the onset of reflux at about 2.2 hours after acid addition. Data on reflux condensate composition are discussed in Appendix D. The acidic MWWT contents contained modest levels of nitrate and formate at the start of reflux, and no detectable nitrite. Reflux triggered another generation period of various oxides of nitrogen, however; apparently at the expense of hydrogen. This may have been related to the large size of the bench-scale MWWT relative to the SRAT compared to DWPF equipment, and to the fact that less acidic condensate from the end of dewatering had not purged it adequately (too few volume turnovers).

A similar, though less pronounced, effect of the onset of reflux on the hydrogen generation rate was observed in runs with SB2 simulant, Koopman (2000). In these runs, the onset of reflux led to a period of slower increase in the rising hydrogen generation rate rather than to a reduction in rate. The SB2 runs started with much less nitrite and nitrate than SB3. Presumably the MWWT condensate contained lower concentrations of potential species that could inhibit hydrogen generation at the start of refluxing compared with the SB3 tests if they are related to nitrite and nitrate. At the time of the SB2 runs, it was only observed that the pause in the rising hydrogen generation rate correlated with a small burst of $\mathrm{N}_{2} \mathrm{O}$ generation. The cause of both was not linked to the onset of reflux. This new data makes that linkage clear.

\subsection{SRAT Product Composition Data}

SRAT product samples were analyzed from each of the tests. These data were used to ensure that Tests 5 and 6 were not biased relative to Tests 1-4, since SRAT receipt samples were not pulled on Tests 5 and 6 , Section 2.2. Elemental results, Table 9, were used to ensure that representative sludge had been used in all six tests. Samples were calcined at $1100^{\circ} \mathrm{C}$ before ICP-ES analysis. The numbers in Table 9 are the wt. \%'s of the elements in the calcined solids. The anion results, Table 11, were also used in material balance calculations. The data do not give insight into hydrogen generation directly, but are an important part of validating the data presented above. 
Table 9. Elemental Composition Data for the SRAT Product Samples

\begin{tabular}{||l|c|c|c|c|c|c|}
\hline & Test 1 & Test 2 & Test 3 & Test 4 & Test 5 & Test 6 \\
\hline $\mathrm{Al}$ & 9.40 & 9.38 & 9.08 & 9.01 & 9.75 & 9.65 \\
\hline $\mathrm{Ba}$ & 0.13 & 0.12 & 0.12 & 0.12 & 0.12 & 0.12 \\
\hline $\mathrm{Ca}$ & 1.98 & 2.02 & 2.07 & 2.06 & 2.23 & 2.15 \\
\hline $\mathrm{Cr}$ & 0.16 & 0.16 & 0.16 & 0.16 & 0.16 & 0.15 \\
\hline $\mathrm{Cu}$ & 0.07 & 0.13 & 0.16 & 0.13 & 0.15 & 0.10 \\
\hline $\mathrm{Fe}$ & 27.3 & 27.6 & 27.8 & 27.5 & 28.5 & 28.4 \\
\hline $\mathrm{Gd}$ & 0.08 & 0.08 & 0.07 & 0.07 & 0.07 & 0.07 \\
\hline $\mathrm{K}$ & 0.11 & 0.13 & 0.12 & 0.11 & 0.12 & 0.12 \\
\hline $\mathrm{Mg}$ & 2.71 & 2.66 & 2.57 & 2.56 & 2.59 & 2.62 \\
\hline $\mathrm{Mn}$ & 3.92 & 3.80 & 3.86 & 3.85 & 3.80 & 3.78 \\
\hline $\mathrm{Na}$ & 15.4 & 16.3 & 15.7 & 15.2 & 15.8 & 15.8 \\
\hline $\mathrm{Ni}$ & 0.98 & 0.97 & 1.04 & 1.02 & 1.05 & 1.04 \\
\hline $\mathrm{P}$ & 0.06 & 0.06 & 0.05 & 0.05 & 0.04 & 0.05 \\
\hline $\mathrm{Pb}$ & 0.02 & 0.01 & 0.01 & 0.01 & 0.02 & 0.01 \\
\hline $\mathrm{S}$ & 0.45 & 0.47 & 0.44 & 0.45 & 0.45 & 0.46 \\
\hline $\mathrm{Si}$ & 1.18 & 1.06 & 1.05 & 1.08 & 1.10 & 1.24 \\
\hline $\mathrm{Zn}$ & 0.33 & 0.32 & 0.32 & 0.32 & 0.33 & 0.40 \\
\hline $\mathrm{Zr}$ & 0.41 & 0.41 & 0.36 & 0.38 & 0.40 & 0.40 \\
\hline $\mathrm{\Sigma}$ oxides & 96.7 & 98.2 & 97.0 & 95.7 & 99.5 & 99.5 \\
\hline
\end{tabular}

Variations about the mean elemental composition are well within historical norms. Sums of oxides around $98 \%$ are acceptable (not all elements are reported). Wt. \% solid, $\mathrm{pH}$, and density data were obtained on these six samples as well. These are given in Table 10.

Table 10. Data for SRAT Products

\begin{tabular}{||l|c|c|c|c|c|c||}
\hline & Test 1 & Test 2 & Test 3 & Test 4 & Test 5 & Test 6 \\
\hline Wt. \% Total Solids & 28.1 & 28.2 & 28.3 & 28.2 & 28.3 & 28.2 \\
\hline Wt. \% Insoluble Solids & 12.9 & 12.6 & 13.2 & 12.9 & 12.9 & 13.3 \\
\hline Wt. \% Soluble Solids & 15.3 & 15.7 & 15.0 & 15.3 & 15.4 & 15.0 \\
\hline Wt. \% Calcined Solids & 17.4 & 17.2 & 17.3 & 17.2 & 17.5 & 17.7 \\
\hline Density, g/mL & 1.18 & 1.24 & 1.26 & 1.26 & 1.28 & 1.21 \\
\hline pH & 5.00 & 4.45 & 4.17 & 4.02 & 4.25 & 4.61 \\
\hline
\end{tabular}

The weight percent total and insoluble solids data both indicate that these tests were dewatered as expected to give approximately the same concentrations of species. Test 1 with the highest formate destruction ended up with the highest $\mathrm{pH}$ as expected. The $\mathrm{pH}$ data for Tests 2-5 were very similar. SRAT vessel $\mathrm{pH}$ readings did not indicate a higher $\mathrm{pH}$ for Test 6 than for Tests $2-5$ unlike the analytical results on the SRAT product samples. Analyses of nitrate and formate in the SRAT products were also performed. Measurements were made using the Mobile Lab Ion Chromatograph (IC). These are given in Table 11. 
Table 11. Anion Data on SRAT Products

\begin{tabular}{||l|c|c|c|c|c|c||}
\hline & Test 1 & Test 2 & Test 3 & Test 4 & Test 5 & Test 6 \\
\hline Nitrate, mg/kg slurry & 39300 & 42300 & 37700 & 43000 & 43100 & 31700 \\
\hline Formate, mg/kg slurry & 70400 & 75700 & 71100 & 75400 & 81600 & 80400 \\
\hline
\end{tabular}

Test 6 had the least product nitrate, consistent with suppressed nitrite to nitrate conversion seen in that run. The SRAT product data confirmed that these six SRAT simulations were performed properly.

\subsection{Formate Loss and Nitrate Gain during Processing}

The quantity of formic acid added and the mass and composition of samples removed, plus the mass of the final SRAT product, were used to track total formate ion during SRAT processing. Formate ion and molecular formic acid are the two species that are being converted to hydrogen by the noble metal catalysts. The starting sludge was free of formate.

Table 12. Formate Change During SRAT Processing

\begin{tabular}{|l|l|c||}
\hline \hline & $\begin{array}{c}\text { Hg } \\
\text { form and concentration } \\
\text { (dried solids basis) }\end{array}$ & \% formate lost \\
\hline Test 0 & $0.119 \% \mathrm{Hg}(\mathrm{HgO})$ & $18.3^{*}$ \\
\hline Test 1 & $0.0 \% \mathrm{Hg}$ & 20.6 \\
\hline Test 2 & $2.0 \% \mathrm{Hg}(\mathrm{HgO})$ & 15.0 \\
\hline Test 3 & $0.119 \% \mathrm{Hg}\left(\mathrm{Hg}\left(\mathrm{NO}_{3}\right)_{2}\right)$ & 18.6 \\
\hline Test 4 & $2.0 \% \mathrm{Hg}\left(\mathrm{Hg}\left(\mathrm{NO}_{3}\right)_{2}\right)$ & 13.6 \\
\hline Test 5 & $0.119 \% \mathrm{Hg}(\mathrm{HgO})$ & 11.4 \\
\hline Test 6 & $0.119 \% \mathrm{Hg}(\mathrm{HgO})$ & $1^{\dagger}$ \\
\hline
\end{tabular}

* Value assumed for Tests 1-6 in the pre-run redox-balanced acid addition calculations.

$\dagger$ Analytical or other source of error suspected here.

Test 1 (no $\mathrm{Hg}$ ) had the greatest formate loss and also produced the most $\mathrm{CO}_{2}$. Tests $0,2,3$, and 4 had similar, intermediate formate losses and $\mathrm{CO}_{2}$ evolution. Based on this, the result for Test 5 formate lost was called into question. It does not seem consistent with Tests 0 and 3, although it probably lies within the range of reproducibility for this scale equipment running during different weeks. Test 6 produced the least $\mathrm{CO}_{2}$ and had the second lowest formate loss (would have been lowest formate loss if Test 5 was thrown out).

It appears that formate loss generally increased with increasing hydrogen generation, and thus with decreasing mercury content. The effect was small, however, relative to other sources of formate loss such as nitrite and manganese reduction. It further appeared that formate loss decreased when oxygen was removed, Test 6 . This was likely due to decreased formic acid reduction of nitrite ion caused by the elimination of $\mathrm{NO}_{2}$ absorption into the condensate on the walls of the SRAT (and subsequent formation of additional nitrite).

Table 13 summarizes the material balance results for the conversion of nitrite to nitrate in the six tests plus the comparable test, Test 0 , from the acid stoichiometry study, Baich (2004). 
WSRC-TR-2004-00548

Revision 0

Table 13. Nitrite and Nitrate Changes During SRAT Processing

\begin{tabular}{|l|l|c|c|}
\hline \hline & $\begin{array}{c}\mathbf{H g} \\
\text { form and concentration } \\
\text { (dried solids basis) }\end{array}$ & $\begin{array}{c}\text { \% nitrate gained } \\
\text { (relative to sludge } \mathrm{NO}_{3}{ }^{-} \\
\text {and } \mathrm{HNO}_{3} \text { added) }\end{array}$ & $\begin{array}{c}\text { \% nitrite to nitrate } \\
\text { (molar basis) }\end{array}$ \\
\hline Test 0 & $0.119 \% \mathrm{Hg}(\mathrm{HgO})$ & - & 46 \\
\hline Test 1 & $0.0 \% \mathrm{Hg}$ & 47 & 47 \\
\hline Test 2 & $2.0 \% \mathrm{Hg}(\mathrm{HgO})$ & 64 & 41 \\
\hline Test 3 & $0.119 \% \mathrm{Hg}\left(\mathrm{Hg}\left(\mathrm{NO}_{3}\right)_{2}\right)$ & 44 & 51 \\
\hline Test 4 & $2.0 \% \mathrm{Hg}\left(\mathrm{Hg}\left(\mathrm{NO}_{3}\right)_{2}\right)$ & 47 & 60 \\
\hline Test 5 & $0.119 \% \mathrm{Hg}(\mathrm{HgO})$ & 63 & 12 \\
\hline Test 6 & $0.119 \% \mathrm{Hg}(\mathrm{HgO})$ & 12 & \\
\hline
\end{tabular}

An uncertainty of $10 \%$ in product nitrate measurement by IC could change a $61 \%$ nitrite to nitrate conversion to a $46 \%$ conversion. Therefore the nitrite to nitrate conversion \%'s shown in Table 13 are inferred to be uncertain by at least $\pm 10 \%$, e.g. $51 \pm 10 \%$. No great difference in nitrogen chemistry due to concentration or form of mercury between Tests 1-5 was suggested by either the $\mathrm{NO}$ or $\mathrm{N}_{2} \mathrm{O}$ data as well, Appendix G. The result for nitrogen-purged Test 6 was unquestionably different from the other five. Far less nitrate was formed in Test 6 than in Tests 1-5. This is probably due to the elimination of absorption of $\mathrm{NO}_{2}$ into drops of condensate on the interior walls of the bench-scale SRAT in Test 6. The absorption forms nitrite and nitrate ions that reflux back into the SRAT slurry.

\subsection{Process Titration Data}

The temperature compensated $\mathrm{pH}$ data in Figure 2 are from the nitric and formic acid addition periods for each of the six test runs. 
Figure 2. Process Titration Curves at $93^{\circ} \mathrm{C}$

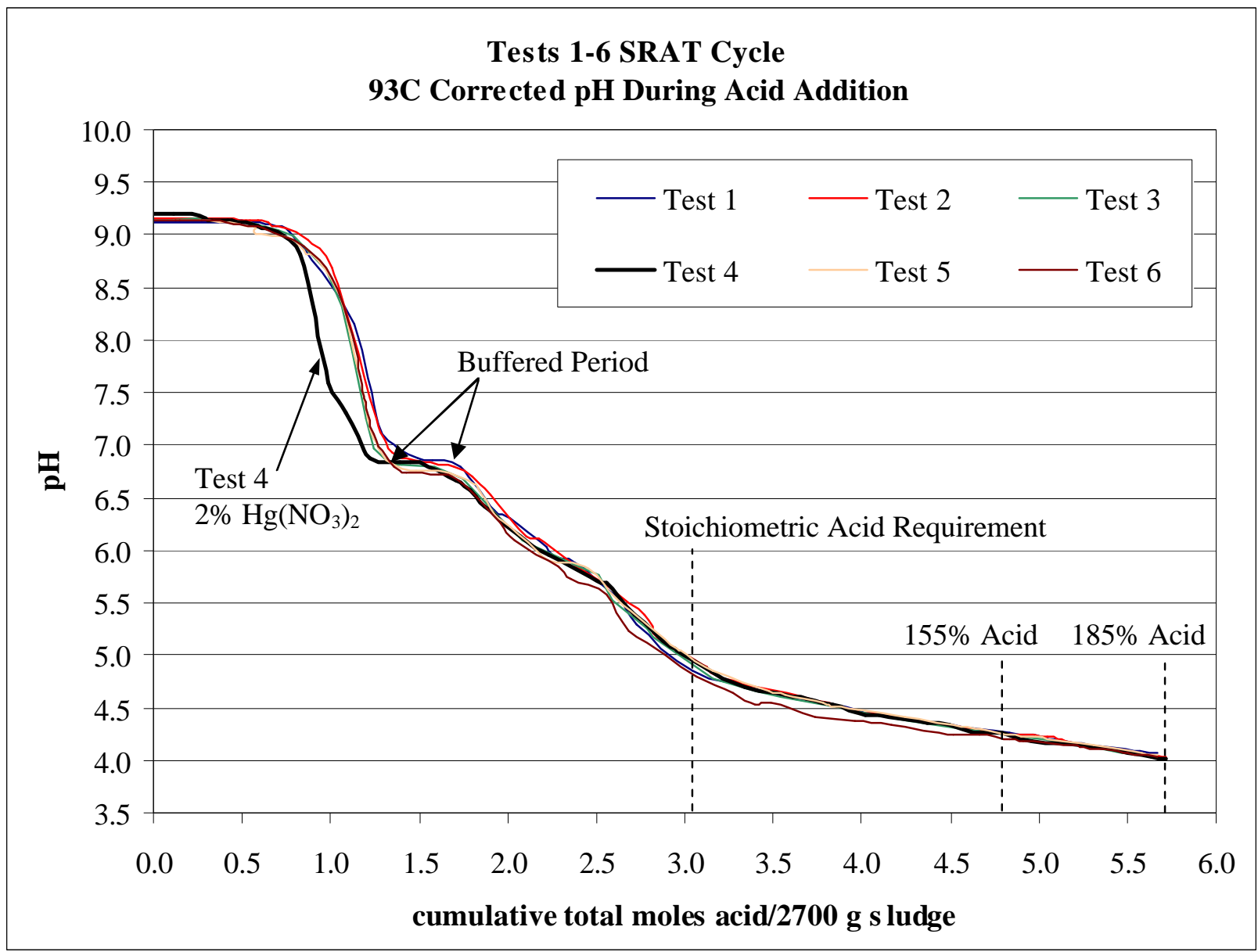

The data were virtually identical for all but a portion of Test 4 ( $2 \% \mathrm{Hg}$ from the nitrate). Samples of the $2 \% \mathrm{Hg}$ from nitrate slurry also performed differently in the auto-titrator, see Appendix B for details. $100 \%$ of the stoichiometric acid demand produced a $\mathrm{pH}$ of about 4.9-5.0. 155\% of the stoichiometric acid demand produced a $\mathrm{pH}$ of about 4.3. This is the nominal SB3 target stoichiometric factor in DWPF.

The process titration data indicate several other things as well. Most important of these is that the sludge plus acids produced six virtually identical slurries at the end of acid addition. This is the ideal starting point to assess hydrogen generation differences as a function of mercury or oxygen. Second, the data confirm generally correct batching of each SRAT and proper delivery of the target acid volumes. SRAT product composition data in section 3.2 were also used to help confirm that these goals were met. A comparison of process titration data to auto-titrator data is included in Appendix B.

\subsection{The Effect of Hg on the Other Off-gas Data}

The data from the six tests were also reviewed to assess the impact of both mercury and oxygen on the generation of $\mathrm{CO}_{2}, \mathrm{~N}_{2} \mathrm{O}$, and NO. Mercury impacted all of the off-gas data to some degree, but the main effects were in the $\mathrm{CO}_{2}$ data. The elimination of oxygen was apparent in the data for all three species as well. Additional graphs of off-gas data are given in Appendix G. 
$\mathrm{CO}_{2}$ generation during acid addition and dewatering is shown in Figure 12. The correlation of this data with slurry $\mathrm{pH}$ is discussed in Appendix $\mathrm{C}$. The acid addition and dewatering period includes conversion of carbonate ( $-5 \mathrm{hrs}$ to $-2.5 \mathrm{hrs})$, reduction of nitrite ( $-3 \mathrm{hrs}$ to $+1 \mathrm{Hrs})$, reduction of $\mathrm{Mn}$, reduction of $\mathrm{Hg}$, and the beginning of hydrogen generation.

Figure 3. Carbon Dioxide Generation early in the SRAT Cycle

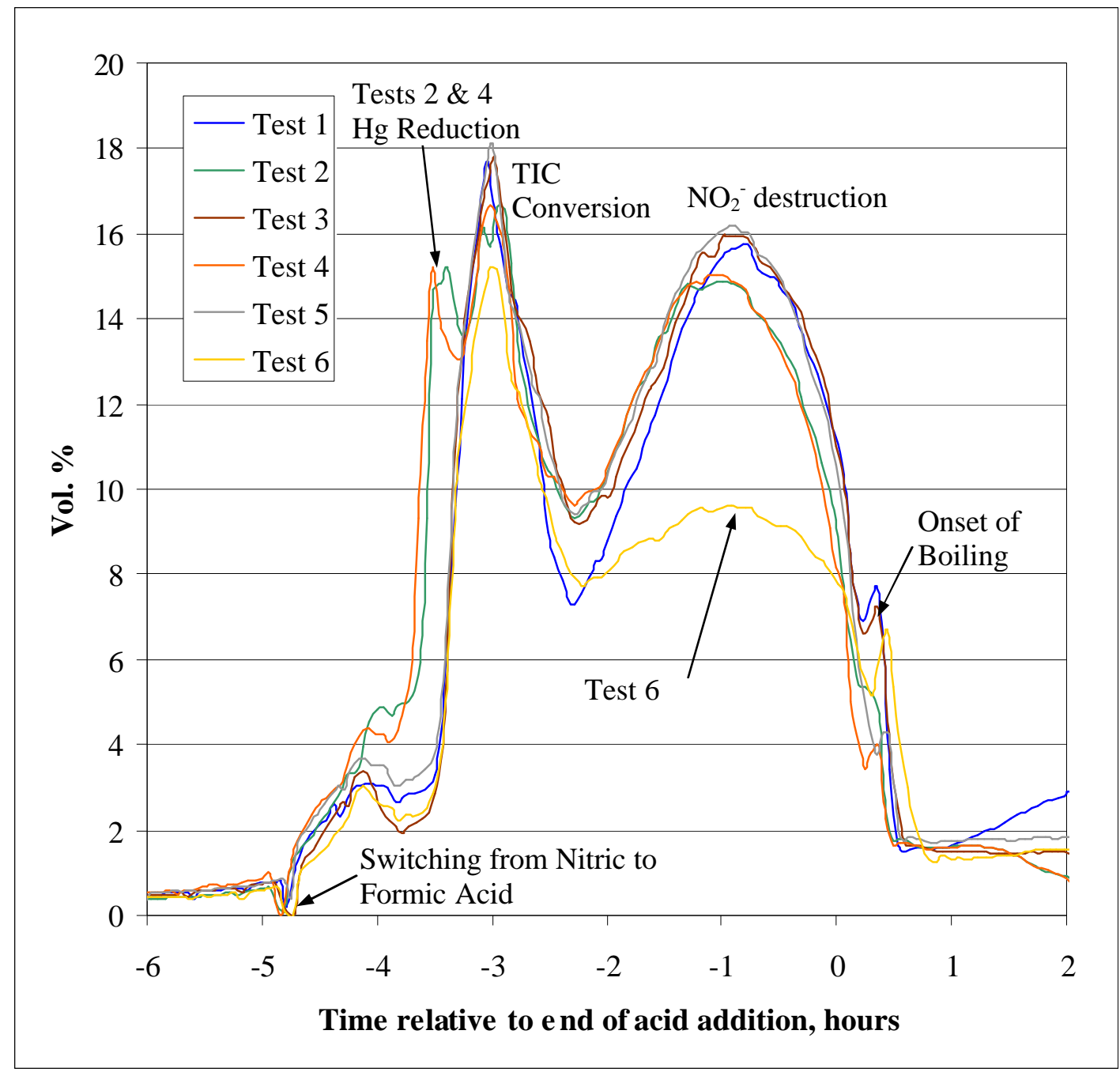

The principal finding with respect to mercury was that there were peaks in $\mathrm{CO}_{2}$ generation rate at -3.6 hours for the two runs with $2 \% \mathrm{Hg}$, Tests 2 and 4, that were absent from the other four runs. This is during formic acid addition, and it is inferred to be chemical reduction of mercury to the element. The principal finding with respect to the nitrogen purged run was the significant reduction in $\mathrm{CO}_{2}$ generation during nitrite destruction compared to the five air-purged runs. This was related to the elimination in nitrite being returned to the slurry after $\mathrm{NO}_{2}$ absorbs into moisture on the vessel walls. Eliminating the refluxed nitrite eliminated the $\mathrm{CO}_{2}$ produced while destroying it.

In addition to the detection of mercury reduction during acid addition, the following observations were made (additional details in Appendix G): 
- As initial mercury concentration increased, the amount of $\mathrm{CO}_{2}$ produced during reflux fell.

- As initial mercury concentration increased, the amount of NO produced increased slightly.

- As initial mercury concentration increased, the amount of $\mathrm{N}_{2} \mathrm{O}$ produced decreased slightly.

- Eliminating oxygen led to decreased $\mathrm{CO}_{2}$ production (and decreased formate destruction).

- $\mathrm{CO}_{2}$ production during reflux in the nitrogen-purged run exceeded hydrogen generation, so the elimination of catalytic wet air oxidation does not entirely explain the $\mathrm{CO}_{2}$ being produced in excess of one mole $\mathrm{CO}_{2}$ per mole $\mathrm{H}_{2}$ during reflux.

- Eliminating oxygen led to less $\mathrm{N}_{2} \mathrm{O}$ production (and lower nitrite to nitrate conversion).

It is possible that the interaction of mercury with the noble metals led to preferential formation of NO at the expense of $\mathrm{N}_{2} \mathrm{O}$, but the observed differences were small.

\subsection{Competing Catalytic Reactions}

Catalytic wet air oxidation (CWAO) is a class of chemical reactions between organic molecules and oxygen. These reactions progressively break carbon-carbon and carbon-hydrogen bonds to produce smaller organic molecules. The ultimate products of complete CWAO are carbon dioxide and water. Noble metals, such as $\mathrm{Pd}, \mathrm{Rh}$, and $\mathrm{Ru}$, catalyze these reactions moderately well at temperatures above $80^{\circ} \mathrm{C}$. The existence of these reactions in the SRAT was demonstrated during preliminary SB3 flowsheet testing using high oxalate content sludges. CWAO of oxalate to formate was observed, in addition to CWAO of formate/formic acid to carbon dioxide and water.

CWAO is potentially important to the study of hydrogen generation for many reasons. First, CWAO attacks formate/formic acid in the slurry. This is the same reactant used to make hydrogen. Second, CWAO is catalyzed by noble metals. These are potentially the same noble metals that are catalyzing hydrogen generation. Third, CWAO produces $\mathrm{CO}_{2}$. This is one of the gases monitored during process simulations. $\mathrm{CO}_{2}$ is also a by-product of hydrogen generation. Fourth, $\mathrm{CWAO}$ and hydrogen generation seem to be occurring simultaneously. This is in contrast to reactions such as nitrite destruction, mercury reduction, and carbonate destruction which primarily occur before hydrogen generation.

During SB3 process simulations, formate loss during processing has been small as a percentage of total formate present. This is due to the large acid demand and to the high nitrate concentration of the sludge. The high nitrate content causes $80-90 \%$ of the total acid to be added as formic acid. Consequently, the depletion of formate by CWAO is not expected to inhibit hydrogen generation by significantly reducing the available formate used for hydrogen generation in SB3 testing. This could potentially be a significant factor in other sludges.

The most likely impact of CWAO on SB3 hydrogen generation appeared to be the potential use of the same noble metal catalyst for both reactions. Catalyst sites engaged in CWAO are presumably not able to simultaneously generate hydrogen. Furthermore, CWAO might be more active in bench-scale equipment than in DWPF because of the small scale that could permit easier uptake of oxygen. Oxygen is consumed by CWAO and must be replenished from the vapor space. The bench-scale equipment has shorter mass transfer distances from the gas phase to any point in the slurry than the full-scale SRAT. Therefore, issues of equipment scale and mixing could be artificially enhancing CWAO at the expense of hydrogen generation. This scenario would give rise to a source of non-conservative error in bench-scale conclusions about hydrogen generation.

The sixth SRAT simulation addressed this issue directly. Oxygen was removed from the purge gas. This prevents catalytic wet air oxidation of formate/formic acid, since this step of CWAO requires oxygen. If 
the acid consuming reactions prior to hydrogen generation remain unchanged, then hydrogen generation should either increase (if CWAO is competing) or remain the same (if CWAO is not competing).

The effect of removing oxygen from the vessel purge on the peak hydrogen generation rate is shown in Figure 4. Tests 5 and 6 were processed identically, except that Test 5 used an air purge, while Test 6 used an equivalent volumetric flow of nitrogen.

Figure 4. Effect of Oxygen on Peak Hydrogen Generation Rate

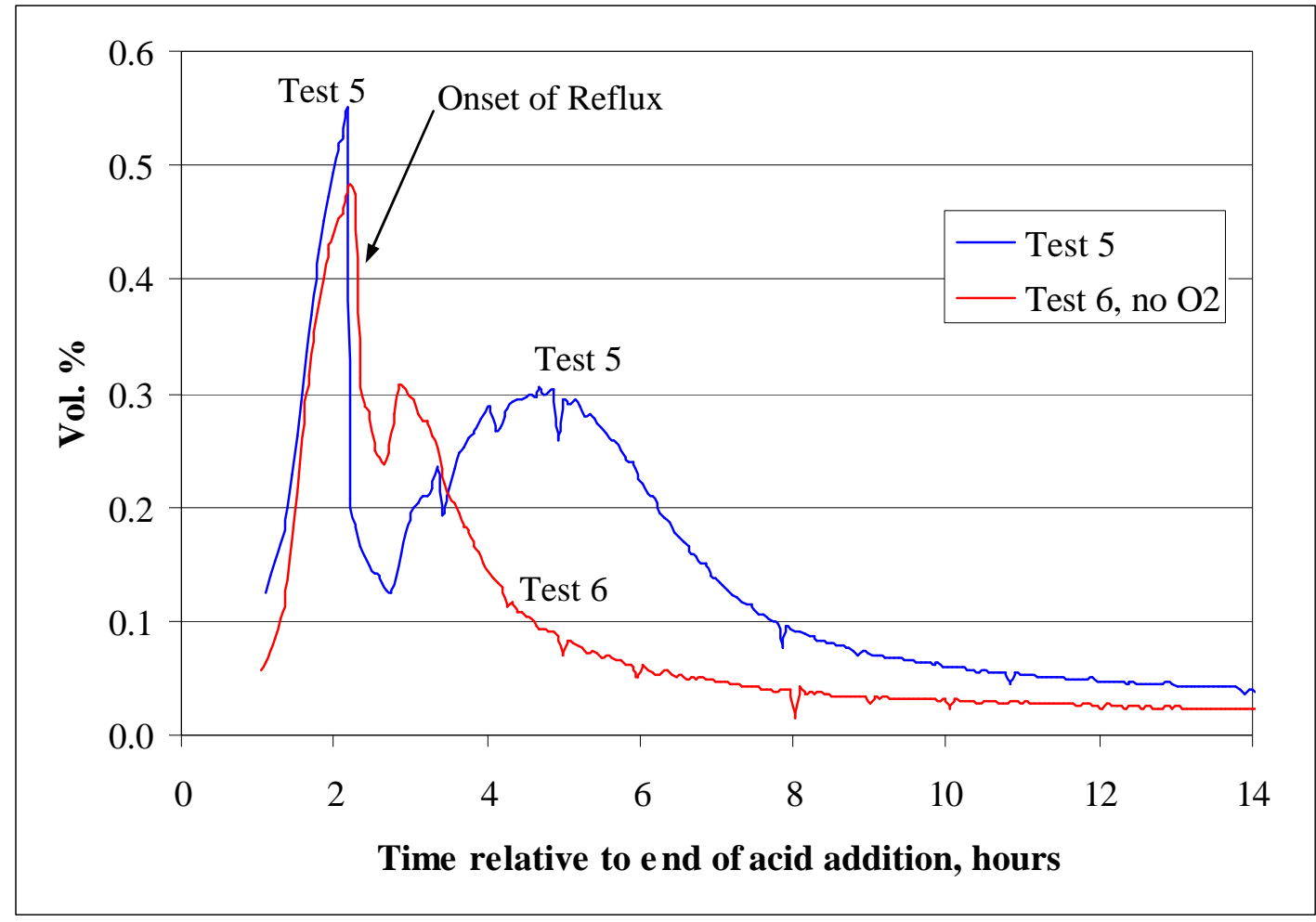

Clearly, there was no increase in hydrogen generation in Test 6 relative to Test 5. Therefore, CWAO is not competing with hydrogen generation for catalyst sites under the conditions tested. By the same logic, the role of mixing intensity in controlling the replenishment of oxygen is not a factor in hydrogen generation, although it could still be a factor controlling the extent of CWAO attack on formate. There is no reason to claim that using an inert purge caused higher hydrogen generation rates.

The preliminary conclusion that CWAO is not competing with hydrogen generation for catalyst sites assumed that the same acid consuming reactions occurred prior to hydrogen generation in both Test 5 and Test 6. As discussed in Appendix H, however, the absence of oxygen may have increased the net acid requirement for nitrite destruction by some amount. If so, then there was somewhat less excess acid available for hydrogen generation in Test 6 than in the other five tests. This is consistent with the somewhat lower hydrogen generation peak for Test 6 in Figure 4. Thus, it would be premature to claim that removing oxygen led to a reduced rate of hydrogen generation, since it may well have been the reduction in excess acid that produced the effect.

Tests 2 and 4 had a broad peak in $\mathrm{CO}_{2}$ generation from 3-8 hours after acid addition, Appendix G, Figure 13 , but there was no corresponding peak in hydrogen generation. Data like this indicate that other $\mathrm{CO}_{2}$ 
producing reactions are occurring besides hydrogen generation. These reactions presumably include CWAO.

Figure 5 was created to assess the significance of non-hydrogen generating reactions during boiling on carbon dioxide generation. $\mathrm{CO}_{2}$ produced above one mole per mole of hydrogen was defined as "excess $\mathrm{CO}_{2}$ ". This was computed as the difference of the volume \%'s of the two species to give the volume \% $\mathrm{CO}_{2}$ not associated with hydrogen generation. For example, if 4 vol. $\% \mathrm{CO}_{2}$ and 1 vol. $\% \mathrm{H}_{2}$ were detected simultaneously, then 1 vol. $\% \mathrm{CO}_{2}$ was associated with hydrogen generation and 3 vol. $\% \mathrm{CO}_{2}$ were in excess of that made by hydrogen generation.

Figure 5. Carbon Dioxide in Excess of Hydrogen During Boiling

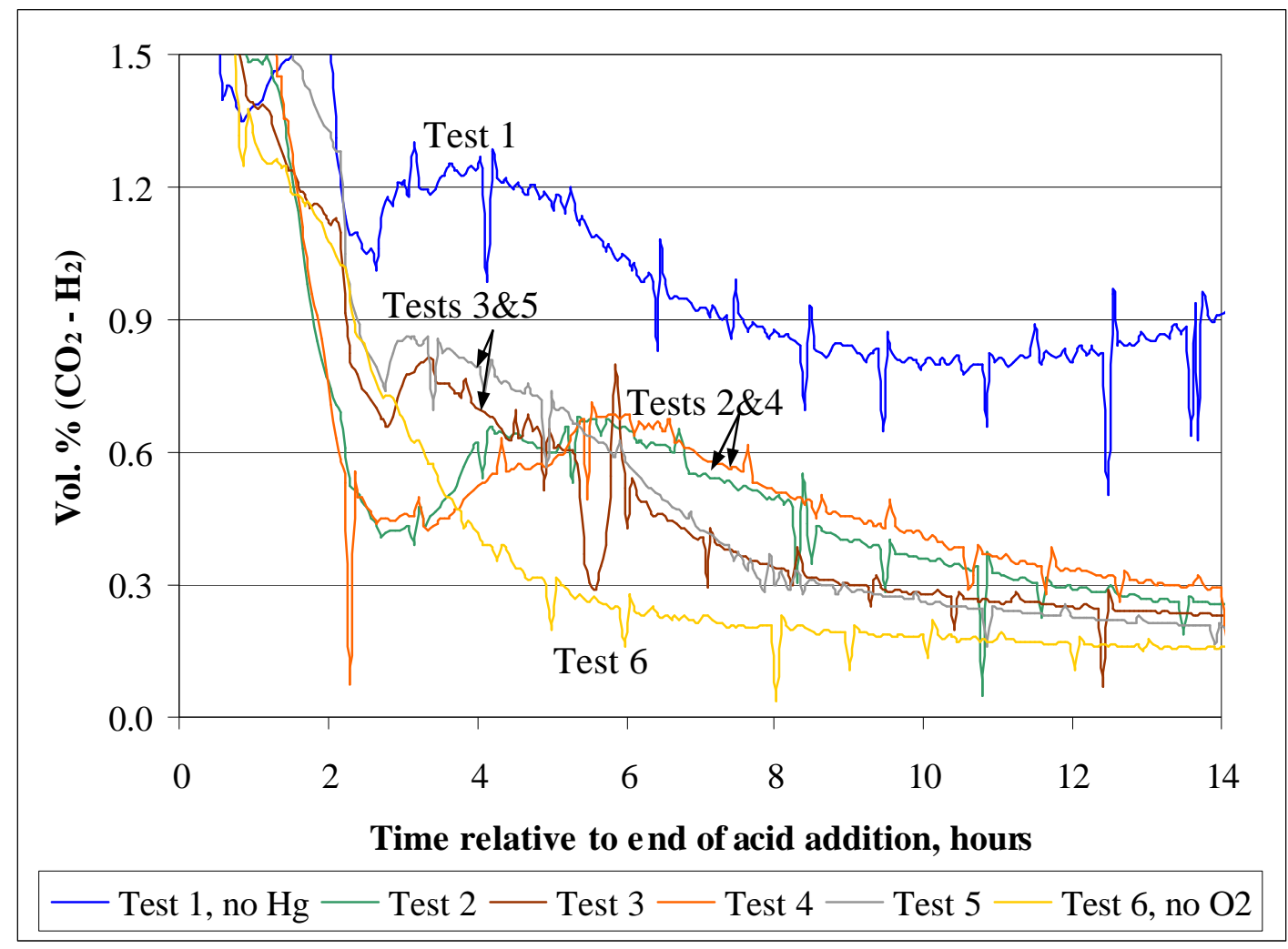

The main finding in Figure 5 came from Test $6 . \mathrm{CO}_{2}$ was being produced in excess of that from hydrogen generation in the absence of CWAO. The reaction rate appeared to be declining with time based on the falling $\mathrm{CO}_{2}$ profile. The identity of this reaction remains unknown. It could be related to manganese reduction or to denitration reactions, but there is no direct evidence to support either of these hypotheses. Specifically, other testing has not shown increasing $\mathrm{Mn}^{+2}$ formation during reflux, and the data in Appendix F do not show signs of on-going nitrate destruction. There is also no evidence for iron reduction in the SRAT. The small spikes in the data every 1-2 hours occur during slurry sampling. These indicate that the $\mathrm{GC}$ was still sensitive to $\mathrm{CO}_{2}$ at and below 0.2 vol. \%. SRAT product IC formate data were generally consistent with the $\mathrm{CO}_{2}$ findings with the exception of the result for Test 5 , as discussed in section 3.3.

Tests 1-5 with oxygen in the purge all produced more excess $\mathrm{CO}_{2}$ than Test 6 with no oxygen. This would support previous assertions that $\mathrm{CWAO}$ is one of the processes occurring during refluxing in 
parallel with hydrogen generation. CWAO in SRAT processing has not been extensively studied in its own right. The five tests with oxygen had a peak in excess $\mathrm{CO}_{2}$ during reflux (during from 2-14 hours after the end of acid addition). The peak in Tests 1-5 may be a CWAO peak similar in principal to the hydrogen generation peaks. This is hypothesized since no peak was seen in Test 6 with no CWAO. The timing of the excess $\mathrm{CO}_{2}$ peak seemed to shift to later times as the mercury content increased. This puts $\mathrm{Hg}$ in the role of both delaying and inhibiting the peak of this reaction. That is, more $\mathrm{Hg}$ led to lower maximum volume \%'s in excess $\mathrm{CO}_{2}$ and caused the maximum to come later in the reflux period.

Conversely, the peak in hydrogen generation at $2 \% \mathrm{Hg}$ came earlier than the peak at $0.119 \% \mathrm{Hg}$. Analytical data confirm that $\mathrm{Hg}$ is still present during the reflux period in Tests 2-6, i.e. increasing $\mathrm{Hg}$ levels inhibited the magnitude of, but did not delay, the hydrogen generation peak. This is a second line of reasoning indicating that $\mathrm{CWAO}$ and hydrogen generation are not competing for the same catalytic sites, since mercury appeared to affect the two reactions differently while they were both occurring simultaneously.

There is a real possibility that the reaction occurring in Test 6 that produced the excess $\mathrm{CO}_{2}$ has not been previously identified. Some data obtained during the SB3 flow sheet development work indicated that $\mathrm{Mn}$ reduction also occurred during acid addition. This was indicated by high $\mathrm{Mn}^{+2}$ content in the postacid addition supernate, Koopman (2003a). King et al. (1997) gave the following reaction, formic acid reduction of nitrate, also known as denitration, as another possible reaction:

$$
5 \mathrm{HCO}_{2} \mathrm{H}+\mathrm{NO}_{3}^{-} \rightarrow \mathrm{NH}_{3}+\mathrm{HCO}_{2}^{-}+4 \mathrm{CO}_{2}+3 \mathrm{H}_{2} \mathrm{O}
$$

A net increase in total nitrate was seen in all six tests, however, rather than a decrease. Nitrate mass loss during refluxing did not appear to be very significant either, see Appendix F. Reaction [1], therefore, may or may not explain the excess $\mathrm{CO}_{2}$ data. The question of this potentially new reaction was not pursued further, since no firm linkage to hydrogen generation has been established. Tests for the occurrence of reaction [1] are best made by checking for ammonia. It may be appropriate to do more frequent spot checks for ammonia in the MWWT condensate and SRAT product.

The hydrogen and $\mathrm{CO}_{2}$ data taken together indicate the following:

- Catalytic wet air oxidation is indicated as occurring in the SRAT cycle.

- Catalytic wet air oxidation is not inhibiting SB3 hydrogen generation (separate catalysts).

- Increasing mercury concentration inhibits but does not delay the peak in hydrogen generation, but it both inhibits and delays catalytic wet air oxidation reactions (separate catalysts).

- Hydrogen generation and catalytic wet air oxidation are not the only reactions occurring during reflux that produce carbon dioxide.

\subsection{Effect of Nitrite on Excess Acid and Hydrogen Generation}

Understanding nitrite destruction is very important to understanding hydrogen generation. Historical (and in some cases unpublished) data have shown that both destruction of most nitrite as well as the initial concentration of nitrite can affect the peak hydrogen generation rate, see the review by Koopman (2004). This raises the question of why the initial nitrite concentration is important, since hydrogen generation is typically not seen until nitrite is virtually destroyed.

One possible reason why the initial nitrite concentration is important is that formation of a $\mathrm{Rh}\left(\mathrm{NO}_{2}\right)_{6}{ }^{-3}$ catalyst complex could be occurring in parallel with nitrite destruction. Some University of Georgia data reviewed in Koopman (2004), as well as some unpublished site data, indicate that this complex may be 
more catalytically active than $\mathrm{Rh}$ metal for hydrogen generation. The fraction of $\mathrm{Rh}^{+3}$ complexed relative to that reduced to the element, $\mathrm{Rh}^{0}$, could be a complicated function of initial nitrite concentration, $\mathrm{pH}$, acid addition rate, etc.

Slower destruction of the nitrite groups complexed with $\mathrm{Rh}$ compared to those present as free ions may be one of the reasons that the hydrogen generation rate peaks then falls to lower non-zero rates during boiling in the SRAT. Eventual nitrite destruction would ultimately eliminate the rhodium complex from the slurry (by destroying the weakly bonded nitrite groups). Supporting data to confirm this scenario do not presently exist. Eventual reduction of all $\mathrm{Rh}^{+3}$ to $\mathrm{Rh}^{0}$ would also eliminate the complex.

Definitive data regarding the relative activities of the two forms of Rh for hydrogen generation in sludge do not exist. Data describing the relative rates of formation and destruction of the two forms in sludge do not exist. These are potential keys to modeling the peak hydrogen generation rate. A prerequisite to understanding these steps is to better understand bulk nitrite destruction during SRAT processing. This is also a prerequisite to improving calculations of the quantity of excess acid present to participate in hydrogen generation. Excess acid is that acid not used to neutralize base, destroy carbonate, and reduce $\mathrm{Hg}, \mathrm{Mn}$, and nitrite. The quantity of excess acid affects the distribution of total formate between formate ion and molecular formic acid. Literature data indicate that the rate of hydrogen generation from formic acid is greater than the rate of hydrogen generation from formate ion.

The chemistry of nitrite ion during these tests was investigated. Five reactions have been developed to explain the cumulative nitrite destruction process. These are given below:

$$
\begin{gathered}
3 \mathrm{HNO}_{2} \rightarrow \mathrm{HNO}_{3}+\mathrm{H}_{2} \mathrm{O}+2 \mathrm{NO} \\
2 \mathrm{HNO}_{2}+\mathrm{HCOOH} \rightarrow \mathrm{CO}_{2}+2 \mathrm{NO}+2 \mathrm{H}_{2} \mathrm{O} \\
\mathrm{HNO}_{2}+\mathrm{HCOOH}+\mathrm{O}_{2} \rightarrow \mathrm{HNO}_{3}+\mathrm{H}_{2} \mathrm{O}+\mathrm{CO}_{2} \\
\mathrm{HNO}_{2}+1 / 2 \mathrm{O}_{2} \rightarrow \mathrm{HNO}_{3} \\
2 \mathrm{HNO}_{2}+2 \mathrm{HCOOH} \rightarrow \mathrm{N}_{2} \mathrm{O}+2 \mathrm{CO}_{2}+3 \mathrm{H}_{2} \mathrm{O}
\end{gathered}
$$

Additional details and discussion are given in Appendix H. Reactions [4] and [5] take place in several steps and involve the condensation of $\mathrm{NO}_{2}$ into water as nitrous and nitric acids. These reactions could not occur in Test 6 , because $\mathrm{NO}$ did not convert to $\mathrm{NO}_{2}$ in the absence of oxygen. Significantly reduced evolution rates of $\mathrm{CO}_{2}$ and $\mathrm{N}_{2} \mathrm{O}$ during formic acid addition were also observed in Test 6 . This was interpreted to mean that a significant amount of nitrous acid was being formed and refluxed on the vessel wall during the other five experiments with air purges. This additional refluxed nitrite should have led to more $\mathrm{CO}_{2}$ generation, more $\mathrm{N}_{2} \mathrm{O}$ generation, and more nitrite to nitrate conversion per the above reactions. All of these differences were observed.

The available acid following nitrite destruction should have been altered by the refluxing of nitrous and nitric acids as well as discussed further in Appendix H. It is difficult to calculate the exact reduction in available acid for hydrogen generation that occurred in Test 6 . It was estimated to be roughly $5 \%$ based on other hydrogen generation data for SB3 taken from Baich (2004). 


\subsection{CONCLUSIONS}

Six SRAT simulations were completed with SB3 simulant and sufficient acid to produce significant quantities of hydrogen. The main findings of the study were:

- Increasing concentrations of mercury inhibit the peak hydrogen generation rate in the SB3 system. Future sludge batches with higher mercury contents are likely to have a larger range of allowable acid additions than batches with lower mercury contents.

- The onset of reflux following dewatering triggered a rapid reduction in the hydrogen generation rate in those tests where the hydrogen generation rate had not yet reached its peak level. The reduction in rate was not permanent.

- The form of mercury used in bench-scale testing, oxide versus nitrate, was not a significant factor to the peak hydrogen generation rate. The oxide and nitrate trimmed slurries produced very similar hydrogen generation profiles at both $0.119 \%$ and $2 \% \mathrm{Hg}$. Future hydrogen generation studies should be able to proceed with either.

- Catalytic wet air oxidation was not interfering with hydrogen generation in SB3 testing. Since catalytic wet air oxidation did not impact hydrogen generation, factors such as mixing intensity, which potentially controls slurry oxygen uptake, are less likely to be critical to simulation results.

- Test data led to a redesign of the SRAT condenser and MWWT portion of the experimental apparatus, as well as to a decision to insulate the SRAT during acid addition to reduce internal refluxing. These changes are expected to make the bench-scale SRAT perform more like the DWPF SRAT.

Some additional findings came out of this study:

- Mercuric nitrate complicated the $\mathrm{pH} 7$ base equivalents titration above 1 wt. \% $\mathrm{Hg}$ in the slurry solids, apparently by shifting the $\mathrm{pH}$ of a buffer in the sludge (Appendix B). Mercuric nitrate seemed to be sampled somewhat better at high concentrations than the oxide, but both sets of data were at lower concentrations than expected (Appendix E). Analytical error was not anticipated to be large enough to explain this. Bench-scale mercury sampling may need to start before the end of acid addition when tracking mercury stripping.

- Varying the initial mercury concentration had affects on various reactions. Increasing mercury concentration seemed to inhibit other $\mathrm{CO}_{2}$ generating reactions during reflux as well as hydrogen generation. Increasing mercury seemed to inhibit $\mathrm{N}_{2} \mathrm{O}$ formation and promote $\mathrm{NO}$ formation during nitrite destruction, but the effect was not large over the range of $\mathrm{Hg}$ concentrations studied.

- At least one other $\mathrm{CO}_{2}$ producing reaction is occurring in parallel with hydrogen generation and catalytic wet air oxidation. The actual reaction has not been identified, so its potential impact on hydrogen generation is unknown.

- Internal refluxing was indicated as a significant mechanism for nitrate formation in the benchscale equipment. This would tend to overstate nitrite to nitrate conversion relative to the plant. 
- There was considerable reproducibility in the off-gas data obtained from the six tests. The implication was that SRAT testing is fairly reproducible at the 4-L vessel (2700 g sludge) scale. The off-gas data suggested higher reproducibility than was indicated by the IC anion data. The tentative conclusion is that carefully executed SRAT tests are more reproducible than IC data suggests. This supports the decision to run single, rather than multiple, tests at each set of variables.

The six scoping SRAT tests brought considerable new insight into SRAT chemistry. A number of recommendations were generated from the data. These are summarized in the next section. 


\subsection{RECOMMENDATIONS/PATH FORWARD}

The initial phase of the hydrogen generation program was a review of past work. The review of site and literature data on hydrogen generation indicated a need to resolve questions concerning mercury, oxygen, and mixing which were addressed in this phase of the hydrogen generation study program. The first experimental phase of the hydrogen generation study indicated that mercury significantly impacts hydrogen and carbon dioxide generation for the SB3 composition studied.

Other factors potentially impacting hydrogen generation were identified in the review of past work. It will be necessary to develop a better understanding of these issues in order to better address the questions raised by the addition of new streams to the DWPF feed slurry, such as canyon wastes and salt processing by-products. Future work has been prioritized. The next issue that should be addressed is the impact of the precipitated form of the noble metals on hydrogen generation. This will look at the difference between noble metals spiked into the finished simulant compared to noble metals co-precipitated with the other simulant insoluble species. The effect of heat-treating some of the co-precipitated simulant to simulate aging effects is included in this phase.

The hydrogen generation literature review also indicated a need to study the extent of sludge washing decisions on hydrogen generation. An opportunity has arisen to gain the first step of this understanding. A source of alkali melt rate study is being conducted. Five SRAT cycles will be performed by taking the recipe for SB3 simulant and either increasing or decreasing the total quantity of the sodium salts added. This will change the base equivalents, TIC, and nitrite concentrations. All runs will target $155 \%$ of the five individual sludge stoichiometric acid requirements. The set of SRAT data will give an indication of how hydrogen generation varies with changing stoichiometric acid requirement at constant stoichiometric factor and noble metal concentration in the presence of identical insoluble solids. A follow-up study could investigate how the size of the permissible acid addition window varies with the stoichiometric acid requirement, i.e. what range of stoichiometric factors would be permissible as the alkali content of the starting sludge changes. This would presumably also be a function of the noble metal concentrations.

An extensive set of recommendations was included in the hydrogen generation review study. The next issue to be addressed after studying precipitated noble metals has not been fixed. It could include the role of silver-noble metal interactions on hydrogen generation, a study to determine which individual noble metal is most important, a program to identify potential poisons (both in the sludge already or that could be added), and so forth. These issues all fall into the category of identifying factors that are important to hydrogen generation.

In addition to identifying the significant factors that influence hydrogen generation, there is a need to better understand how the major factors produce their effects. Such work could include a series of process simulations where the noble metal concentrations are varied while other parameters are kept constant, to determine the dependence of hydrogen generation on changes in noble metal concentration. Another area where predictive capabilities could be improved is in calculating how much of the acid added during the SRAT cycle will be left over for hydrogen generation. This would be of particular benefit to programs proposing to add secondary streams to DWPF. Secondary streams lead to changes in the stoichiometric acid calculation, while only the acid present in excess of actual requirements seems to be associated with hydrogen generation. 
WSRC-TR-2004-00548

Revision 0

This page intentionally left blank. 


\subsection{REFERENCES}

Bannochie, C. J. and T. L. Fellinger, Tank 11H Analytical Results as Input to DWPF Sludge Batch 4. WSRC-TR-2004-00473, Savannah River Site, Aiken, SC 29808 (2004).

Cotton, F. A., and G. Wilkinson, F. R. S. Advanced Inorganic Chemistry, A Comprehensive Test. $3^{\text {rd }}$ ed., pp. 354-360, Interscience Publishers, a Division of John Wiley \& Sons, Inc., New York (1972).

Baich, M. A., D. R. Best, T. K. Snyder, and M. F. Williams, Sludge Batch 2-3 Blend Flowsheet Simulations: Determination of the Acid Addition Window (U). WSRC-TR-2004-00042, Savannah River Site, Aiken, SC 29808 (2004).

Baich, M. A., D. R. Best, M. E. Stone, and M. F. Williams, Sludge Batch 2-3 Blend Flowsheet Simulations: Process Variability Study (U). WSRC-TR-2004-00225, Savannah River Site, Aiken, SC 29808 (2004).

Bannochie, C. J. and T. L. Fellinger, Tank 11H Analytical Results as Input to DWPF Sludge Batch 4. WSRC-TR-2004-00473, Savannah River Site, Aiken, SC 29808 (2004).

Eibling, R. E., Nitric Acid - Formic Acid Compatibility in DWPF (U). WSRC-RP-92-1247, Savannah River Site, Aiken, SC 29808 (1992).

Herman, C. C., T. L. Fellinger, N. E. Bibler, and D. C. Koopman, Scoping SRAT Runs with Simulated Sludge Batch 3. SRT-GPD-2002-00044, Savannah River Site, Aiken, SC, April 12, 2002.

Herman, C. C. and M. F. Williams, Scoping Run to Evaluate a Nitric Acid Only Flowsheet for Sludge Batch 3. SRT-GPD-2003-00022, Savannah River Site, Aiken, SC, March 20, 2003.

Hsu, C. S. and J. A. Ritter, Study on Hydrogen Evolution During Treatment of SRS High Level Radioactive Sludge Simulant with Formic Acid (U). WSRC-MS-92-270, Savannah River Site, Aiken, SC 29808 (1992).

King, R. B., and N. K. Bhattacharyya, H. D. Smith, and K. D. Wiemers, "Noble Metal-Catalyzed Ammonia Generation by Formic Acid Reduction of Nitrate in Simulated Nuclear Waste Media". Environmental Science and Technology 31, 4, p. 984 (1997).

Koopman, D. C., Review of Catalytic Hydrogen Generation in the Defense Waste Processing Facility (DWPF) Chemical Processing Cell (U). WSRC-TR-2002-00334, Savannah River Site, Aiken, SC 29808 (2004).

Koopman, D. C., C. M. Jantzen, and T. B. Edwards, Acid Addition Stoichiometry for Sludge Batch 3 Processing in the Defense Waste Processing Facility (U). WSRC-TR-2003-00118, Savannah River Site, Aiken, SC 29808 (2003b).

Koopman, D. C., C. C. Herman, and N. E. Bibler, Sludge Batch 3 Preliminary Acid Requirement Studies with Tank 8 Simulant (U). WSRC-TR-2003-00041, Savannah River Site, Aiken, SC 29803 (2003a).

Koopman, D. C., Sludge Batch 2 (Macrobatch 3) Flowsheet Studies With Simulants (U). WSRC-TR2000-00398, Savannah River Site, Aiken, SC 29808 (2000). 


\subsection{ACKNOWLEDGEMENTS}

The authors wish to acknowledge the contributions of David Best, Jennifer Jantzen, and Pat Toole for their work on sample analysis. We would also like to thank Joe Wheeler and Frances Williams, along with Tony Burckhalter, Jon DuVall, Sammie King, Debbie Marsh, Irene Reamer, Vickie Williams, and Phyllis Workman for their support during the experimental phase. The authors also wish to thank Henry Bolton and Shirley McCollum of the Waste Processing Technology Section who assisted the Immobilization Technology Section in the experimental phase. 
WSRC-TR-2004-00548

Revision 0

\section{APPENDIX A. General SRAT Material Balance Closure}


General SRAT material balance closure provides a check on equipment performance and gives another estimate of total off-gas generation. All six tests started with 2700 grams of fully trimmed sludge simulant. They each received about $260 \mathrm{~g}$ of formic acid solution and $72 \mathrm{~g}$ of nitric acid solution. They received identical antifoam additions. They had nearly identical sample losses during SRAT processing (the exception was Test 1 with no $\mathrm{Hg}$, which had five fewer $\sim 14 \mathrm{~g}$ samples removed). The six tests used a similar dewatering target. Table 14 compares the running accounts of additions and removals to the SRAT vessels by the end of the SRAT cycle with the actual slurry mass recovered from the equipment.

Table 14. SRAT Product Material Balance Closure

\begin{tabular}{||l|c|c|c|c||}
\hline & Accounting Mass, $\mathrm{g}$ & Measured Mass, g & Mass Difference, $\mathrm{g}$ & \% Lost \\
\hline Test 1 & 2264.5 & 2160.5 & 104.0 & 4.8 \\
\hline Test 2 & 2115.2 & 2010.6 & 104.6 & 5.2 \\
\hline Test 3 & 2160.9 & 2069.3 & 91.6 & 4.4 \\
\hline Test 4 & 2183.6 & 2111.3 & 72.3 & 3.4 \\
\hline Test 5 & 2204.2 & 2085.1 & 119.1 & 5.7 \\
\hline Test 6 & 2195.5 & 2038.8 & 156.7 & 7.7 \\
\hline
\end{tabular}

The mass difference is primarily due to off-gas generation, which is not weighed. Test 6 had about 30 grams less nitrate in the SRAT product than Test 5. This explains some of the greater mass difference in this test relative to the others - more off-gas lost instead of converted to and recovered as nitrate.

Results for Tests 1-5 may not show any clear trends. Differences of 10-20 grams are only a fraction of $1 \%$ of the mass of the slurry and glassware being weighed and tracked. If the mass data were accurate to three significant figures, however, then it appears that the two runs with $\mathrm{Hg}\left(\mathrm{NO}_{3}\right)_{2}$ as the trim chemical, Tests 3 and 4, had a smaller mass loss than the other four tests. The only reproducible reason for a smaller mass loss would be less net off-gas generation. There did seem to be somewhat less $\mathrm{CO}_{2}$ generation during those runs compared to the other three. It was uncertain whether or not that difference was large enough to be detectable in the overall material balance, but perhaps it was detected. 
WSRC-TR-2004-00548

Revision 0

APPENDIX B. Base Equivalents Titration Data 
Mercury as it approached $2 \%$ in the slurry solids appeared to be affecting the base equivalents titration data. A detailed discussion of base equivalents data was placed in this appendix, because it was not directly relevant to hydrogen generation in DWPF. It is primarily of concern to SRNL experimental programs. There was a concern that using mercury nitrate instead of $\mathrm{HgO}$ might affect the base equivalent results of SRAT receipt samples. It was known that mercury nitrate in water produces an acidic solution. Unexpected results were obtained, however, when using mercury nitrate in SB3 simulant at $2 \%$. The following paragraphs describe the data that was obtained.

Titration of the blended SB3 sludge without mercury and noble metals proceeded as it had in previous preparations of the recipe. A value of $0.566 \mathrm{M}$ was obtained. This was compared to the base equivalents values obtained from previous preparations of the blended SB3 recipe, Table 15.

Table 15. Comparison of Base Equivalents Measurements

\begin{tabular}{||l|c|c||}
\hline Program & Base Equivalents, pH 7 & Reference \\
\hline Hydrogen Study & $0.566 \mathrm{M}$ & WSRC-TR-2004-00548 \\
\hline Acid Window Study & $0.544 \mathrm{M}$ & WSRC-TR-2004-00042 \\
\hline Redox and Heel Study & $0.505 \mathrm{M}$ & WSRC-TR-2004-00225 \\
\hline April 2004 feed for 22L runs & $0.6035 \mathrm{M}$ & No reference/unpublished \\
\hline Late 2003 feed for 22L runs & $0.589 \mathrm{M}$ & No reference/unpublished \\
\hline
\end{tabular}

The new value of $0.566 \mathrm{M}$ was consistent with the four previous values, which averaged to $0.560 \mathrm{M}$.

Base equivalents titrations were also conducted on the SRAT receipt samples for Tests 1-4 that were fully trimmed sludge with the mercury and noble metals added. These titration results are summarized in Table 16.

Table 16. Base Equivalents of SRAT Receipt samples

\begin{tabular}{|c|c|}
\hline Sample & pH 7 Base Equivalents \\
\hline Test $1(0 \% \mathrm{Hg})$ & $0.539 \mathrm{M}$ \\
\hline Test $2(2 \% \mathrm{Hg}$ from $\mathrm{HgO})$ & $0.585 \mathrm{M}$ \\
\hline Test $3\left(0.119 \% \mathrm{Hg}\right.$ from $\left.\mathrm{Hg}\left(\mathrm{NO}_{3}\right)_{2}\right)$ & $0.538 \mathrm{M}$ \\
\hline Test $4\left(2 \% \mathrm{Hg}\right.$ from $\left.\mathrm{Hg}\left(\mathrm{NO}_{3}\right)_{2}\right)$ & $0.727 \mathrm{M}$ \\
\hline
\end{tabular}

The titration result for Test 4 was unexpected. It was about $0.2 \mathrm{M}$ higher than the others, while mercury was present at only $0.024 \mathrm{M}$. The direction of change was also unexpected. The mercury nitrate was expected to lower, rather than raise, the base equivalents value due to its acidic nature. The results for Tests 1-3 were consistent with the variations seen in titrating simulant without mercury given in Table 15 . Tests 1 and 3 reflect the small dilution of the slurry that accompanies adding the trim chemicals. The result for Test 2 was somewhat higher than for the untrimmed sludge. This could be reasonable analytical variation, but it could also be a weaker manifestation of the same phenomenon that caused the Test 4 result to jump.

A better understanding of what was occurring during titration was desired before considering switching from $\mathrm{HgO}$ to $\mathrm{Hg}\left(\mathrm{NO}_{3}\right)_{2}$ on a routine basis. Several special sludge samples were prepared for base equivalents titration. One was a second preparation of $2 \% \mathrm{Hg}$ from $\mathrm{Hg}\left(\mathrm{NO}_{3}\right)_{2}$ without noble metals, one was a preparation of $1 \% \mathrm{Hg}$ from $\mathrm{Hg}\left(\mathrm{NO}_{3}\right)_{2}$ without noble metals, and one was a preparation of $2 \% \mathrm{Hg}$ from $\mathrm{Hg}\left(\mathrm{NO}_{3}\right)_{2}$ without noble metals combined with 2 moles of $\mathrm{NaOH}$ per mole of $\mathrm{Hg}\left(\mathrm{NO}_{3}\right)_{2}$. The original thinking behind the third sample was that the $\mathrm{NaOH}$ might make this sample behave more like $\mathrm{HgO}$ spiked sludge, since $\mathrm{Hg}\left(\mathrm{NO}_{3}\right)_{2}$ reacts with $\mathrm{NaOH}$ in the simulant after it is added. By adding the 
necessary $\mathrm{NaOH}$ with the mercury, it would not be necessary to consume $\mathrm{NaOH}$ already in the simulant. These titration results are summarized in Table 17.

Table 17. Base Equivalents of Special Samples

\begin{tabular}{||l|c||}
\hline Sample & $\mathrm{pH} 7$ Base Equivalents \\
\hline $2 \% \mathrm{Hg}$ from $\mathrm{Hg}\left(\mathrm{NO}_{3}\right)_{2}$ & $0.773 \mathrm{M}$ \\
\hline $1 \% \mathrm{Hg}$ from $\mathrm{Hg}\left(\mathrm{NO}_{3}\right)_{2}$ & $0.565 \mathrm{M}$ \\
\hline $2 \% \mathrm{Hg}$ from $\mathrm{Hg}\left(\mathrm{NO}_{3}\right)_{2}+\mathrm{NaOH}$ & $0.62 \mathrm{M}-0.84 \mathrm{M}$ \\
\hline
\end{tabular}

The first result in Table 17 confirmed that the SRAT Receipt sample result from Test 4 was not due to improper batching of the final trim chemicals. The result at $1 \% \mathrm{Hg}$ was similar to the majority of the data obtained with no $\mathrm{Hg}$ or with $\mathrm{HgO}$ spiked simulants. Five titrations were made on the third sample before stopping. These failed to produce an acceptable mean value for the $\mathrm{pH} 7$ base equivalents. A range was obtained instead. The individual results were $0.621 \mathrm{M}, 0.646 \mathrm{M}, 0.800 \mathrm{M}, 0.808 \mathrm{M}$, and $0.838 \mathrm{M}$.

Some data from the auto-titrator were obtained and plotted to investigate the titration phenomenon, Figure 6. Data were for the initial blended sludge without mercury and noble metals (labeled as Sim-1, Sim-2, Sim-3, and "Sim, pH 7" in the figure) with an average $\mathrm{pH} 7$ base equivalents of $0.566 \mathrm{M}$, Table 15 , and also for the initial blended sludge trimmed with $2 \% \mathrm{Hg}$ from $\mathrm{Hg}\left(\mathrm{NO}_{3}\right)_{2}$ plus added $\mathrm{NaOH}$, "Sim+Hg+NaOH 2" and 2B.

Figure 6. Data from Auto-Titrator for Untrimmed Sludge and $\mathrm{Hg}-\mathrm{NaOH}$ Sludge

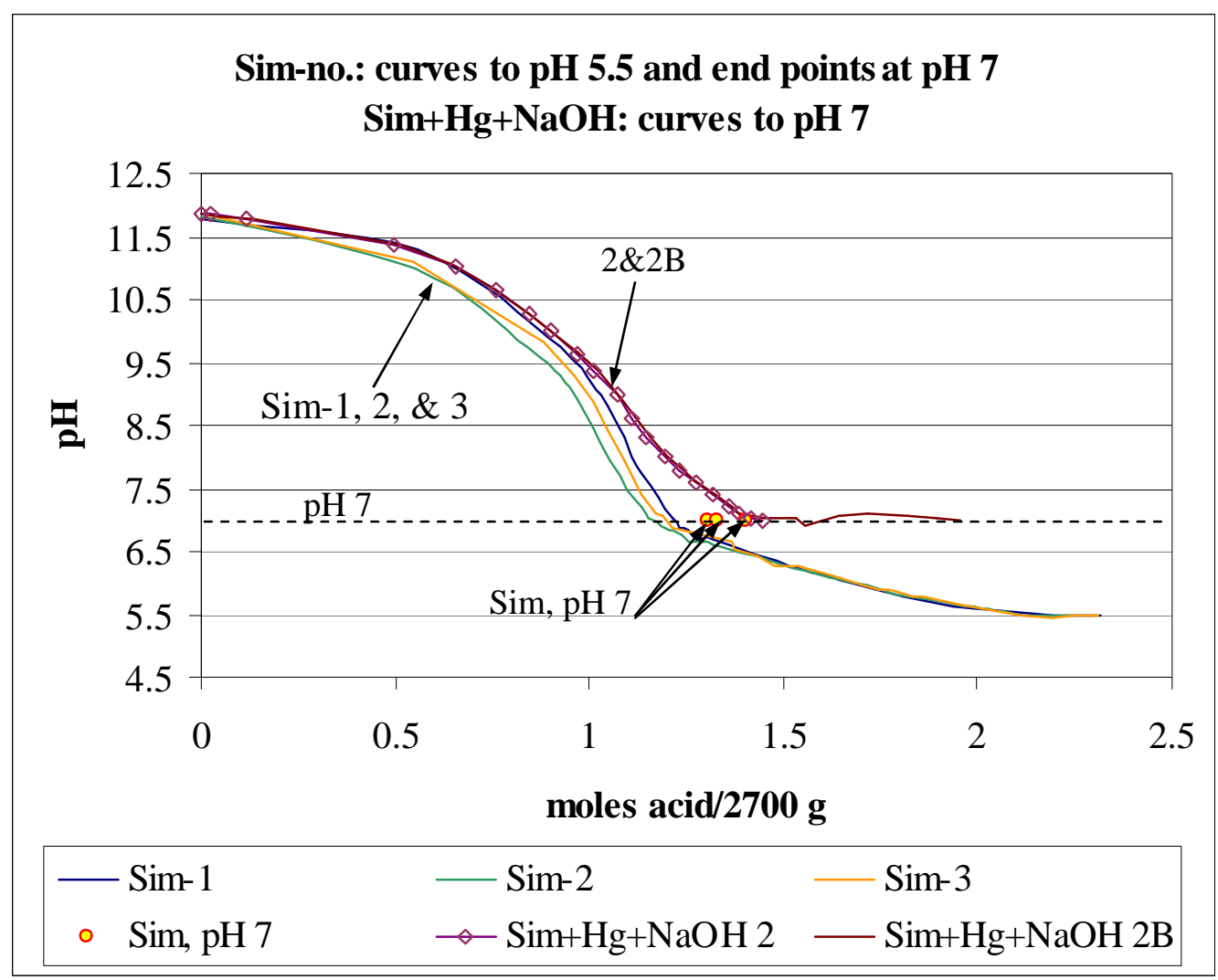


The auto-titrator does not hold the sample until $\mathrm{pH}$ equilibrium is achieved except at the specified end point of the titration. The need for holding the sample before terminating the titration can be seen when comparing the starting simulant curves from the $\mathrm{pH} 5.5$ titrations to the circles for the end points of the $\mathrm{pH} 7$ titrations (about 15\% more acid required to hold at $\mathrm{pH} 7$ when the slurry was allowed to come to steady state in the auto-titrator). Also evident is that the titration curve begins a transition from sharply falling to gently falling very close to $\mathrm{pH}$ 7. Sharply falling curves are characteristic of equivalence points in the system, while gently sloping curves are not. Titrations are more reproducible when performed near an equivalence point.

The first titration to $\mathrm{pH} 7$ of simulant with $\mathrm{Hg}$ and caustic, "Sim $+\mathrm{Hg}+\mathrm{NaOH}$ 2" (trace with diamonds), completed at the right-most of the three circles for $\mathrm{pH} 7$ end points of the untrimmed blend, "Sim, $\mathrm{pH}$ 7". This endpoint would have indicated only a minor impact of $\mathrm{NaOH}$-balanced $\mathrm{Hg}\left(\mathrm{NO}_{3}\right)_{2}$ on the base equivalents measurement if it had been reproducible. The curves for this titration and for "Sim $+\mathrm{Hg}+\mathrm{NaOH} 2 \mathrm{~B}$ " are essentially identical down to $\mathrm{pH} 7.03$ on the scale of Figure 6.

The titration curve for " $\mathrm{Sim}+\mathrm{Hg}+\mathrm{NaOH} 2 \mathrm{~B}$ " continued on for a considerable period of time beyond that of "Sim $+\mathrm{Hg}+\mathrm{NaOH} 2$ ". Minute quantities of acid were being added regularly and periodically during this time. There were approximately 180 auto-titrator data points following the first $\mathrm{pH}$ reading of 6.99 before the instrument concluded that the end point was stable (all points not shown on graph). There were about 130 points before initially reaching $\mathrm{pH} 6.99$, which was the first value less than $\mathrm{pH} 7.03$ reported, i.e. more than half of the auto-titrator effort was taken up with bringing the endpoint to an internally recognized stable state.

While the slow $\mathrm{pH}$ equilibration might suggest an issue with the instrument, it is more likely indicating that there is a slow buffer in the simulant that has been shifted just enough to interact with the $\mathrm{pH}$ endpoint setting. Slight shifts in the $\mathrm{pH}$ reading from the probe are typical when working with sludge simulant. The proximity of a $\mathrm{pH}$ buffer near the targeted endpoint of the titration coupled with the tendency of sludge over time to produce small shifts in the $\mathrm{pH}$ reading apparently combined to significantly impact the calculated molarity of the sample in some cases.

A simple follow-up study could be performed to investigate the behavior of several of these $\mathrm{Hg}\left(\mathrm{NO}_{3}\right)_{2}$ samples versus a baseline with no mercury at several other titration end points, e.g. $\mathrm{pH} 7.5$ and 6.5. Until this matter is better understood, the use of $\mathrm{Hg}\left(\mathrm{NO}_{3}\right)_{2}$ as the spiking agent for mercury must be made with caution. This might be necessary for Sludge Batch 4 testing if the mercury concentration is at the anticipated level and if $\mathrm{HgO}$ gives rise to ambiguous stripping data.

Process titration data is compared to room temperature auto-titrator data in Figure 7 . It must be understood that some of the reactions that occur during processing were probably not occurring during the cold titration with hydrochloric acid, i.e. this is a relative, not an absolute, comparison. The 30:1 dilution of the auto-titrator sample was another difference between the two sets of data. Process $\mathrm{pH}$ data from Test 3 was used, since it was typical of the data seen in Figure 2. Data were only extended to $\mathrm{pH}$ 5.5, the auto-titrator endpoint, although the process was taken to lower $\mathrm{pH}$ 's. The cumulative acid addition at pH 5.5 was less $100 \%$ of the calculated stoichiometric acid demand. 
Figure 7. Comparison of Cold and in situ Acid vs. pH Data

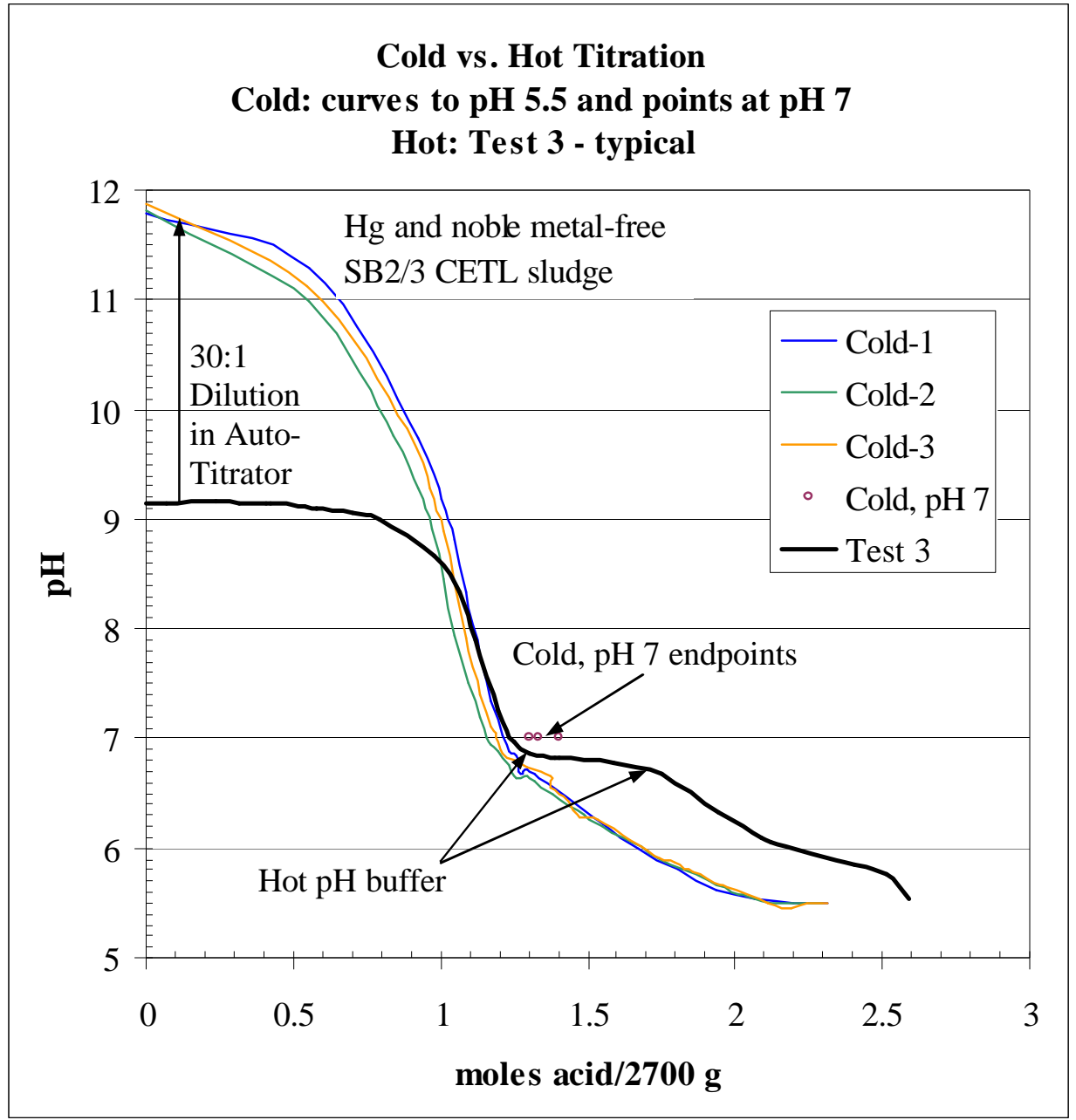

The acid addition that brought the process slurry to $\mathrm{pH} 7$ was actually less than that measured in the three analytical titrations to a cold, $\mathrm{pH} 7$ endpoint (circles). The agreement was within 10\%, however. The acid addition needed to bring the process slurry to $\mathrm{pH} 5.5$, however, was more than that measured in the cold titration. The difference was about $10-15 \%$. The process titration shows more evidence of a $\mathrm{pH}$ buffer just below pH 7 than the auto-titrator data. The graph suggests that any titration end point between $\mathrm{pH} 7$ and $\mathrm{pH} 8$ would probably be reproducible, would correspond to an approximation of an equivalence point, and would have a correspondence between the cold and the hot data. The graph suggests that titration end points below $\mathrm{pH} 7$ would lack these desirable features. 
WSRC-TR-2004-00548

Revision 0

APPENDIX C. Carbon Dioxide and pH 
The carbon dioxide data during acid addition and dewatering were correlated with process $\mathrm{pH}$ data, Figure 8 , to relate mercury reduction, carbonate conversion, and nitrite destruction to $\mathrm{pH}$.

Figure 8. Relationship between $\mathrm{CO}_{2}$ and pH

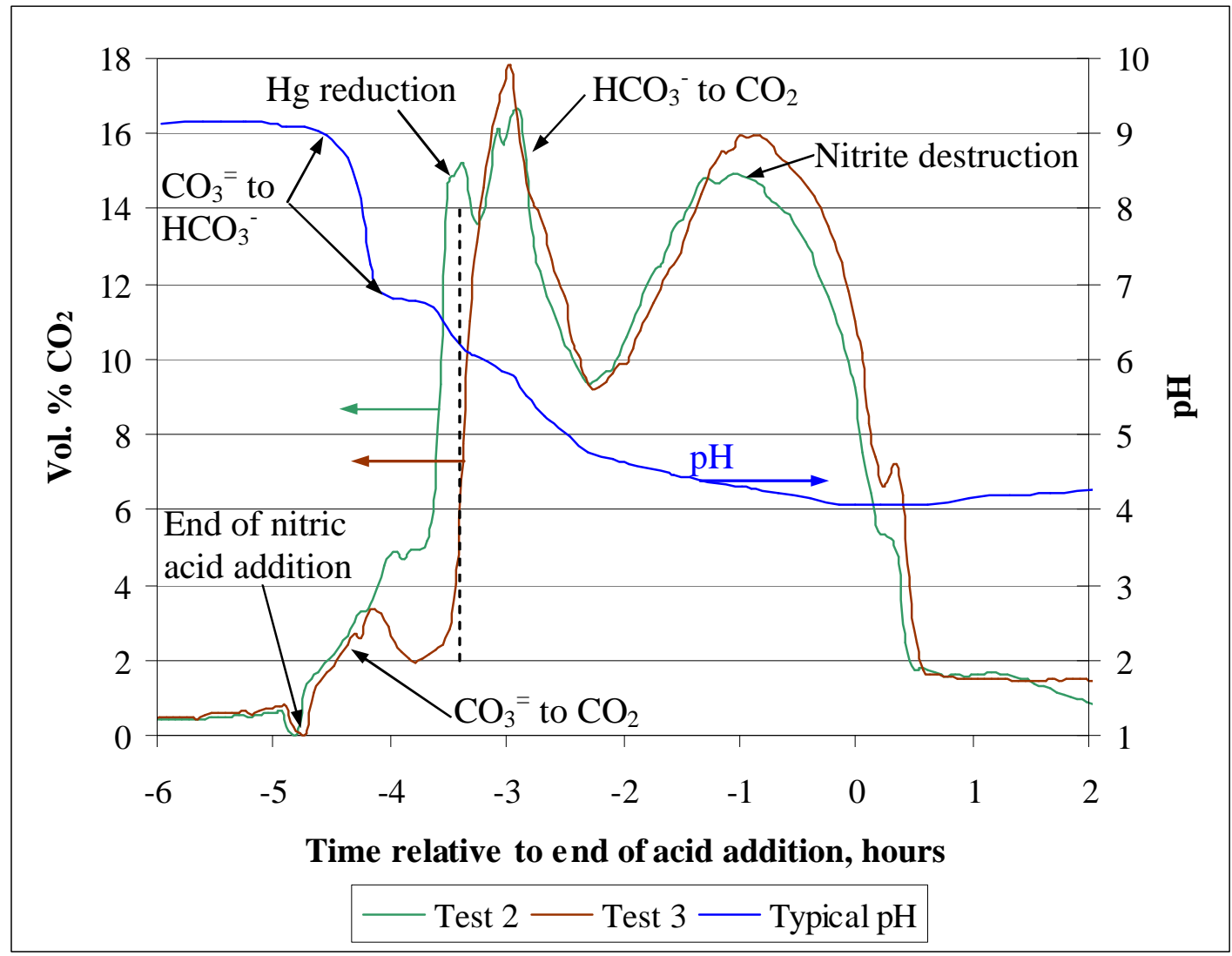

$\mathrm{CO}_{2}$ produced before the $\mathrm{pH}$ fell below 7-8 may have come from localized regions of low $\mathrm{pH}$ where strong acid was initially contacting the slurry. The $\mathrm{pH}$ profile from 9.1 down to 6.8 resembles that of the sodium carbonate-bicarbonate system titrated with a strong acid. It appears that the rate of $\mathrm{CO}_{2}$ generation increased when the majority of the carbonate was converted to bicarbonate at about -3.5 hours. This is the expected trend, since carbonate must transition through bicarbonate to carbonic acid before forming $\mathrm{CO}_{2}$ and water. The carbonate conversion peak died out at about -2 hours with the $\mathrm{pH}<5$.

Nitrite destruction seemed to start at about $\mathrm{pH} 5.5$ and continued until it was essentially gone with the $\mathrm{pH}$ remaining below this value. Mercury reduction occurred at about $\mathrm{pH} 6.7$. 
WSRC-TR-2004-00548

Revision 0

APPENDIX D. Condensate Composition During Boiling 
Data were obtained on condensate removed from the MWWT during dewatering and at the end of the SRAT cycle. These samples were taken in anticipation of a potential need to monitor mercury stripping efficiency and to assess whether or not changing the slurry mercury content would impact the concentration of the condensate. This was seen as potential baseline data, since MWWT sampling has been a regular part of recent studies. During SRAT testing, it was observed that there was a dramatic reduction in hydrogen generation at the onset of reflux. Therefore, these samples were examined in more detail than originally planned. The findings are discussed below.

The bench-scale MWWT is initially charged with de-ionized water. De-ionized water is not the expected composition inside the DWPF MWWT following a SRAT cycle. It had been previously observed, however, that the acidity of the condensate falls as the SRAT cycle progresses. It had also been observed that the acidity in the MWWT rises during acid addition and dewatering in the SRAT. Since the concentration inside the MWWT is not constant during processing, and since there is the potential for it to be changed significantly prior to the end of dewatering, then it may not be particularly important what is in the MWWT initially during an experiment.

De-ionized water has been used as a reproducible starting point in process simulations. The only defensible goal is to have the composition in the bench-scale MWWT approximately prototypical by the start of reflux. (Bench-scale dewatering period condensate does not go to a SMECT to be used as reflux in an ammonia scrubber, so there is no concern that the dewatering period condensate might impact the measured off-gas composition.)

The current MWWT used with the bench-scale 4-L SRAT has a liquid hold-up that is about three times larger than would be prototypical of DWPF. A small amount of condensate typically accumulates in the MWWT during acid addition. When the SRAT is taken to boiling, significant condensate begins to accumulate in the MMWT. This is weighed and timed to determine and adjust the boil-up rate. The MWWT is not mechanically agitated. It does tend to get some shaking from vibrations to the equipment caused by the agitator. This causes some mixing that varies from test to test.

Condensate is removed during dewatering. The current MWWT draws from near the top of the liquid reservoir for dewatering, but from near the bottom of the reservoir for refluxing. The underflow-overflow reflux path is prototypical. Liquid at the top of the MWWT is potentially more representative of recent condensate than that at the inlet to the underflow reflux line. All data taken indicate that there are significant concentration gradients within the bench-scale MWWT, i.e. that the volume is not "wellmixed".

Samples were taken of the condensate coming out of the MWWT during dewatering. This was primarily a learning exercise. The goal was to obtain some baseline information about the MWWT composition and any potential effects on hydrogen generation. The capability exists to simultaneously sample from the top and from the bottom of the MWWT, but such sampling was considered to be beyond the scope of a hydrogen generation study.

The dewatering period was divided into a first third, middle third, and final third. The contents of the MWWT at the end of the SRAT cycle were also collected. These samples were analyzed for $\mathrm{pH}$ and for nitrate, nitrite, and formate. An example of the data obtained is given in Table 18 for Test 1 with no Hg. 
Table 18. Test 1 Condensate Sample Results

\begin{tabular}{||l|c|c|c|c||}
\hline \hline Test 1 & $\begin{array}{c}\text { Nitrate, } \\
\mathrm{mg} / \mathrm{kg}\end{array}$ & $\begin{array}{c}\text { Nitrite, } \\
\mathrm{mg} / \mathrm{kg}\end{array}$ & $\begin{array}{c}\text { Formate, } \\
\mathrm{mg} / \mathrm{kg}\end{array}$ & $\mathrm{pH}$ \\
\hline Initial Dewatering & 13600 & 174 & 4170 & 1.31 \\
\hline Middle Dewatering & 2850 & $<100$ & 5560 & 1.81 \\
\hline Final Dewatering & 1440 & $<100$ & 5670 & 2.09 \\
\hline End of SRAT & 87 & $<100$ & 1495 & 2.85 \\
\hline
\end{tabular}

The trends were typical of all of the runs: falling nitrate, falling nitrite, relatively constant formate during dewatering that fell off during reflux, as well as generally rising $\mathrm{pH}$. The nitrate concentrations converted to molarities would lead to lower predicted $\mathrm{pH}$ 's for the first three samples assuming solution ideality and that the nitrate is present as nitric acid. Non-idealities tend to produce higher $\mathrm{pH}$ 's at this end of the $\mathrm{pH}$ scale, and there is also an acid error with glass electrodes that tends to give higher $\mathrm{pH}$ 's. Thus, the measured $\mathrm{pH}$ 's are reasonable. The "end of SRAT" sample nitrate is equivalent to $0.0014 \mathrm{M}$ nitrate. If this were all nitric acid, then the calculated $\mathrm{pH}$ would be 2.85 for an ideal solution. This matches the measured value. Formic acid at this $\mathrm{pH}$ should be present primarily as molecular formic acid that does not contribute to the $\mathrm{pH}$ reading.

Several general observations will be made on the full data set for all six tests. First, formate ion is a fairly consistent and significant component of the condensate. Second, the $\mathrm{pH}$ trend is increasing with time after the initial minimum acidity is established. Third, there is almost no nitrite ion. The condensation of $\mathrm{NO}_{2}$ into aqueous solution produces both $\mathrm{HNO}_{3}$ and $\mathrm{HNO}_{2}$ in equal parts. Apparently, the nitrous acid is not stable. It could either be reduced by the formic acid in the condensate or converted to nitric acid as discussed in the SRAT nitrogen chemistry section, Appendix H. Compositions are such that a denitration reaction is possible per Eibling, WSRC-RP-92-1247, since the $\mathrm{pH}<3$. Two potential mitigating factors to having a significant loss of nitrate and formate by denitration are that the temperature is $20-40^{\circ} \mathrm{C}$ rather than $93-101^{\circ} \mathrm{C}$ and that the $\mathrm{pH}$ is mostly above 2 (lower $\mathrm{pH}$ accelerates denitration).

Finally, the bench-scale MWWT is clearly not well mixed (the full-scale MWWT is not intended to be well-mixed either). The initial dewatering mass was 129.8 grams while the initial MWWT mass was $156.8 \mathrm{~g}$ of de-ionized water. If it was assumed that the MWWT was well-mixed, and that the first drop of dewatering mass was nitrate free, i.e. equivalent to de-ionized water, then it is virtually impossible to model this data. Nitrate has to shoot up rapidly in the MWWT contents, taking the concentration well above $13,600 \mathrm{mg} / \mathrm{kg}$ and then fall rapidly to $5200 \mathrm{mg} / \mathrm{kg}$ or less (less if the fresh SRAT condensate still has any nitrate in it following the initial dewatering). The MWWT concentration has to go well above $13,600 \mathrm{mg} / \mathrm{kg}$ so that the average over the initial dewatering period comes out to $13,600 \mathrm{mg} / \mathrm{kg}$ even though it starts at zero and ends at $<5200 \mathrm{mg} / \mathrm{kg}$.

For modeling a well-mixed MWWT, it was assumed that the nitrate concentration was falling exponentially with time in the fresh condensate. This would be consistent with a reaction in the SRAT that is going to completion by first-order kinetics while producing the $\mathrm{NO}_{2}$ that is making the nitrate. The assumed reaction order is not that critical to the MWWT mixing model. A model where the concentration fell non-linearly with time was needed to be consistent with observed depletion of nitrite in the SRAT. It was not possible to obtain even a $10 \%$ difference in the MWWT concentration after two hours relative to the maximum during dewatering using a wide range of adjustable parameters. It is more likely that nitrate rich condensate is preferentially removed before is mixes with the bulk MWWT contents. This implies that the concentration at the bottom of the MWWT does not match that at the top. 
The high nitrate in the initial dewatering sample was seen in the five air-purged tests, Table 19. This indirectly confirms that $\mathrm{NO}_{2}$ absorption into the condensate is the primary source of the nitrate.

Table 19. Initial Dewatering Period Condensate Comparison

\begin{tabular}{|l|c|c|c|c|}
\hline & Nitrate & Formate & Nitrite & $\mathrm{pH}$ \\
\hline Test 1 & 13600 & 4170 & 174 & 1.31 \\
\hline Test 2 & 14900 & 4325 & 398 & 1.22 \\
\hline Test 3 & 18700 & 3535 & 457 & 1.19 \\
\hline Test 4 & 17850 & 4345 & 245 & 1.18 \\
\hline Test 5 & 10900 & 5630 & $<100$ & 0.93 \\
\hline Test 6 & 1070 & 2765 & $<100$ & 1.90 \\
\hline
\end{tabular}

Variations in nitrate and formate may be more related to the MWWT mixing than to process changes for Tests 1-5. Test 6 is quite different from Tests 1-5. Formate is about half as large. Nitrate is an order of magnitude lower. Apparently some mechanism exists for formation of nitrate from $\mathrm{NO}$ in the absence of oxygen to convert the $\mathrm{NO}$ to $\mathrm{NO}_{2}$. One alternative would be some entrainment of acidic supernate to the SRAT condenser. No evidence of $\mathrm{N}_{2} \mathrm{O}$ was seen, so conversion of three NO's to $\mathrm{N}_{2} \mathrm{O}$ plus $\mathrm{NO}_{2}$ appears to be excluded as a possible source of $\mathrm{NO}_{2}$. The $\mathrm{pH}$ reading for Test 5 seems inconsistent with the low nitrate value compared to Tests 1-4.

Results for the middle of the dewatering period are given in Table 20.

Table 20. Middle Dewatering Period Condensate Comparison

\begin{tabular}{|l|c|c|c||}
\hline & Nitrate & Formate & $\mathrm{pH}$ \\
\hline Test 1 & 2850 & 5610 & 1.81 \\
\hline Test 2 & 2975 & 5805 & 1.80 \\
\hline Test 3 & 2965 & 6625 & 1.87 \\
\hline Test 4 & 2710 & 7250 & 1.89 \\
\hline Test 5 & 3315 & 6985 & 1.34 \\
\hline Test 6 & 430 & 3480 & 2.13 \\
\hline
\end{tabular}

Test 6 continued to have much less nitrate and less formate along with the highest $\mathrm{pH}$. Formate increased relative to the initial dewatering period while nitrate fell. Nitrite was below detection limits from the middle of dewatering to the end of the SRAT cycle.

Table 21. Final Dewatering Period Condensate Comparison

\begin{tabular}{|l|c|c|c||}
\hline & Nitrate & Formate & $\mathrm{pH}$ \\
\hline Test 1 & 1440 & 5570 & 2.09 \\
\hline Test 2 & 1715 & 6110 & 2.05 \\
\hline Test 3 & 1275 & 6960 & 2.12 \\
\hline Test 4 & 1420 & 7730 & 2.17 \\
\hline Test 5 & 2165 & 6235 & 1.51 \\
\hline Test 6 & 260 & 4010 & 2.28 \\
\hline
\end{tabular}


Test 6 continued to have much less nitrate, less formate, and the highest $\mathrm{pH}$. Nitrate continued to fall and $\mathrm{pH}$ to rise in all tests. Formate was comparable to the middle dewatering period. Formate appeared to be reaching a steady-state concentration for some of the tests. The end of SRAT formate values were only about $20 \%$ lower than these values for Tests $2-5$.

After the MWWT was switched to reflux, there was no longer any condensate removed to track composition until the end of the SRAT cycle. At that point, the contents of the MWWT were drained and analyzed. The data are given in Table 22.

Table 22. MWWT Composition at End of SRAT Cycle

\begin{tabular}{|l|r|c|c||}
\hline & Nitrate & Formate & $\mathrm{pH}$ \\
\hline Test 1 & 87 & 1495 & 2.85 \\
\hline Test 2 & 99 & 4620 & 2.67 \\
\hline Test 3 & $<100$ & 5250 & 2.67 \\
\hline Test 4 & 101 & 5720 & 2.71 \\
\hline Test 5 & 130 & 4850 & 2.28 \\
\hline Test 6 & $<100$ & 2560 & 2.56 \\
\hline
\end{tabular}

Test 1 with no $\mathrm{Hg}$ had less formate than the four runs with $\mathrm{Hg}$ and an air purge. This is consistent with Test 1 being lower in formate than Tests $2-5$ by the last third of dewatering. The relative difference is larger than might be expected from the total slurry formate. The $\mathrm{pH}$ 's have all increased from the end of dewatering to the end of the SRAT cycle. Nitrate is barely detectable, and it is much lower than at the end of dewatering. More nitrate tended to correlate well with lower $\mathrm{pH}$. Test 6 was no longer lowest in formate or highest in $\mathrm{pH}$.

The composition in the MWWT at the start of reflux can not be accurately extracted from the above data. The SRAT condenser condensate composition was almost certainly falling in nitrate content from the middle of dewatering until the end of the SRAT cycle. Similarly, pH was almost certainly rising from this period on. It is unclear as to what species triggered the dramatic drop in hydrogen generation seen in Tests 1, 3, 5, and 6 at the onset of reflux. The work of Hsu and Ritter, WSRC-MS-92-270, indicated that incremental additions of nitric acid during SRAT boiling caused brief periods of increased hydrogen generation. One conclusion was that formic acid reacts to form hydrogen more readily than formate ion. This conclusion was supported during the literature review, WSRC-TR-2002-00034. The data from this study are indicating that something more complicated happens with refluxed acid than happens with pure nitric acid addition during boiling. The effect cannot be attributed to mercury, however, since Test 1 with no $\mathrm{Hg}$ showed the largest drop in hydrogen generation at the onset of reflux.

The presence of mercury did not appear to have a systematic effect on the composition of the condensate produced during the SRAT cycle. The absence of oxygen did have an effect on the composition of the condensate, which was generally less acidic than in comparable runs with an air purge. Other data in this study led to a redesign of the bench-scale SRAT condenser and MWWT. These changes are expected to change the compositional data obtained from the MWWT. 
WSRC-TR-2004-00548

Revision 0

APPENDIX E. Changes in Hg Concentration During Boiling 
Mercury was added in two different forms, $\mathrm{HgO}$ and $\mathrm{Hg}\left(\mathrm{NO}_{3}\right)_{2} \cdot \mathrm{H}_{2} \mathrm{O}$, during this test program. There was a concern that $\mathrm{HgO}$ might not disperse and steam strip as prototypically as the precipitated nitrate. The oxide trim chemical probably stays in the form of the particles that were added until they are attacked during acid addition. $\mathrm{HgO}$ particles are very dense with a crystalline density of $11.1 \mathrm{~g} / \mathrm{cm}^{3}$. Consequently, they may be hard to suspend. The nitrate was expected to initially dissolve in sludge simulant and then re-precipitate as fine $\mathrm{HgO}$ particles as it reacted with $\mathrm{NaOH}$ in the sludge simulant.

Sampling data for $\mathrm{Hg}$ was obtained from the end of acid addition until nine hours into the reflux period. This data was taken to assess mercury sampling and/or to evaluate the efficiency of the steam stripping of mercury. Historical data indicate that mercury is primarily removed by steam stripping. Therefore, it was assumed that the trimmed mercury in each test was still $100 \%$ present at the end of acid addition. SRAT product samples could have been checked if the preliminary data indicated that is was necessary to extend the sampling period through 12 hours of refluxing. Preliminary data did not indicate this need.

Data in Table 23 summarize sample results for the three tests with $\mathrm{HgO}$, Tests 2, 5, and 6. The trimmed mass of $\mathrm{Hg}$ is given along with the calculated mass present at five different times during the SRAT cycle after acid addition.

Table 23. Computed Hg Mass and Analytical Results with HgO

\begin{tabular}{|l|l|c|c|}
\hline Test & Sample Time & $\begin{array}{l}\text { Calculated } \\
\text { Mass Hg, g }\end{array}$ & $\begin{array}{l}\text { Measured Wt. \% Hg in } \\
\text { Slurry }\end{array}$ \\
\hline Test 2 & Mass Hg added & 12.182 & \\
\hline & After Acid Addition & 0.456 & 0.0155 \\
\hline & After Dewatering & 1.040 & 0.0415 \\
\hline & After 4 hours reflux & 0.401 & 0.0160 \\
\hline & After 6 hours reflux & 0.413 & 0.0165 \\
\hline & After 9 hours reflux & 0.338 & 0.0135 \\
\hline \hline Test 5 & Mass Hg added & 0.7123 & \\
\hline & After Acid Addition & 0.556 & 0.0190 \\
\hline & After Dewatering & 0.212 & 0.0085 \\
\hline & After 3 hours reflux & 0.162 & 0.0065 \\
\hline & After 6 hours reflux & 0.175 & 0.0070 \\
\hline & After 9 hours reflux & 0.125 & 0.0050 \\
\hline \hline Test 6 & Mass Hg added & 0.7123 & \\
\hline & After Acid Addition & 0.448 & 0.0155 \\
\hline & After Dewatering & 0.221 & 0.0090 \\
\hline & After 3 hours reflux & 0.233 & 0.0095 \\
\hline & After 6 hours reflux & 0.123 & 0.0050 \\
\hline & After 9 hours reflux & 0.061 & 0.0025 \\
\hline
\end{tabular}

The results in Table 23 are not unreasonable for Tests 5 and 6 at $0.119 \mathrm{wt}$ \% $\mathrm{Hg}$ in the dried solids. They both show a gradual, if somewhat noisy, reduction in mercury mass with time at boiling. Masses determined from the samples following acid addition, however, are only 63-78\% of the expected $\mathrm{Hg}$ content.

The results for Test 2 are somewhat disappointing. The sample following acid addition contained only $3.7 \%$ of the added $\mathrm{Hg}$, but none was expected to have been removed prior to this sample. Tests 5 and 6 both had more $\mathrm{Hg}$ present in the initial sample after acid addition than Test 2 even though they started with nearly 20 times less. This could indicate a sampling issue with the insoluble species. No systematic 
study has been done on the ability of the bench-scale sampler to remove representative samples of the insoluble solids, although it has been adequate for characterizing the soluble supernate anions. Additional purging of the sample dip tube was employed in Tests 5 and 6 that may account for the higher relative recovery there. The sample from Test 2 following dewatering, if more representative of the residual mercury in the slurry than the first sample, indicates that about $40 \mathrm{~g}$ of steam were required to strip each gram of $\mathrm{Hg}$ from $12.18 \mathrm{~g}$ down to $1.04 \mathrm{~g}$. The slurry was calculated to be less than $0.45 \mathrm{wt}$. $\% \mathrm{Hg}$ at this point.

Equivalent data are given in Table 24 for the two tests using $\mathrm{Hg}\left(\mathrm{NO}_{3}\right)_{2}$, Tests 3 and 4.

Table 24. Computed $\mathrm{Hg}$ Mass and Analytical Results with $\mathrm{Hg}\left(\mathrm{NO}_{3}\right)_{2}$

\begin{tabular}{|l|l|c|c||}
\hline \hline Test & Sample Time & $\begin{array}{l}\text { Calculated } \\
\text { Mass Hg, g }\end{array}$ & $\begin{array}{l}\text { Measured Wt. \% Hg in } \\
\text { Slurry }\end{array}$ \\
\hline Test 3 & Mass Hg added & 0.7135 & \\
\hline & After Acid Addition & 0.486 & 0.0165 \\
\hline & After Dewatering & 0.226 & 0.0090 \\
\hline & After 3 hours reflux & 0.314 & 0.0125 \\
\hline & After 6 hours reflux & 0.151 & 0.0060 \\
\hline & After 9 hours reflux & 0.226 & 0.0090 \\
\hline Test 4 & Mass Hg added & 12.182 & \\
\hline & After Acid Addition & 2.863 & 0.0960 \\
\hline & After Dewatering & 1.768 & 0.0695 \\
\hline & After 3 hours reflux & 0.903 & 0.0355 \\
\hline & After 6 hours reflux & 0.407 & 0.0160 \\
\hline & After 9 hours reflux & 0.356 & 0.0140 \\
\hline
\end{tabular}

Results for Test 3 at $0.119 \% \mathrm{Hg}$ are similar to those for the two tests at this $\mathrm{Hg}$ level based on $\mathrm{HgO}$. These levels already meet the DWPF SRAT product specification, however. The result from the first Test 4 sample following acid addition contained only $23.5 \%$ of the added mercury. This is much better than Test 2 with $2 \% \mathrm{HgO}$, but was still not a very high recovery. The calculated stripping load during dewatering was $45 \mathrm{~g} \mathrm{H}_{2} \mathrm{O} / \mathrm{g} \mathrm{Hg}$ removed. This load could be four times higher if the samples are only routinely getting only about a quarter of the $\mathrm{Hg}$ in the system. The calculated stripping load is fairly similar to the result obtained in Test 2 with $\mathrm{HgO}$. This could have happened because the two samples after dewatering were representative or because both samples indicated that only about $10 \%$ of the added mercury remained. The stripping load over the three hours following dewatering was $830 \mathrm{~g} \mathrm{H}_{2} \mathrm{O} / \mathrm{g} \mathrm{Hg}$. The sample after dewatering, however, was calculated to be less than $0.45 \mathrm{wt}$. \% $\mathrm{Hg}$ in the solids.

Mercury mass as a function of boiling time is plotted for the two tests at $2 \%$ initial $\mathrm{Hg}$ in Figure 9. 
WSRC-TR-2004-00548

Revision 0

Figure 9. Hg Mass versus Boiling Time at 2\% Initial $\mathrm{Hg}$

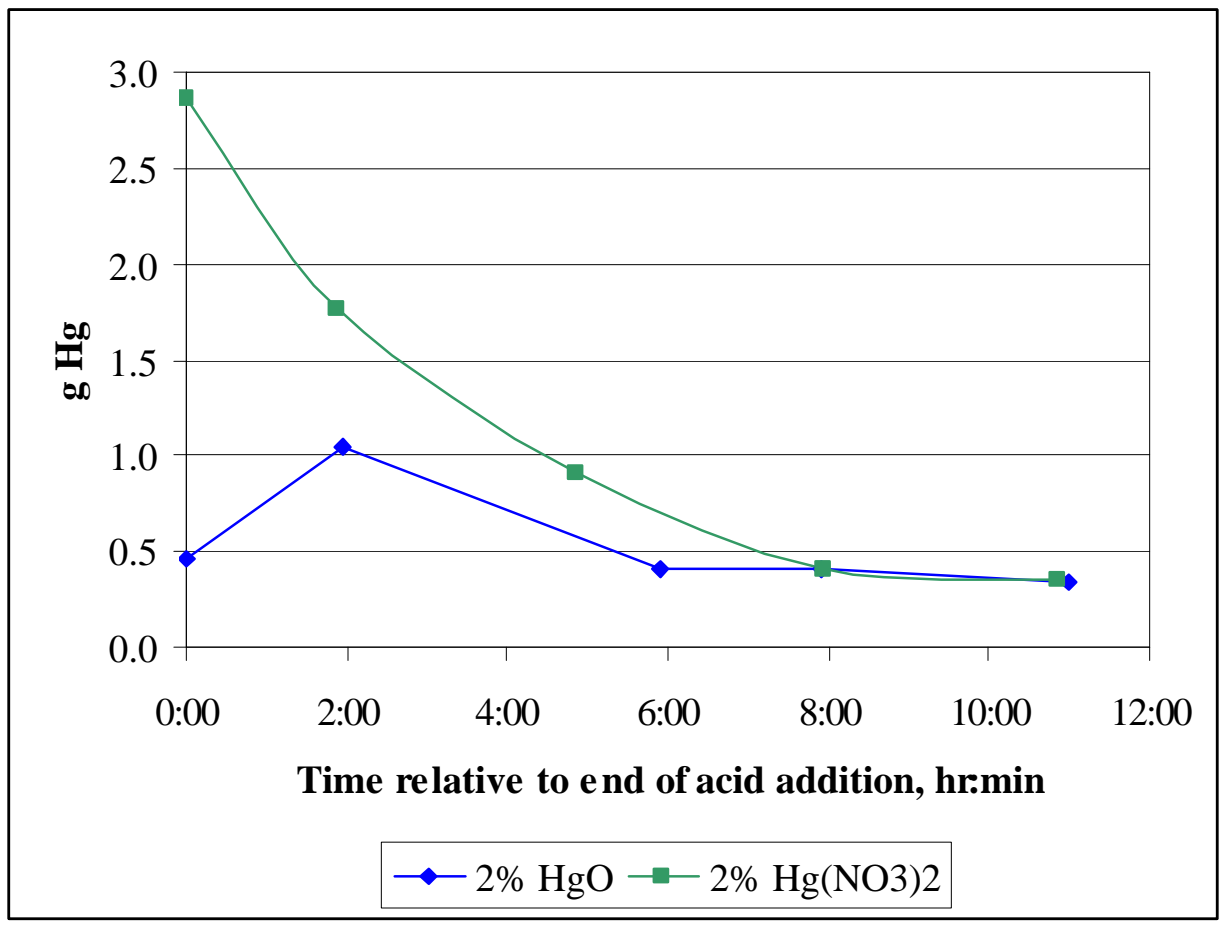

The data for the $2 \% \mathrm{Hg}$ from the nitrate follow a curve typical of batch distillation data, even though the initial value was lower than the expected value of about $12 \mathrm{~g}$. This may be an indication that much of the mercury was already out of the SRAT at the start of boiling rather than that the mercury was not being sampled well. This could relate to the internal refluxing determined to be impacting the nitrite destruction and nitrite to nitrate conversion chemistry. Perhaps mercury was volatilized, but it did not condense on the SRAT walls and left in the off-gas. Another possibility was that significant mercury was present at the surface of the slurry although this could not be visually verified. It is also interesting that, at sufficiently long boiling times, the two data sets came together.

The three sets of data at $0.119 \% \mathrm{Hg}$ are plotted as $\mathrm{g} \mathrm{Hg}$ versus time in Figure 10. 
Figure 10. Hg Mass versus Boiling Time at $0.119 \%$ Initial Hg

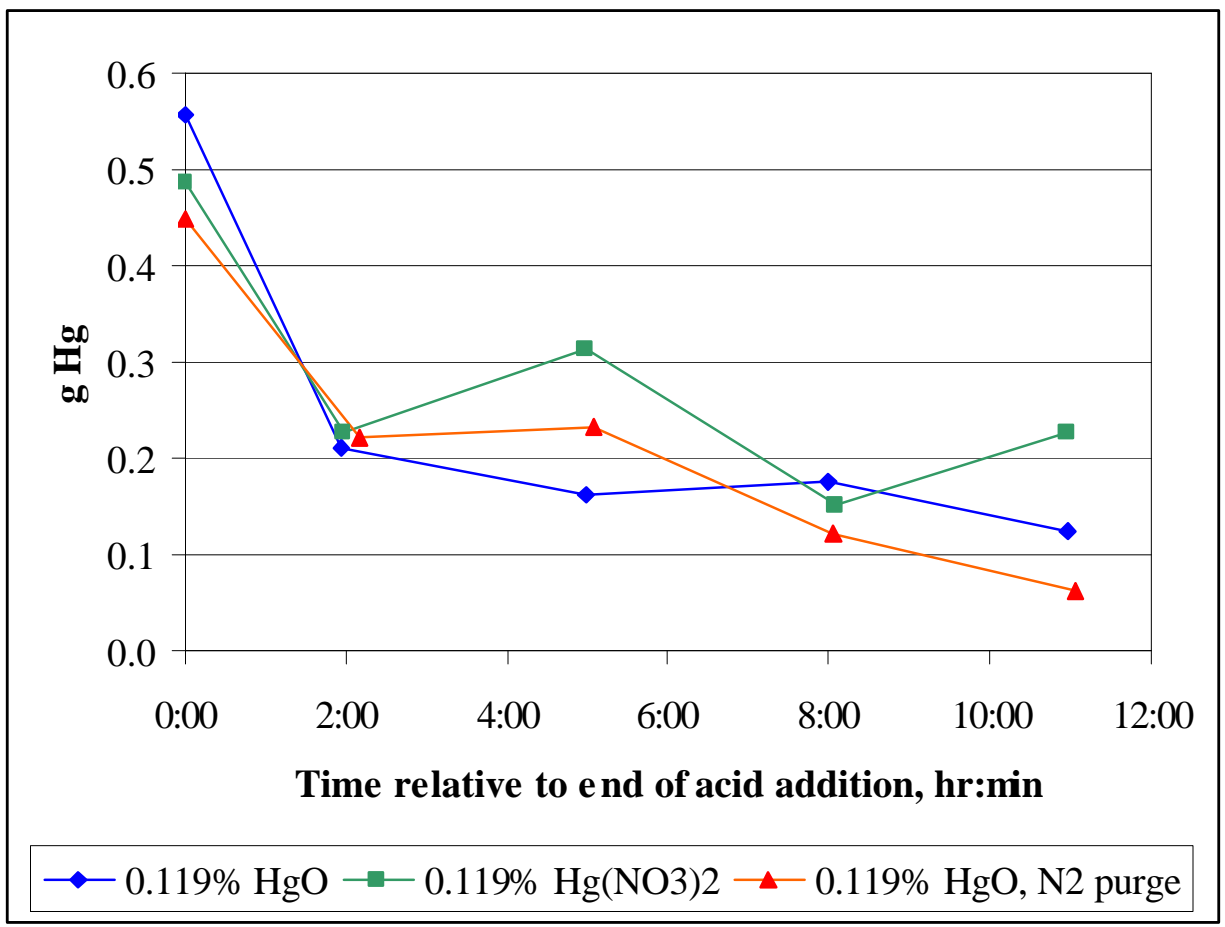

Data are noisier than in the $2 \% \mathrm{Hg}$ case, but show a general trend toward lower $\mathrm{Hg}$ levels as time at boiling increased. The most dramatic drop was during dewatering. The mercury is in 2300-2400 $\mathrm{g}$ of SRAT slurry at this time. The two sets of $\mathrm{HgO}$-based data are actually smoother than the one run with $\mathrm{Hg}\left(\mathrm{NO}_{3}\right)_{2}$ in this group. This could mean that mercury dissolution is complete in all of these runs so there is no longer an advantage to performing in situ precipitation of the mercury nitrate in the starting sludge when the mercury level is low.

The complete data set seems to indicate a small advantage to using $\mathrm{Hg}\left(\mathrm{NO}_{3}\right)_{2}$ over $\mathrm{HgO}$ from a sampling perspective at higher mercury loadings. The $2 \%$ data, however, seem to indicate that sampling is an issue with either starting material. Another possibility was that there were analytical issues at higher $\mathrm{Hg}$ loadings. This was investigated by submitting a simulant spiked to $0.19 \mathrm{wt}$ \% $\mathrm{Hg}$ on a slurry basis (about $1 \mathrm{wt} . \%$ on a dried solids basis). A measured value of $0.20 \mathrm{wt} . \% \mathrm{Hg}$ on a slurry basis was obtained. This seems to indicate that the $\mathrm{Hg}$ data were not low because of analytical issues.

It is also possible that $\mathrm{Hg}$ is no longer uniformly distributed in the slurry following acid addition. This could be investigated further. Mercury was observed to reduce and collect in the froth on the free surface of the slurry during formic acid addition. It then faded away. It may have coalesced back into the slurry or it may have started to evaporate. These issues are not primarily hydrogen generation issues, but they do relate to future studies with high mercury sludges. There are no data available for how mercury will behave in the real SRAT to guide the selection of the most prototypical bench-scale situation.

The issue of mercury sampling appears to need further investigation prior to any studies that have monitoring mercury stripping efficiency as a goal. The use of mercuric nitrate instead of mercuric oxide did not seem to provide an automatic solution. Sampling for mercury should start sooner than the end of acid addition, in case significant mercury is steamed off during acid addition at $93^{\circ} \mathrm{C}$. 
WSRC-TR-2004-00548

Revision 0

APPENDIX F. Changes in Anion Concentrations during Boiling 
Catalytic hydrogen generation destroys formate. Catalysts in the sludge, however, appear to destroy additional formate beyond that associated with hydrogen generation. The catalysts also appear to affect nitrite destruction. If mercury interacted with the noble metal catalysts, then evidence of this could show up in the concentrations of the primary slurry anions (formate, nitrate, and nitrite).

Samples of the SRAT were taken and quenched with $\mathrm{NaOH}$ during processing following acid addition. This enables changes in anion concentrations to be monitored as a function of time and mercury, as well as providing a means for monitoring nitrite destruction following acid addition. This data has little direct relationship to hydrogen generation, so it is included here as an appendix.

Table 25 gives the nitrite ion concentration in the SRAT slurry following the completion of formic acid addition and two hours later.

Table 25. Nitrite Ion Concentrations After Acid Addition

\begin{tabular}{||l|l|c|c|c||}
\hline \hline & $\mathrm{Hg}$ & $\begin{array}{c}\text { Immediately After Acid } \\
\text { Addition, } \mathrm{mg} \mathrm{NO}_{2}^{-} / \mathrm{kg}\end{array}$ & $\begin{array}{c}\text { Time from End of Acid } \\
\text { Addition to Sampling }\end{array}$ & $\begin{array}{c}2 \text { Hours After Acid } \\
\text { Addition, } \mathrm{mg} / \mathrm{kg}\end{array}$ \\
\hline Test 1 & $0.0 \%$ & 991 & 9 minutes & $<100$ \\
\hline Test 2 & $2.0 \%$ & $<100$ & 11 minutes & $<100$ \\
\hline Test 3 & $0.119 \%$ & 1220 & 9 minutes & $<100$ \\
\hline Test 4 & $2.0 \%$ & 427 & 6 minutes & $<100$ \\
\hline Test 5 & $0.119 \%$ & 453 & 11 minutes & $<100$ \\
\hline Test 6 & $0.119 \%$ & 1095 & 8 minutes & $<100$ \\
\hline
\end{tabular}

Nitrite destruction occurred very quickly at this level of acid addition (185\% of stoichiometry). Small differences in sampling technique or speed can lead to detectable changes from test to test. Sampling and quenching can easily take several minutes. The time to actually pull and quench a sample is a significant fraction of the given times from the end of acid addition to the start of sampling. Tests 2 and 4 had the least nitrite in the sample pulled after acid addition. These were the two runs with $2 \% \mathrm{Hg}$. This is not consistent with a mercury-noble metal interaction inhibiting nitrite destruction. It might indicate the opposite, that mercury was promoting nitrite destruction. Conversely, the data in Table 25 may simply reflect the inherent variability in sampling speed and technique.

Data on calculated nitrate ion mass during boiling are shown in Figure 11. The first point at $\sim 2: 30$ is artificial. It is added to baseline the nitrate mass added in the sludge, in the trim chemicals, and as nitric acid. The timing places it near the middle of formic acid addition, when nitrite destruction is peaking. 
Figure 11. Nitrate Mass During Boiling

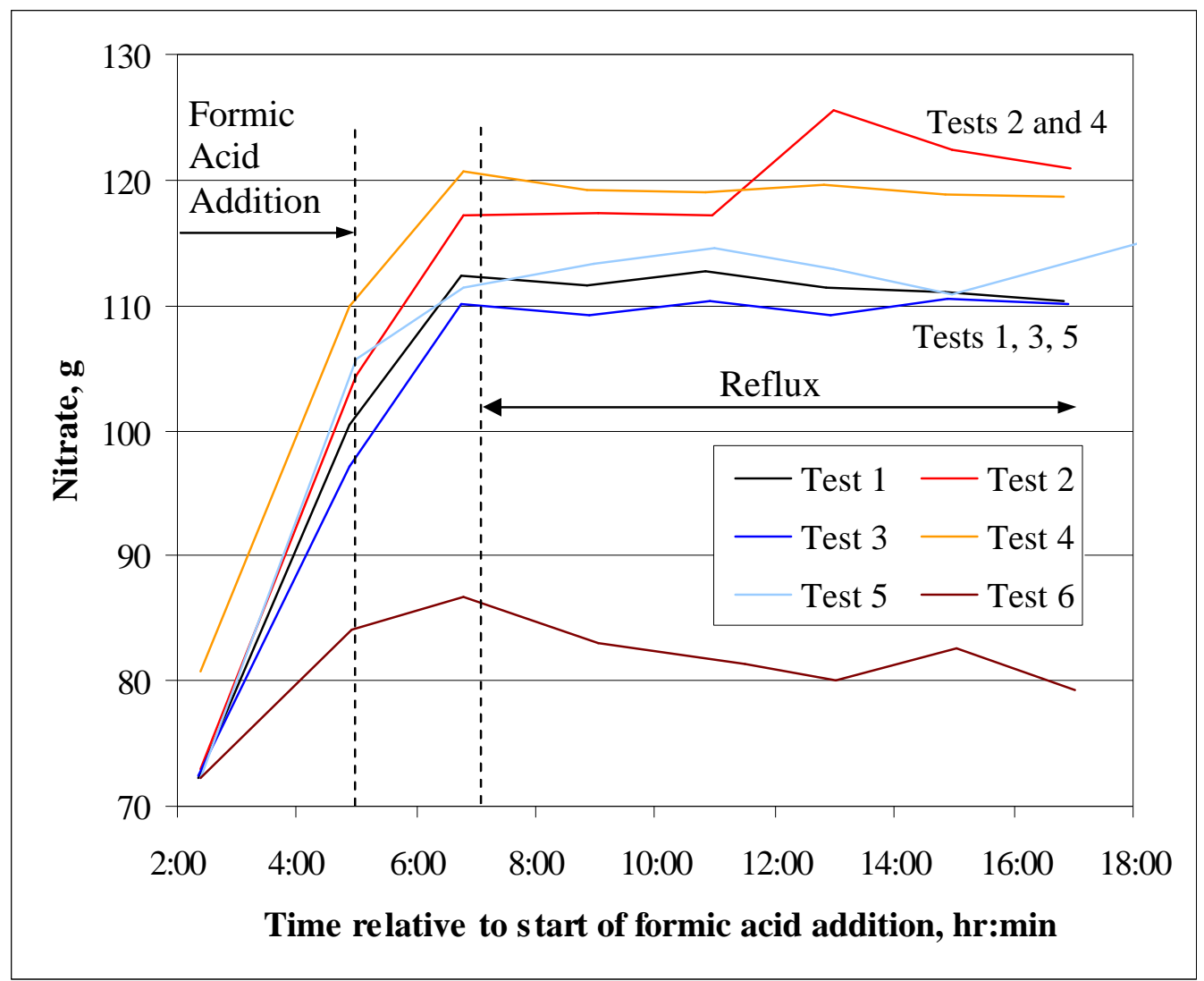

The data indicate that nitrate formation started before the end of formic acid addition, but was not completed by the end of formic acid addition ( 4:45 on the time scale). Nitrate formation continued during dewatering ( 7:00). This is not easy to explain. It is probably not due to analytical error, since it was seen in five different runs. Nitrite was nearly all consumed by the start of dewatering per Table 25 . This nitrate increase may be nitrate residing in drops of condensate on the vessel surfaces that are being rinsed back down into the slurry by fresh condensate that forms once the SRAT starts boiling (a wall droplet rinsing effect). In all tests, the sample at 7:00 was taken before reflux was initiated, so the nitrate mass gain is not due to return of MWWT nitrate in the reflux stream.

Tests 2 and 4, both with $2 \% \mathrm{Hg}$, appear to be at a higher nitrate level than Tests 1, 3, and 5. These two tests also seemed to have the most rapid nitrite destruction, Table 25. Test 6 is clearly different from the other five. Evidence for nitrate mass loss during refluxing is minimal in all six tests, suggesting that denitration during boiling was not a significant concern. Similar mass versus time data for formate ion was noisy across the data set. No clear trends were seen, and a plot is not included. 
WSRC-TR-2004-00548

Revision 0

\section{APPENDIX G. Supplemental Off-gas Data}


$\mathrm{CO}_{2}$ generation during acid addition and dewatering is shown in Figure 12. The general impression of the $\mathrm{CO}_{2}$ volume \% data in Figure 12 is one of fairly high reproducibility from run to run. This is consistent with the process titration curve data, section 3.4. The acid addition and dewatering period includes conversion of carbonate, reduction of nitrite, $\mathrm{Mn}$, and $\mathrm{Hg}$, and the beginning of hydrogen generation.

Figure 12. Carbon Dioxide Generation early in the SRAT Cycle

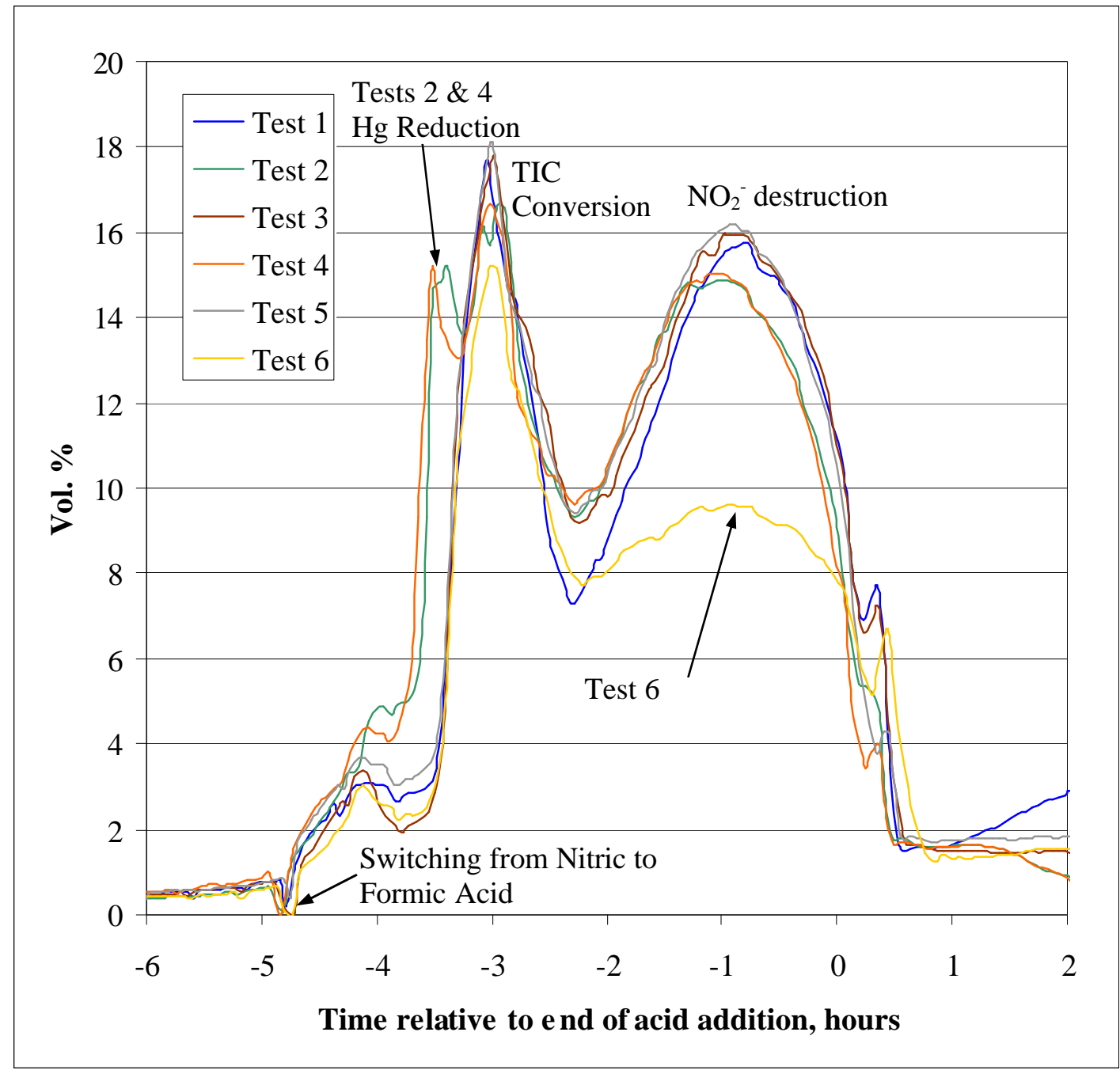

The principal finding with respect to mercury was that there were peaks in $\mathrm{CO}_{2}$ generation rate at -3.6 hours for the two runs with $2 \% \mathrm{Hg}$, Tests 2 and 4, that were absent from the other four runs. This is during formic acid addition, and it is inferred to be chemical reduction of mercury to the element. Numerical integration of the corresponding mass flow rate data indicated that the moles of carbon dioxide produced in this interval were more than sufficient to be the by-products of $\mathrm{Hg}$ reduction by formic acid. The $\mathrm{pH}$ at the time of this peak was in the range $6.7 \pm 0.3$.

The peak at -1 hours corresponds to the generation of $\mathrm{NO}$ and $\mathrm{N}_{2} \mathrm{O}$, see below, and to the consumption of oxygen. It is due to nitrite reduction reactions. Test 6 without oxygen produced considerably less $\mathrm{CO}_{2}$ during nitrite destruction. From this and experience with previous SRAT simulations, it is inferred that the peak at -3 hours is associated with TIC (carbonate) conversion to carbon dioxide. The mass of $\mathrm{CO}_{2}$ 
produced from the beginning of the run until about -3 hours corresponds to the mass of $\mathrm{CO}_{2}$ that would be produced by converting all carbonate to $\mathrm{CO}_{2}$.

The major SRAT chemistry occurred during acid addition and dewatering based on the off-gas data. Slower reactions, including hydrogen generation, continued through refluxing. Carbon dioxide continued to be generated throughout the SRAT cycle as well. Figure 13 shows the data.

Figure 13. Carbon Dioxide Generation During Boiling

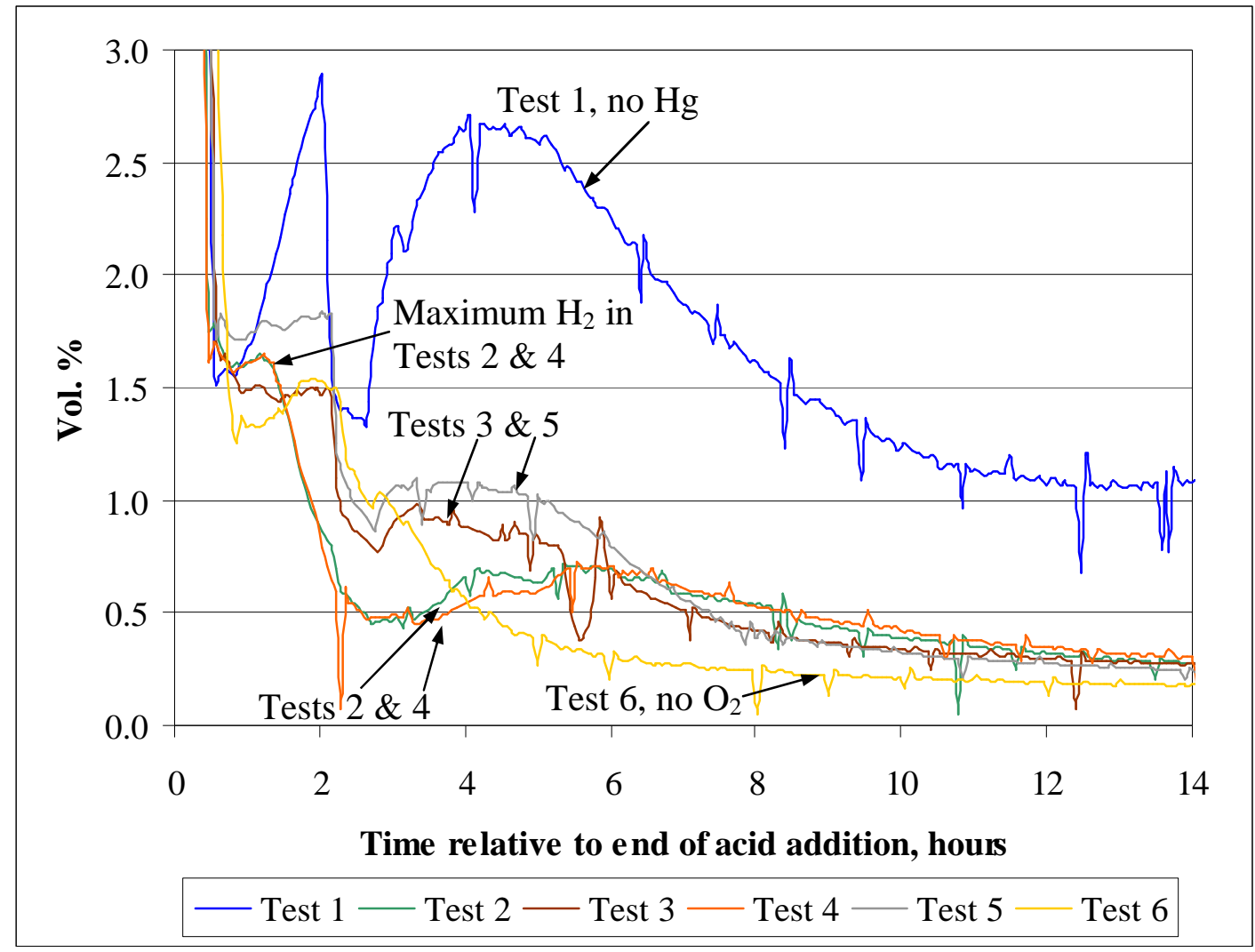

The concentration of mercury clearly influenced the shape of the carbon dioxide profiles. As mercury increased the peak carbon dioxide concentration during reflux fell. The effect of switching from dewatering to refluxing at about 2.2 hours was clearly seen in Tests 1, 3, 5, and 6 (low mercury runs). This coincided with the reduction seen in hydrogen concentration, Figure 1, but it was a relatively smaller percent reduction for $\mathrm{CO}_{2}$ than for $\mathrm{H}_{2}$. There was no dramatic change at this time in Tests 2 and $4(2 \%$ Hg runs).

Carbon dioxide generation while boiling was largest during Test 1 with no Hg. Tests 2 and 4 had nearly identical $\mathrm{CO}_{2}$ profiles, indicating that the choice of $\mathrm{HgO}$ versus $\mathrm{Hg}\left(\mathrm{NO}_{3}\right)_{2}$ at $2 \% \mathrm{Hg}$ had negligible impact on the $\mathrm{CO}_{2}$ gas generation chemistry during boiling. This could indicate that sufficient $\mathrm{Hg}$ was present that the starting form was not relevant. Both had a peak in $\mathrm{CO}_{2}$ generation at about six hours after acid addition that was not associated with hydrogen generation. Tests 3 and 5 also had nearly identical profiles indicating negligible dependence on the form of mercury at $0.119 \% \mathrm{Hg} . \mathrm{CO}_{2}$ fell in Test 6 relative to Tests 3 and 5. This is probably due to the suppression of catalytic wet air oxidation of formate and antifoam by the removal of oxygen. 
An overall view of the $\mathrm{N}_{2} \mathrm{O}$ test data is shown in Figure 14. Small adjustments have been made to the raw GC data to offset small drifts in the baseline during the SRAT cycle.

Figure 14. Nitrous Oxide $\left(\mathbf{N}_{2} \mathrm{O}\right)$ Generation During SRAT Cycle

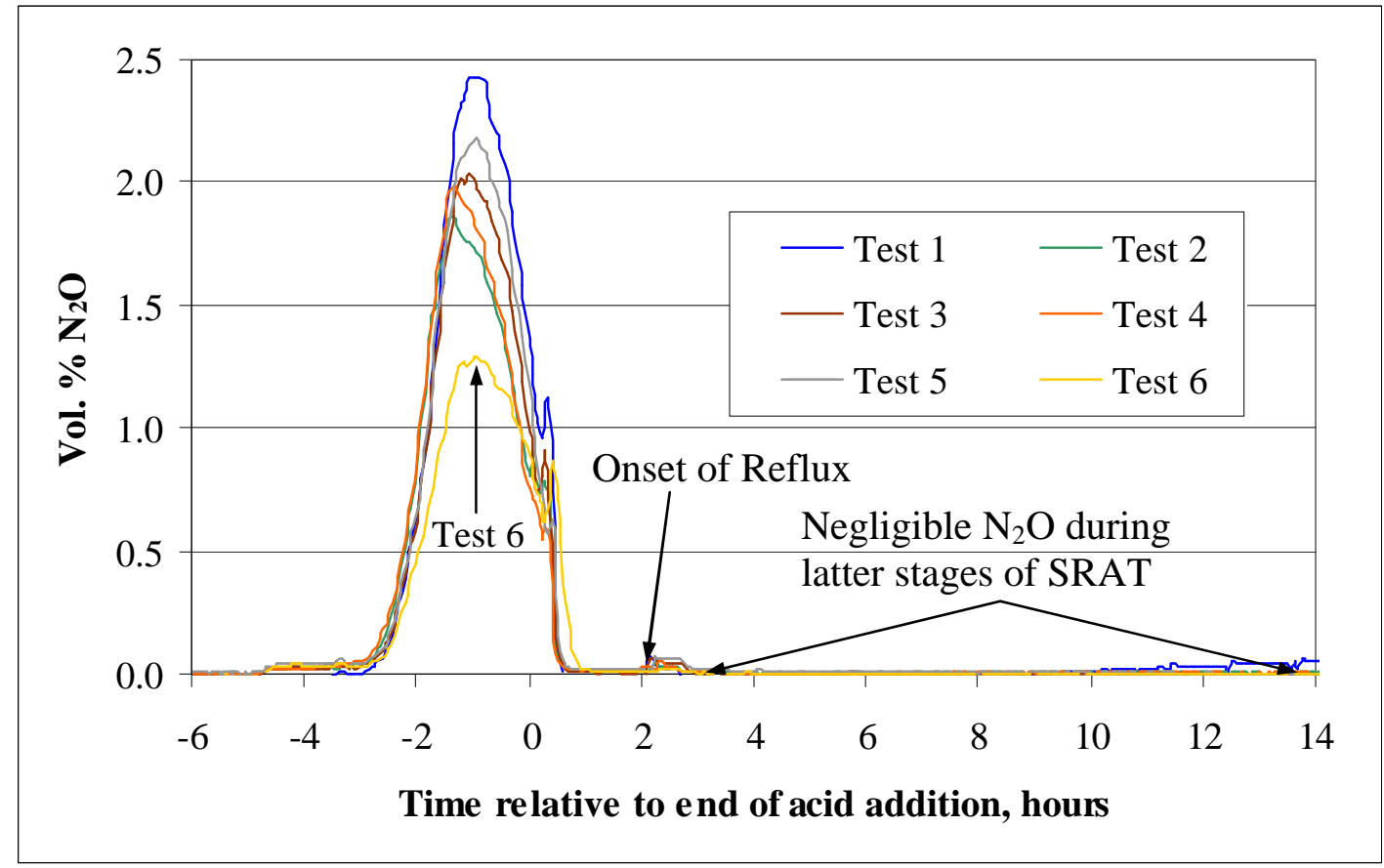

$\mathrm{N}_{2} \mathrm{O}$ generation occurred primarily during and immediately following formic acid addition. There was a brief period of additional $\mathrm{N}_{2} \mathrm{O}$ generation following the onset of reflux. This may be due to species in the MWWT condensate that are returning to the SRAT. Additional $\mathrm{N}_{2} \mathrm{O}$ production following the start of reflux is typical of bench-scale data seen in prior work, e.g. Koopman (2000). The peak generation rate of $\mathrm{N}_{2} \mathrm{O}$ was relatively low in all six tests. The portion of the data containing the interesting features was re-plotted to show more detail, Figure 15. 
Figure 15. Impact of Hg on Nitrous Oxide Detected

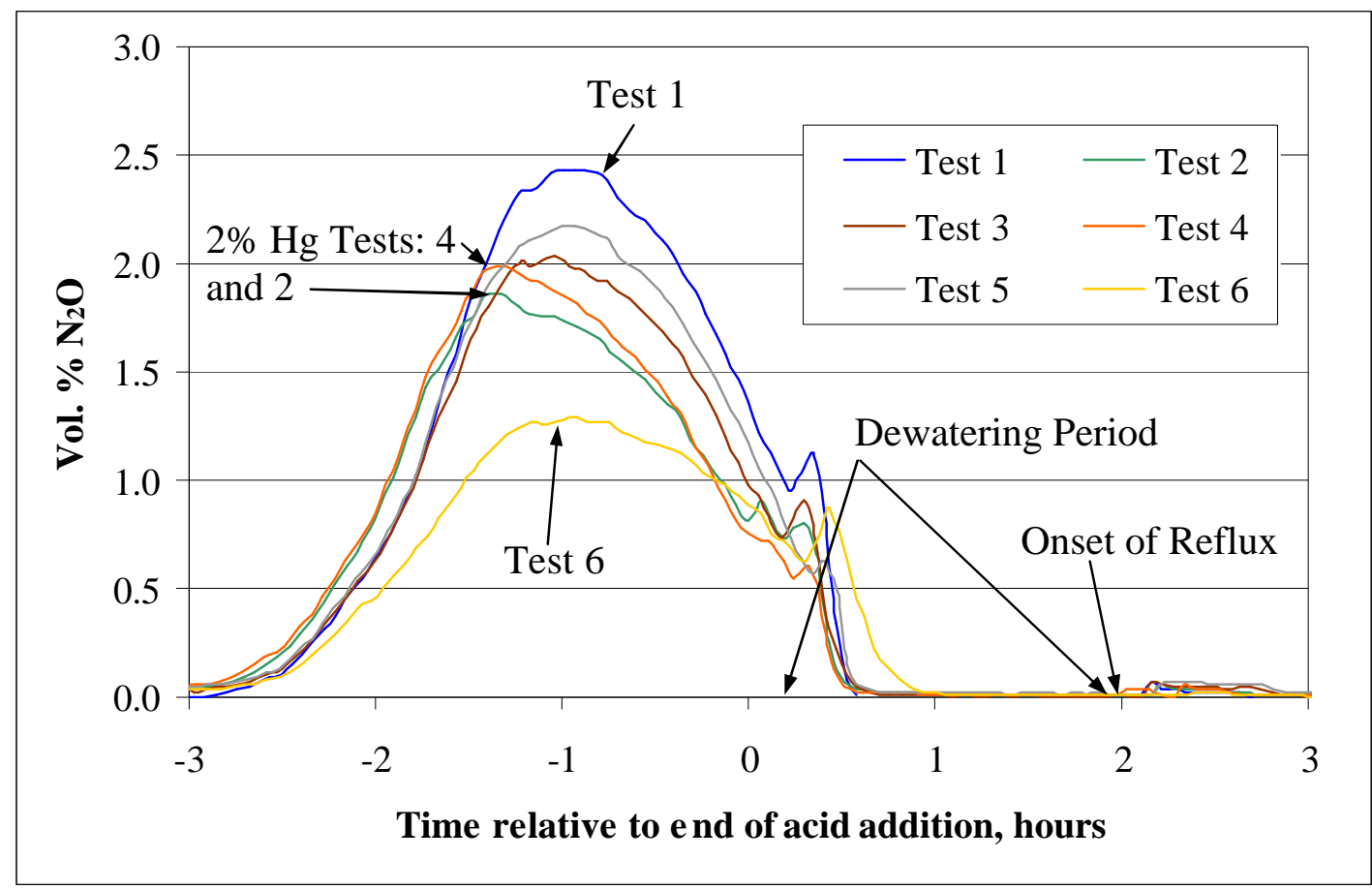

Tests 1, 3, and 5 with little $\mathrm{Hg}$ had the most $\mathrm{N}_{2} \mathrm{O}$, while Tests 2 and 4 with $2 \% \mathrm{Hg}$ had less $\mathrm{N}_{2} \mathrm{O}$. Test 6 with no oxygen had the smallest peak in $\mathrm{N}_{2} \mathrm{O}$. The broad peak from -3 hours to +0.5 hours corresponds to peaks seen for carbon dioxide and NO. These are collectively associated with the destruction of nitrite and perhaps other formic acid reduction reactions, e.g. Mn reduction. The small peaks at about +0.5 hours are associated with the start of boiling. The onset of boiling sweeps accumulated gases out of the SRAT and largely replaces them with water vapor. It is not associated with a specific change in chemistry of the slurry.

The two curves at $2 \% \mathrm{Hg}$ were very similar to each other, Tests 2 and 4 . The two curves at $0.119 \% \mathrm{Hg}$ with an air purge were very similar to each other, Tests 3 and 5. Apparently the form of mercury was not significantly affecting the $\mathrm{N}_{2} \mathrm{O}$ data. The overall impression was one of fairly high reproducibility in the off-gas composition data for $\mathrm{N}_{2} \mathrm{O}$ for the set of six tests.

The off-gas GC's were also calibrated for NO. SRAT NO data have not been obtained in many years. $\mathrm{NO}$ co-exists with $\mathrm{NO}_{2}$ in the presence of oxygen. The data suggest that an equilibrium conversion may have been achieved (given the similarity between runs). NO measurements were particularly significant in Test 6, which had the nitrogen purge. The absence of oxygen prevents $\mathrm{NO}$ from reacting to form $\mathrm{NO}_{2}$. The NO calibration was at $10 \%$, so values above that are outside of the calibration range, $0-10 \%$. The impact of removing oxygen was very obvious, Figure 16. Data shown have been adjusted somewhat for small drifts in the baseline. The data presented here were also used in Appendix $\mathrm{H}$ in the discussion of nitrite destruction chemistry. 
WSRC-TR-2004-00548

Revision 0

Figure 16. Nitric Oxide (NO) Generation During SRAT Cycle

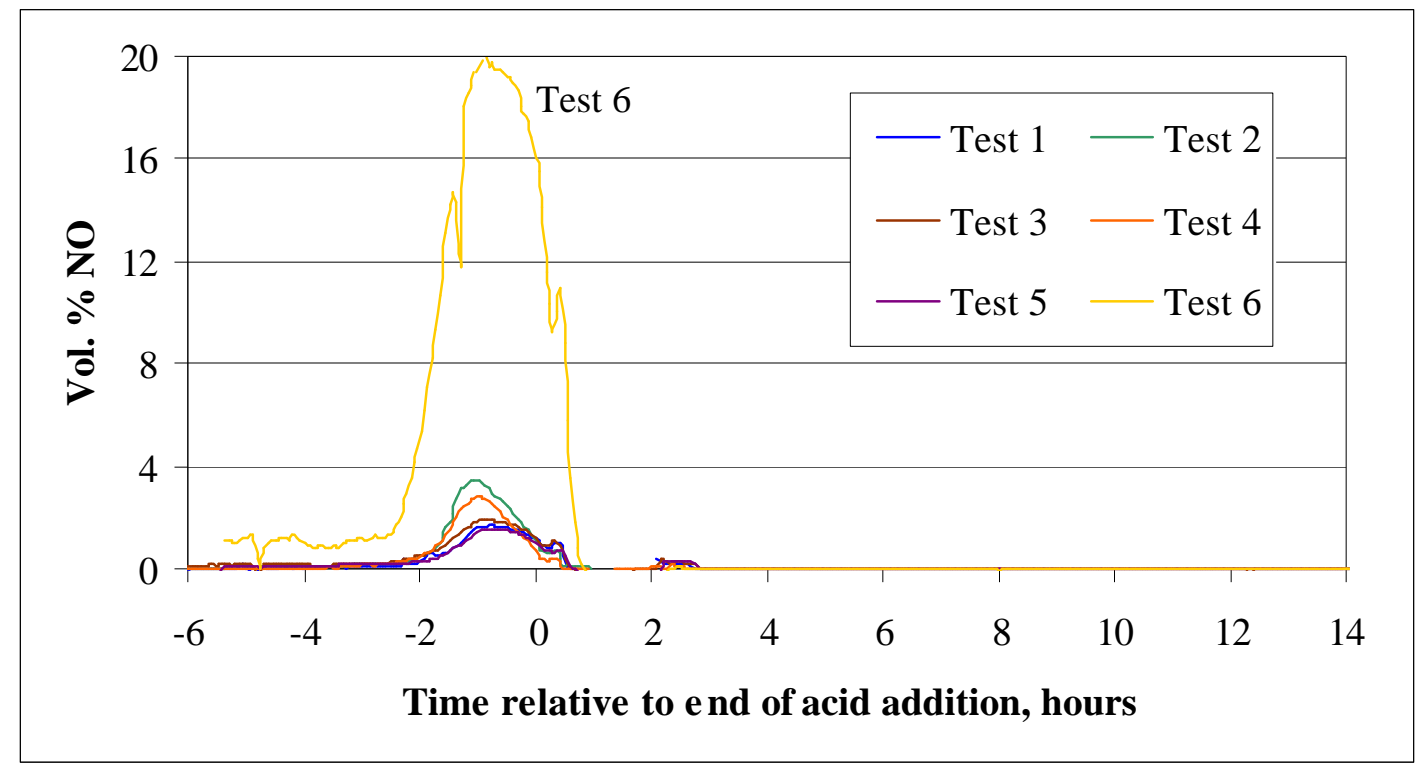

NO production occurred primarily during formic acid addition and the initial part of dewatering, plus a final burst following the onset of reflux (at approximately +2 hours). The NO detected was obviously much less than that generated in the SRAT except for Test 6 . The NO in Test 6 was presumably the entire quantity of $\mathrm{NO}$ produced, since conversion to $\mathrm{NO}_{2}$ was precluded by the inert atmosphere. In Test 1-5 a large fraction of the $\mathrm{NO}$ was converted to $\mathrm{NO}_{2}$ through reaction with oxygen in the purge air. The resulting brown gas can be seen in the glass bench-scale SRAT, even though the GC does not detect it. The associated depletion in oxygen is also seen in the GC data. (This assumption can be checked with a more thorough analysis of oxygen depletion data. A quick check was done in Appendix H.)

Data from Tests 1-5 are re-plotted with a similar scale change, Figure 17. 
Figure 17. Impact of Hg on NO Detected

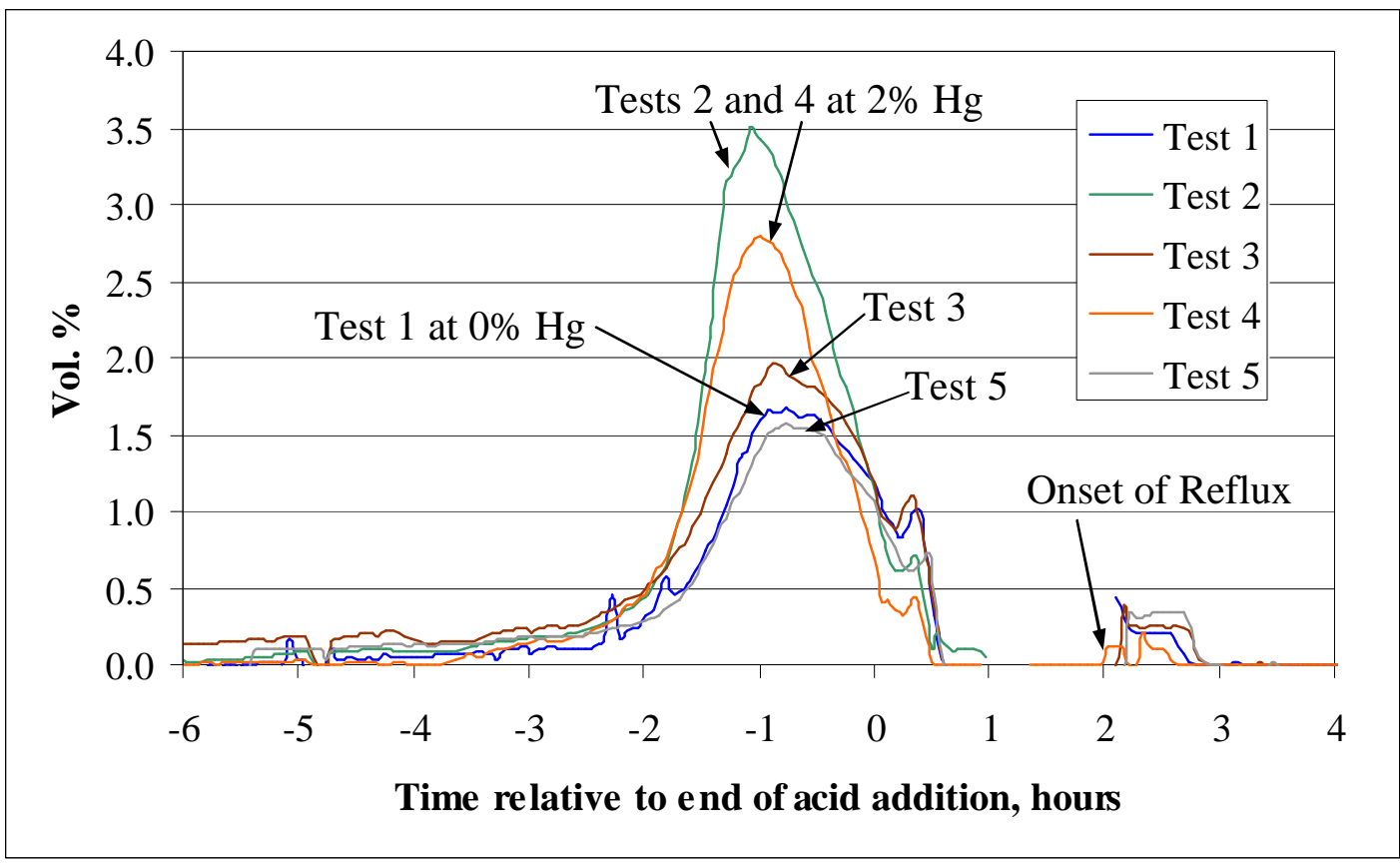

The trend of most to least $\mathrm{NO}$ as a function of mercury and oxygen was essentially the reverse of that seen for $\mathrm{N}_{2} \mathrm{O}$. The "peak" at +0.5 hours in all five tests is due to the onset of boiling. All tests, except perhaps Test 2, showed additional NO formation corresponding to the onset of reflux. There was a small blip in the Test 2 data as well.

Tests 2 and 4 with $2 \% \mathrm{Hg}$ had higher detected levels of NO than the other three tests. They also appeared to have somewhat more NO production by mass (proportional to area under the curves). The reason(s) for this were not determined, but one possibility is that the mercury was already impacting the noble metals. Conversely, Tests 2 and 4 had the lowest levels of $\mathrm{N}_{2} \mathrm{O}$. Noble metals have been associated with accelerated nitrite destruction in previous SRAT simulations, SRT-GPD-2002-00044 and other studies. An interaction between mercury and the noble metals could be promoting nitrite destruction to NO or inhibiting nitrite destruction to $\mathrm{N}_{2} \mathrm{O}$ or both simultaneously.

Tests 3 and 5 with $0.119 \% \mathrm{Hg}$ bracketed Test 1 with no $\mathrm{Hg}$. All three tests were very similar. The variation between the data from these three runs may be nothing more than small differences in calibration or baseline drifts in the GC. These three runs had the highest levels of $\mathrm{N}_{2} \mathrm{O}$ production. The observations are consistent with the last line of the previous paragraph.

The strong correlation between the timing of $\mathrm{NO}$ and $\mathrm{N}_{2} \mathrm{O}$ generation is illustrated in the tiled plots of Figure 18. These plots are from the four $\mathrm{HgO}$ based runs but are illustrative of the phenomenon in general. 
Figure 18. Comparison of $\mathrm{NO}$ to $\mathrm{N}_{2} \mathrm{O}$ Generation.
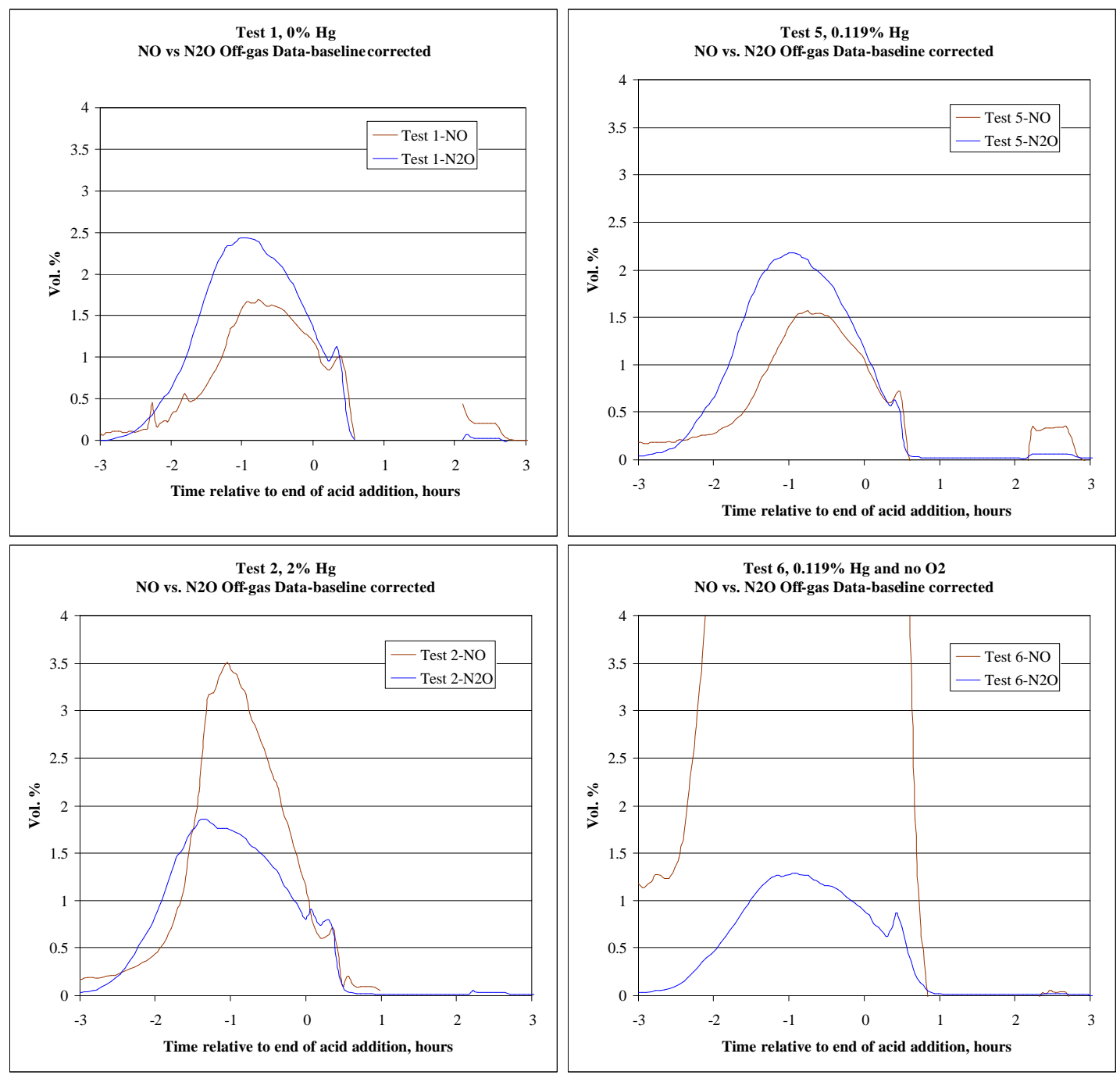

The plots are identically scaled, so that the effect of $\mathrm{Hg}$ is more easily seen in the first three graphs in the figure ( $\mathrm{NO}$ rising, $\mathrm{N}_{2} \mathrm{O}$ falling). A general observation that held for all six tests was that the $\mathrm{N}_{2} \mathrm{O}$ peaked slightly ahead of the NO. One interpretation of the $\mathrm{NO}-\mathrm{N}_{2} \mathrm{O}$ data could be that the presence of increased concentrations of $\mathrm{NO}$ acted to suppress formation of $\mathrm{N}_{2} \mathrm{O}$, or vice versa. No reaction schemes have been found as yet to support such a hypothesis. 
WSRC-TR-2004-00548

Revision 0

\section{APPENDIX H. Assessment of Nitrite Destruction Chemistry}


An overview of developments in the understanding of nitrite destruction was given in section 3.7. A more detailed basis is needed to document the development of competing reaction paths for nitrite destruction. This appendix covers the details.

Nitrite destruction occurs by several simultaneous reaction paths. The acid consumption requirement for each path is different, as is the conversion of nitrite to nitrate and the amount of carbon dioxide produced. Changes in the distribution of nitrite destruction among the parallel paths were indicated. These changes affect the quantity of excess acid at the onset of hydrogen generation and probably the maximum hydrogen generation rate. It is important to evaluate these changes when evaluating hydrogen generation data.

A portion of nitrite is converted directly to nitrate as it is destroyed. It is also possible to produce nitrate from nitrite by less direct routes. The addition of the NO measurement capability plus the performance of a nitrogen-purged SRAT have helped to clarify some open issues with nitrite destruction chemistry that were identified during the preliminary SB3 simulant flow sheet work, Koopman (2003a, 2003b).

The simplest path to destroy nitrite and produce nitrate is given by:

$$
3 \mathrm{HNO}_{2} \rightarrow \mathrm{HNO}_{3}+\mathrm{H}_{2} \mathrm{O}+2 \mathrm{NO}
$$

This is the only fundamental reaction that has been identified for SRAT nitrite destruction in the absence of formic acid. SRAT tests using only nitric acid do have nitrite destruction, Herman (2003) and unpublished SRAT data from the SB3 melt rate program. Reaction [A] is partly responsible for nitrate formation from nitrite destruction. NO is produced by reaction $[\mathrm{A}]$ and also by:

$$
2 \mathrm{HNO}_{2}+\mathrm{HCOOH} \rightarrow \mathrm{CO}_{2}+2 \mathrm{NO}+2 \mathrm{H}_{2} \mathrm{O}
$$

Reaction [B] is one of the reactions responsible for $\mathrm{CO}_{2}$ generation during formic acid addition. $\mathrm{N}_{2} \mathrm{O}$ production from nitrite and $\mathrm{Mn}(\mathrm{IV})$ reduction both contribute additional $\mathrm{CO}_{2}$ during formic acid addition. It is chemically possible to convert $\mathrm{NO}$ to $\mathrm{NO}_{2}$ and $\mathrm{N}_{2} \mathrm{O}$ by:

$$
3 \mathrm{NO} \rightarrow \mathrm{N}_{2} \mathrm{O}+\mathrm{NO}_{2}
$$

at $30-50^{\circ} \mathrm{C}$, but higher than atmospheric pressures significantly increase the rate of this reaction as cited in Cotton and Wilkinson (1972). In SRAT simulations using only nitric acid and no formic acid, $\mathrm{N}_{2} \mathrm{O}$ was not observed in the off-gas, see Figure 19. Some of this data, obtained during SRAT simulations in support of SB3 melt rate studies, is presented here, since it has not been included in previous reports. 
Figure 19. GC Data from SRAT Test with no Formic Acid

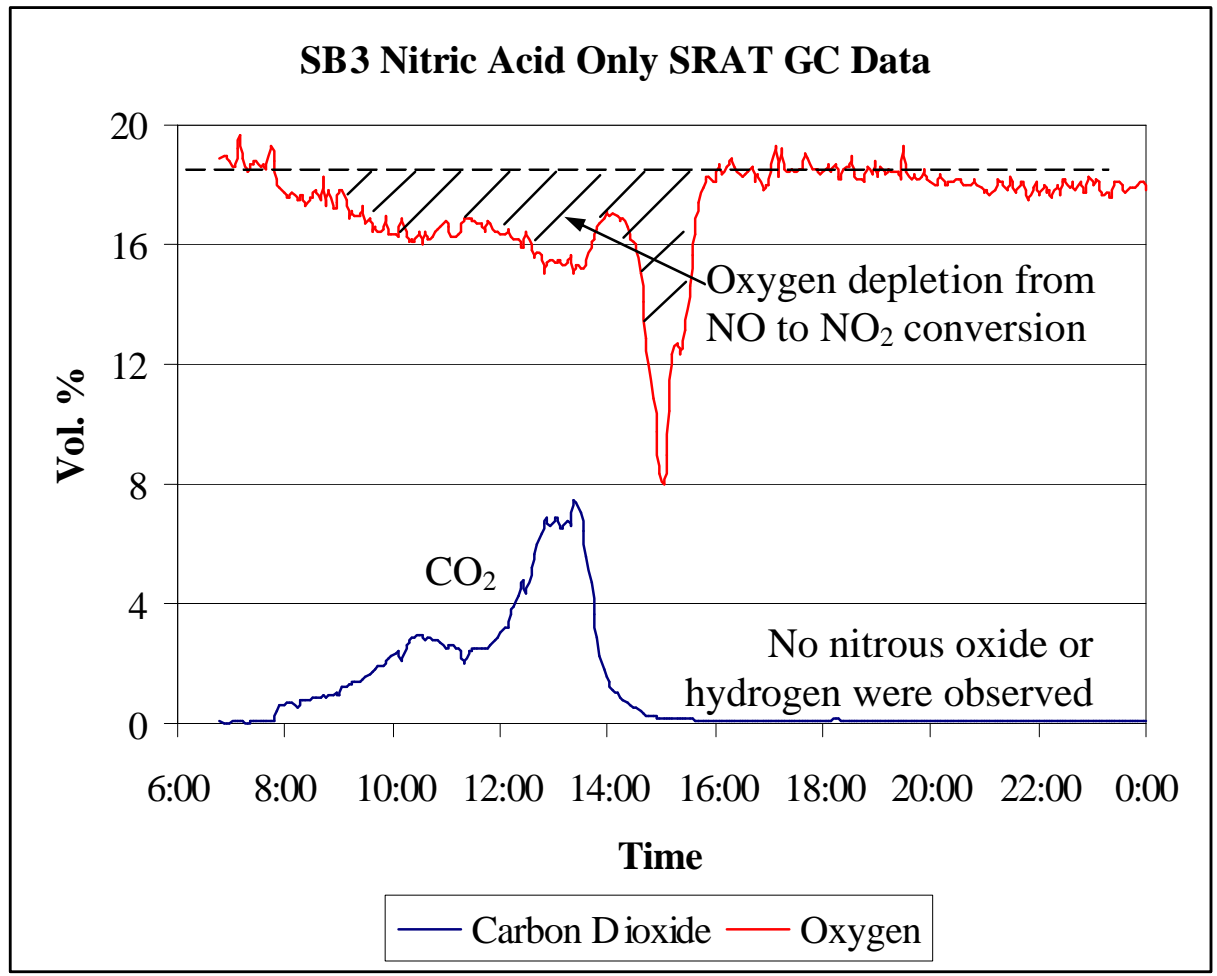

These data indicate that formation of $\mathrm{N}_{2} \mathrm{O}$ from $\mathrm{NO}$ was negligible during SRAT processing (NO present but no $\mathrm{N}_{2} \mathrm{O}$ detected). Carbon dioxide generation was spread out, because the prototypical molar acid addition rate of nitric acid is about half that of formic acid. The quantity of carbon dioxide produced was also less, since no formate reduction reactions occurred in this run.

$\mathrm{NO}$ reportedly reacts instantly with oxygen to form $\mathrm{NO}_{2}$ according to Cotton and Wilkinson.

$$
2 \mathrm{NO}+\mathrm{O}_{2} \rightarrow 2 \mathrm{NO}_{2}
$$

Nevertheless, NO was detected in the presence of oxygen in the first five tests of this study. Therefore the statement in Cotton and Wilkinson does not generalize to SRAT conditions.

The $\mathrm{NO}_{2}$ can combine with water to give back nitrite and nitrate as acids per:

$$
2 \mathrm{NO}_{2}+\mathrm{H}_{2} \mathrm{O} \rightarrow \mathrm{HNO}_{3}+\mathrm{HNO}_{2}
$$

This is the most likely reaction that puts acidity into the MWWT condensate. It is also partly responsible for nitrite to nitrate conversion. The $\mathrm{NO}_{2}$ was generated by two nitrite ions and the reaction yields one nitrite ion and one nitrate ion back (net loss of one nitrite ion per nitrate ion formed). This reaction is more likely to occur in aqueous solution than in the gas phase, since tri-molecular gas phase reactions are both rare and slow.

Combining reactions $[\mathrm{B}],[\mathrm{D}]$, and $[\mathrm{E}]$ gives: 


$$
\mathrm{HNO}_{2}+\mathrm{HCOOH}+\mathrm{O}_{2} \rightarrow \mathrm{HNO}_{3}+\mathrm{H}_{2} \mathrm{O}+\mathrm{CO}_{2}
$$

This is a net alternative pathway to [A] for nitrate formation from nitrite. This pathway, however, is based on formic acid reduction chemistry. Reactions $[\mathrm{B}]$ and $[\mathrm{F}]$ require different consumption levels of acid per mole nitrite destroyed. Reaction $[\mathrm{F}]$ is a net alternative pathway to $[\mathrm{B}]$ for nitrite destruction by formic acid reduction in the presence of $\mathrm{NO}_{2}$ conversion back to nitrous and nitric acids. It consumes only one mole of acid per mole nitrite compared to 1.5 moles of acid per mole of nitrite in [B].

Combining reactions $[\mathrm{A}],[\mathrm{D}]$, and $[\mathrm{E}]$ similarly to what was done to derive $[\mathrm{F}]$ gives:

$$
\mathrm{HNO}_{2}+1 / 2 \mathrm{O}_{2} \rightarrow \mathrm{HNO}_{3}
$$

This is a net alternative pathway to [A] for nitrate formation from nitrite. It does not require formic acid, and probably occurs to some extent in SRAT simulations using only nitric acid. It is not a fundamental reaction like $[\mathrm{A}]$, so the statement that reaction $[\mathrm{A}]$ is solely responsible for nitrite destruction in the absence of formic acid is still valid. Note that $[\mathrm{G}]$ consumes no net acid unlike reaction $[\mathrm{A}]$, which consumes $2 / 3$ mole of acid per mole of nitrite consumed.

In addition to these four routes for nitrite destruction associated with $\mathrm{NO}$, there is also the direct formation of nitrous oxide from nitrite by:

$$
2 \mathrm{HNO}_{2}+2 \mathrm{HCOOH} \rightarrow \mathrm{N}_{2} \mathrm{O}+2 \mathrm{CO}_{2}+3 \mathrm{H}_{2} \mathrm{O}
$$

This reaction consumes one mole of formic acid and one mole of any available acid per mole of nitrite destroyed. Nitrous oxide is observed in the off-gas from SRAT simulations with formic acid. It is inferred to come from $[\mathrm{H}]$ rather than from $[\mathrm{C}]$, since $\mathrm{N}_{2} \mathrm{O}$ is not observed in simulations without formic acid.

Reactions, $[\mathrm{A}],[\mathrm{B}],[\mathrm{F}],[\mathrm{G}]$, and $[\mathrm{H}]$ are now considered the key reactions for net nitrite destruction during bench-scale testing. They bound the likely range of the total stoichiometric acid requirement coefficient for nitrite to the interval 0-2.0 moles acid/mole nitrite destroyed. These also bound the quantity of $\mathrm{CO}_{2}$ produced to the interval 0-1.0 moles $\mathrm{CO}_{2} /$ mole nitrite destroyed. The extent to which reactions $[\mathrm{F}]$ and $[\mathrm{G}]$ replace reactions $[\mathrm{A}]$ and $[\mathrm{B}]$ relates to internal refluxing, since the middle reaction, $[D]$, in the derivation of $[\mathrm{F}]$ and $[\mathrm{G}]$ from $[\mathrm{A}]$ and $[\mathrm{B}]$ is the absorption of $\mathrm{NO}_{2}$ into an aqueous liquid phase, presumably in the form of droplets on the vessel wall.

Based on the data from Test 6 (nitrogen purge), there is significant additional nitrite to nitrate conversion, $\mathrm{CO}_{2}$ generation, and $\mathrm{N}_{2} \mathrm{O}$ generation in the five runs with an air purge relative to Test 6 . These are potential measures of the significance of internal refluxing during $\mathrm{NO}$ evolution. One consequence of this shift from reactions $[\mathrm{A}]$ and $[\mathrm{B}]$ to reactions $[\mathrm{F}]$ and $[\mathrm{G}]$ is a net reduction in the acid consumed during nitrite destruction. This reduction in acid consumption should have an associated increase in hydrogen generation based on historical work. Test 5 with an air purge produced more hydrogen than Test 6 , and that is also consistent with this analysis. Reducing internal refluxing should move the bench-scale results closer to DWPF and should lead to higher stoichiometric factors for hydrogen generation rates at the DWPF design basis limit.

The above observations indicate that the understanding of some of the critical reactions occurring before the onset of hydrogen generation has reached a fairly mature level. More specifically, the NO is generated in the slurry, where this is plenty of water but very little oxygen. The NO does not immediately 
absorb into the aqueous phase. As the NO bubbles out of the slurry it encounters oxygen to convert most of it to $\mathrm{NO}_{2}$. The gaseous $\mathrm{NO}_{2}$ is swept by the air purge toward the SRAT condenser. If it makes it to the SRAT condenser without being absorbed by a water droplet in the SRAT, then it can be condensed in the SRAT condenser to give $\mathrm{HNO}_{2}$ and $\mathrm{HNO}_{3}$, but these are lost during dewatering to the SMECT.

This analysis suggests that delaying dewatering until near the end of the SRAT cycle could increase the nitrite to nitrate conversion of the SRAT slurry. This would lead in turn to a shift in future acid additions toward higher formic acid and lower nitric acid at constant total acid. This would not seem to be the direction to shift the process in order to minimize hydrogen generation. The potential off-setting feature would be that some species in the reflux, which would begin immediately following acid addition in this scenario, could suppress hydrogen generation in the manner seen in Figure 1 at the onset of reflux. The question of when best to dewater with respect to hydrogen generation appears to require experimentation to answer. There now is a context for explaining whichever result is obtained. 
Distribution:

E. W. Holtzscheiter, 773-A

D. A. Crowley, 999-W

S. L. Marra, 999-W

T. B. Calloway, 999-W

N. E. Bibler, 773-A

C. M. Jantzen, 773-A

J. R. Harbour, 773-42A

G. C. Wicks, 773-A

T. F. Fellinger, 773-A

C. C. Herman, 773-42A

J. M. Pareizs, 773-A

C. J. Bannochie, 773-42A

M. S. Miller, 704-S

J. E. Occhipinti, 704-S

R. M. Hoeppel, 704-27S

H. H. Elder, 766-H

J. F. Iaukea, 704-30S

J. W. Ray, 704-S

P. M. Patel, 704-27S

F. A. Washburn, 704-27S

R. N. Mahannah, 704-28S

A. B. Sanders, 704-27S

W. B. Van-Pelt, 704-S 